\title{
GENEALOGIES OF AFFECT AMONG A YOUNG VETERINARIAN'S PUBLIC LETTER: AN EXPLORATORY STUDY OF HIDDEN CURRICULA IN A COLLEGE OF VETERINARY MEDICINE
}

\author{
A Dissertation \\ presented to \\ the Faculty of the Graduate School \\ At the University of Missouri \\ In Partial Fulfillment \\ of the Requirements for the Degree \\ Doctor of Philosophy
}

by
TAMARA S. HANCOCK
D. Sadler, Dissertation Supervisor

May 2018 
The undersigned, appointed by the dean of the Graduate School,

have examined the dissertation entitled

GENEALOGIES OF AFFECT AMONG A YOUNG VETERINARIAN'S PUBLIC LETTER: AN EXPLORATORY STUDY OF HIDDEN CURRICULA IN A COLLEGE OF VETERINARY MEDICINE

Presented by TAMARA S. HANCOCK

A candidate for the degree of

DOCTOR OF PHILOSOPHY OF LEARNING, TEACHING, AND CURRICULUM EMPHASIS IN SCIENCE EDUCATION

And hereby certify that, in their opinion, it is worthy of acceptance.

TROY D. SADLER, PH.D., CHAIR

LINDA M. BERENT, DVM, PH.D.

PAT FRIEDRICHSEN, PH.D.

CANDACE R. KUBY, PH.D. 
Dedicated to Goosie. You are a light. I love being invited into your blossoming world.

Thank you for being so awesomely you. You keep me going. 


\section{Acknowledgements}

There is so much to acknowledge here; I must begin by saying these words will never be enough or say enough, but for now, must suffice.

To Jason, for your unwavering support of my endless academic endeavors. You keep me grounded. You make me laugh. You are a fabulous partner in life and a wonderful dad. Thank you for everything along the way-I could not have completed this without you. I love you and I promise this is the last academic degree.

To Edward G., this Ph.D. is as much about my scholarly endeavors as it is about you—you have been with me for nearly the whole ride. You are a beacon of light, you are hilarious and fun, and I love you.

To my friends and fellow doctoral students. In particular, (in alphabetical order by first name because I fear what it might mean otherwise to seemingly rank that which cannot be ranked): Andrew Kinslow, Christy Goldsmith, Oona Fontanella-Nothom, and Terese Zidon. You helped me persevere in many ways, some unspoken. Andrew, Christy, and Oona: Thank you for always being there, a shoulder to cry on or hug, a source of laughter, and for your endless support when I wondered if it all even matters. I want you three to know you are and will always be enough. Terese, thank you for helping establish the needed support of the Hogwarts Writing Club.

To Kate Anderson, for her assistance, humor, and support in the library, in EndNote, and in life.

To Becky Christ for her time, energy, effort, and thoughtful feedback on my methods chapter. Thank you! 
To Kerry Karaffa who said, "you are not your dissertation,” and Chris Baines who asked, "how are you?" and meant it. Both at times when it was needed most.

To the participants in this project. None of this would have been possible without you. Thank you for sharing your time and giving yourself so freely to the process. I am grateful for all you contributed to this study and give to the profession. Thank you!

To my committee members, but especially Troy and Linda. Thank you two for taking a chance on what might have been (or still is) a quirky idea of supporting the studies of a woman who wants to change the world of veterinary medical education. To everyone, it has been a ride — thank you all for joining me. You have been supports in so many ways I have probably never given a voice to. I am so grateful and feel so lucky to be supported by and learn with you. Thank you, thank you, thank you.

To my sisters. As impossible triangles, together we have, if nothing else, endlessly persisted. Thank you for always being there. I love you.

To myself. This may seem odd, but I have learned extending compassion and gratitude inward is a big challenge (and I am not alone in being challenged by it). I have done a lot. There is so much more to completing a $\mathrm{Ph} . \mathrm{D}$. that is personal and does not make it into the dissertation. In including myself here, I am also acknowledging all the other personal sacrifice, growth, joys, and sorrows (and everything else in between) we all trade-off along the way, along the hours of each day, in pursuant of what it is we think matters. We work hard. May we all feel we are enough. At times, The Beatles help remind me, may they also help remind you.

Hold your head up, you silly girl

Look what you've done

When you find yourself in the thick of it

Help yourself to a bit of what is all around you (McCartney, 1968) 


\section{Table of Contents}

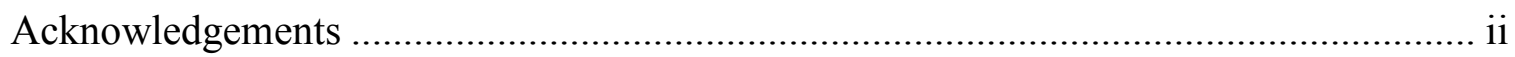

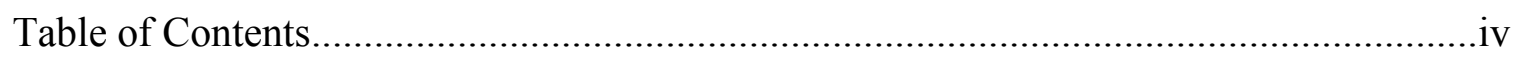

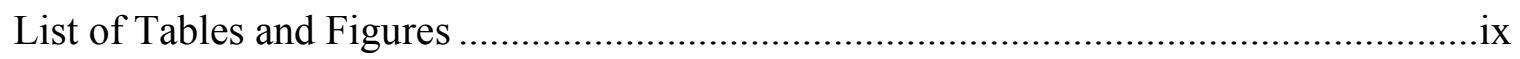

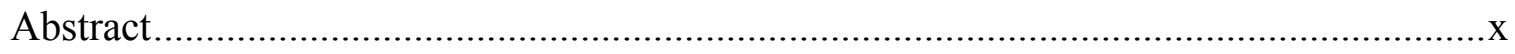

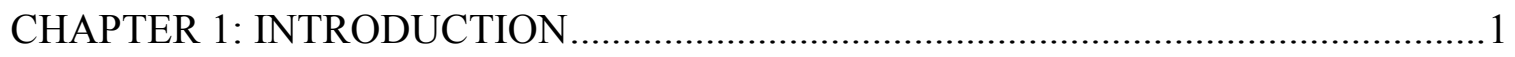

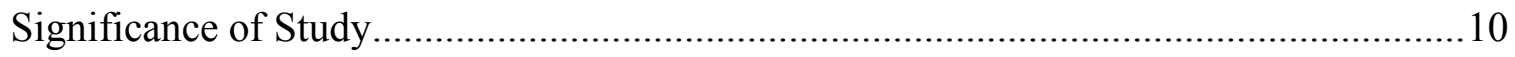

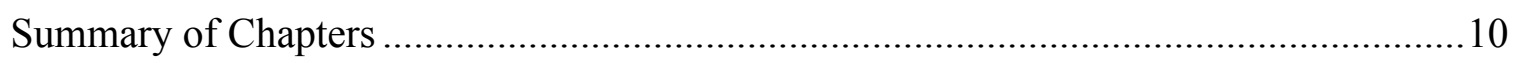

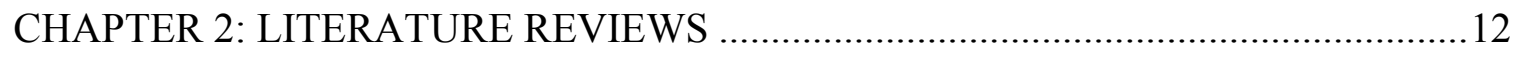

Mental Health and Well-being in Veterinary Medicine ............................................. 12

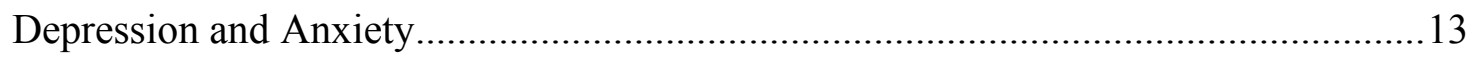

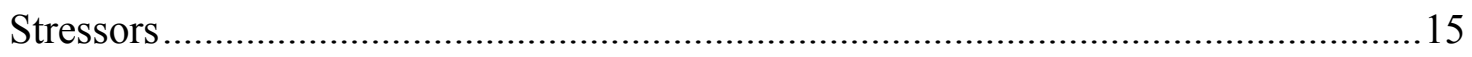

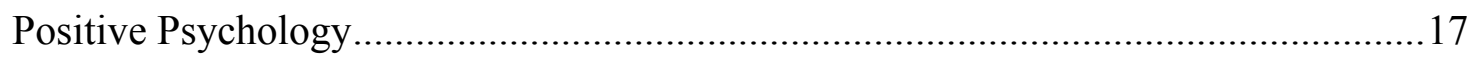

Promise Among Peril........................................................................................... 20

Emotions in Health Professions Education ..............................................................22

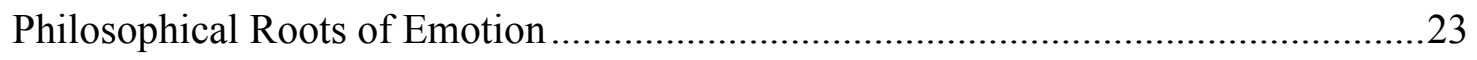

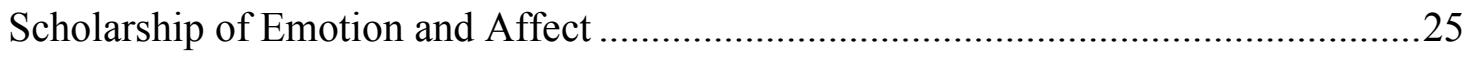

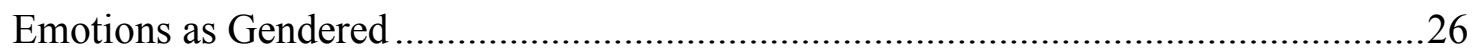

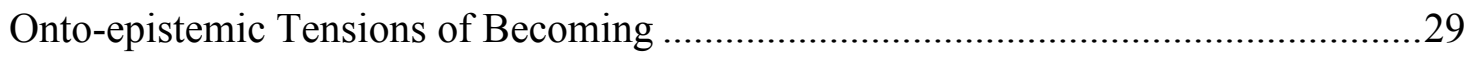

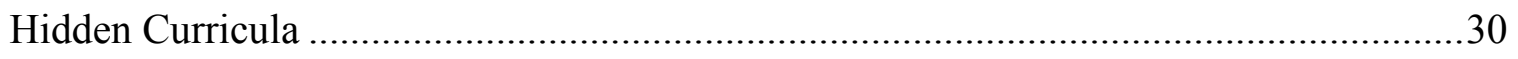

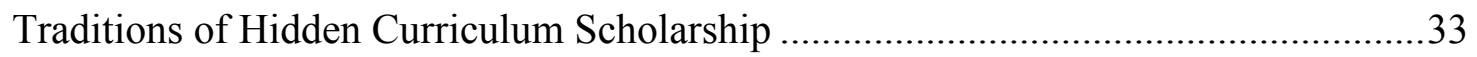

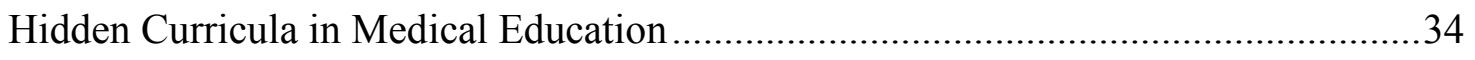

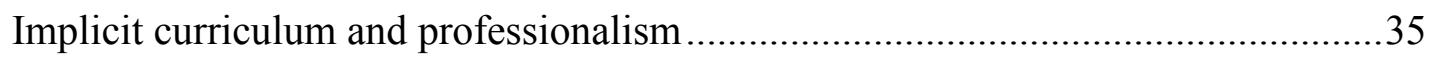


Hidden curricula of veterinary medical education ............................................... 38

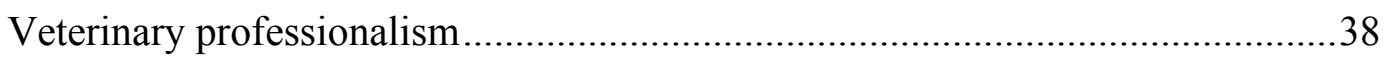

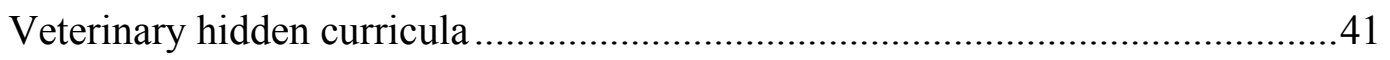

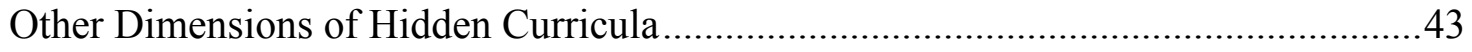

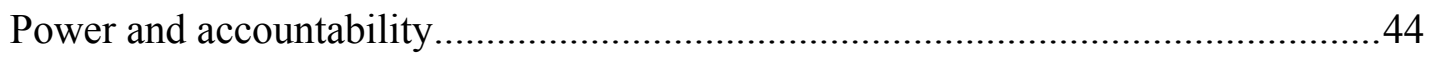

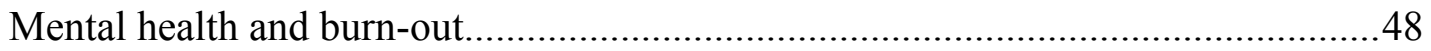

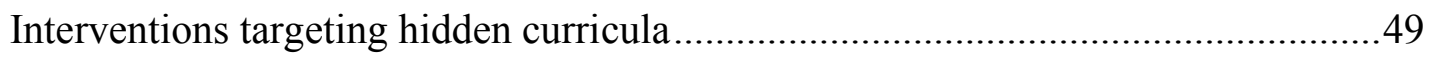

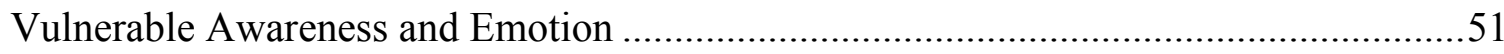

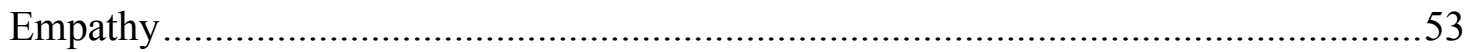

Relational Professionalism ..............................................................................54

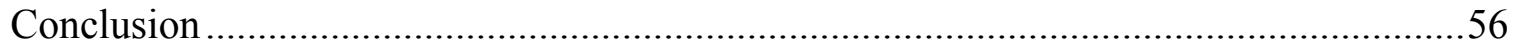

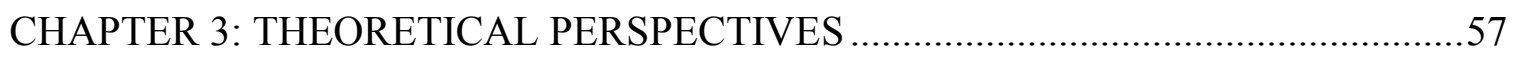

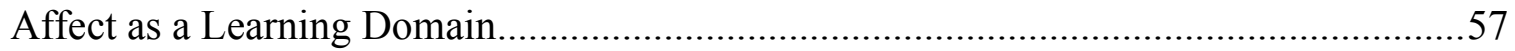

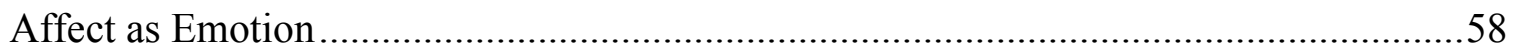

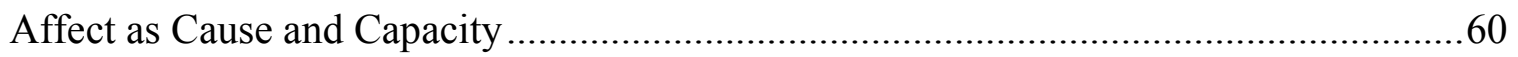

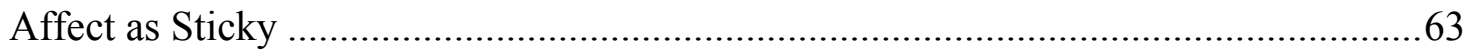

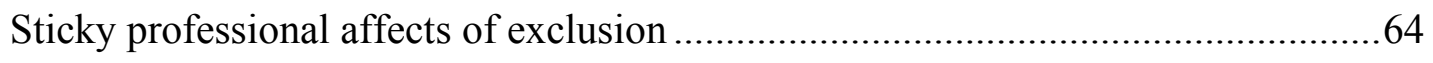

CHAPTER 4: DATA-METHODS-METHODOLOGY ................................................67

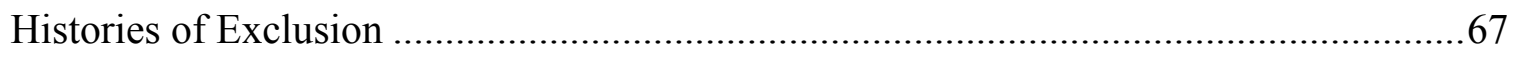

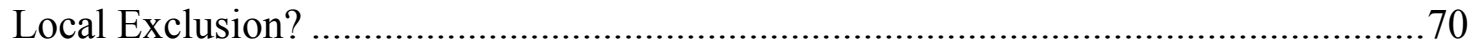

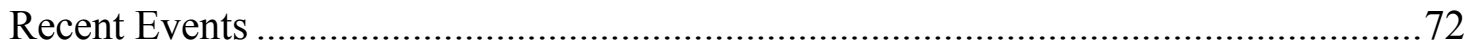

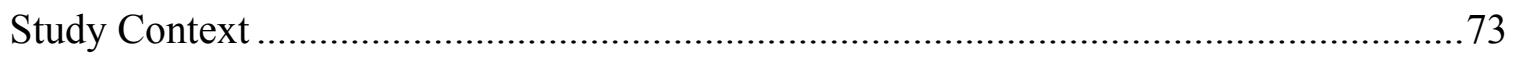

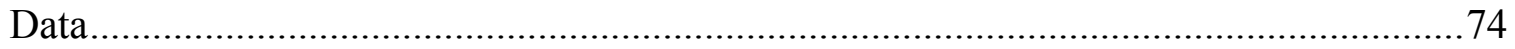




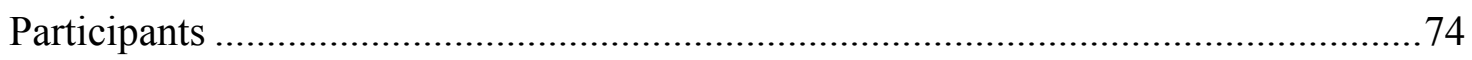

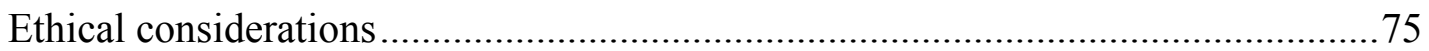

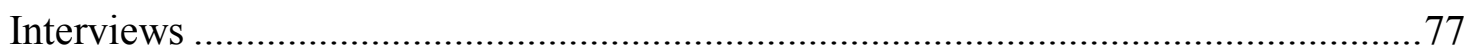

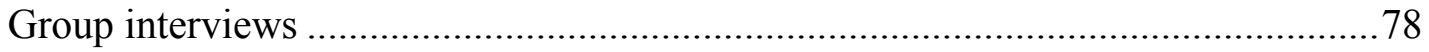

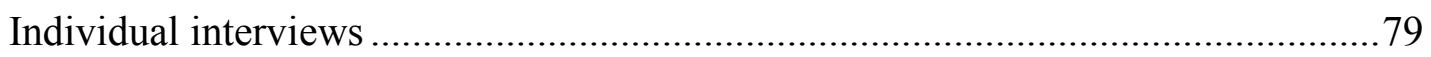

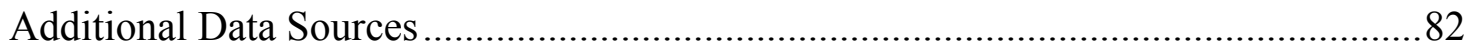

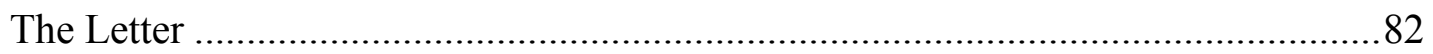

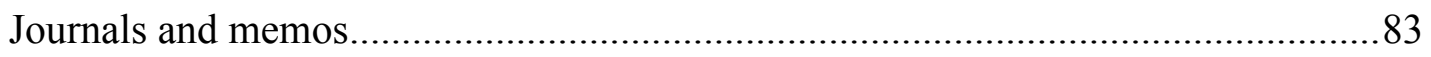

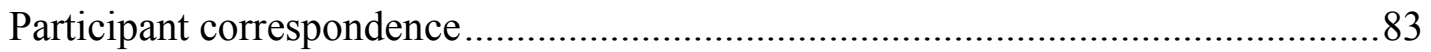

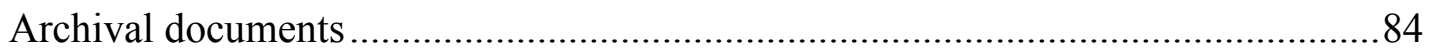

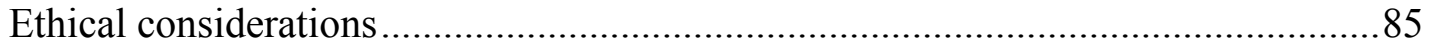

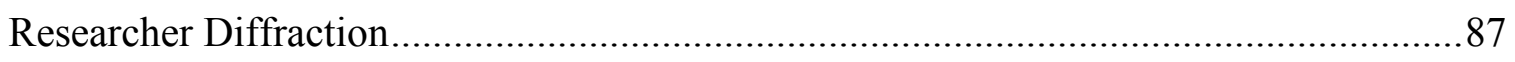

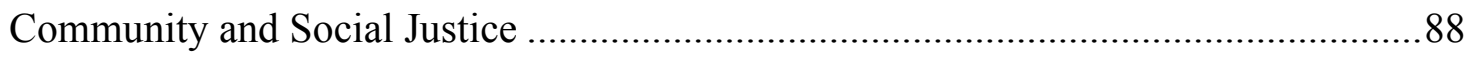

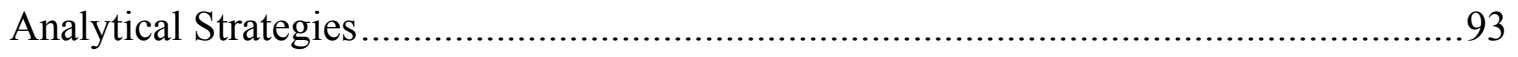

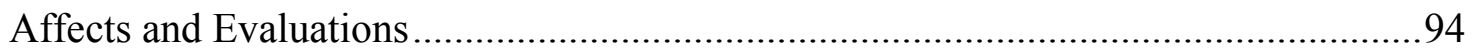

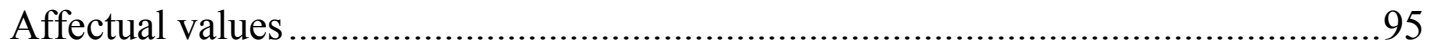

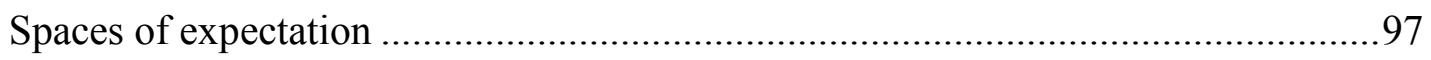

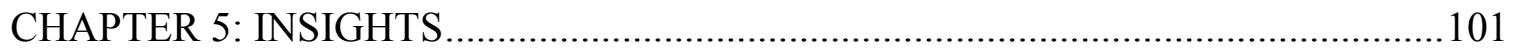

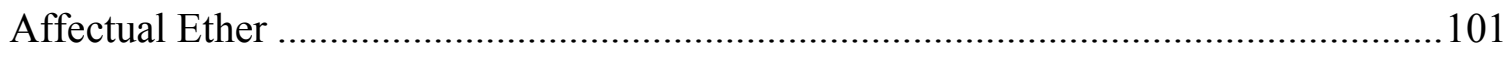

Responsibility, Accountability, and Respect.............................................................103

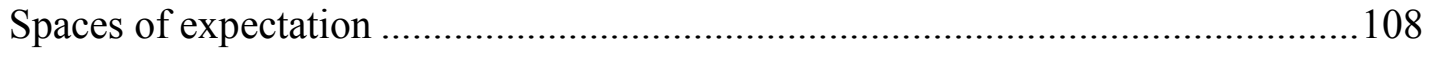

Loyalty, Gratitude, and Thoughtfulness ...............................................................110

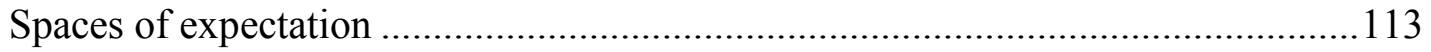




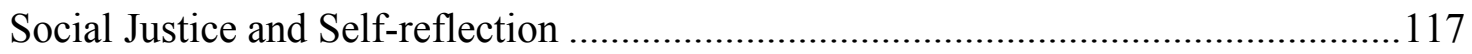

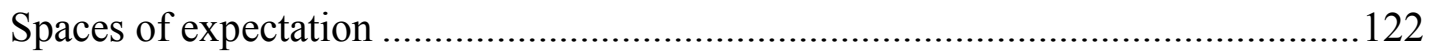

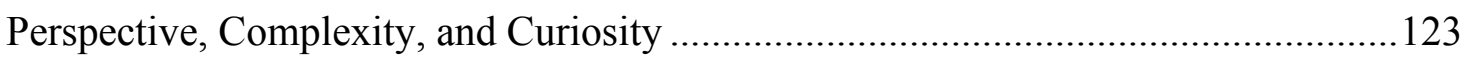

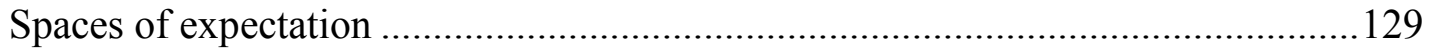

Resilience, Balance, and Emotional Neutrality ......................................................131

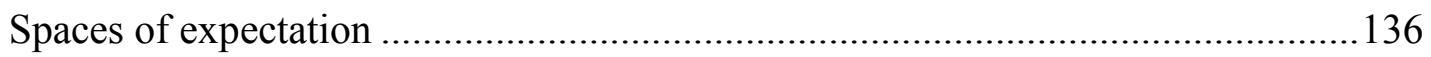

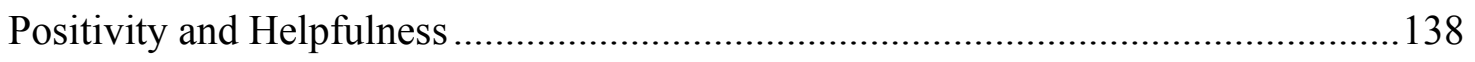

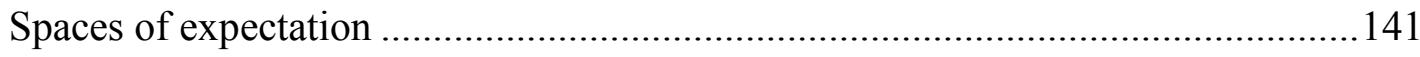

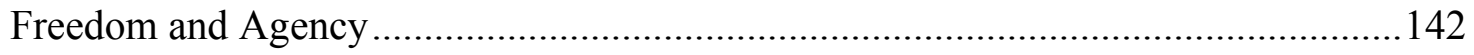

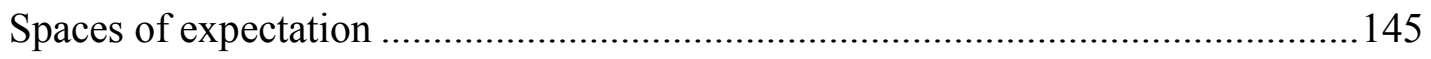

CHAPTER 6: DISCUSSIONS AND DELIBERATIONS ..............................................147

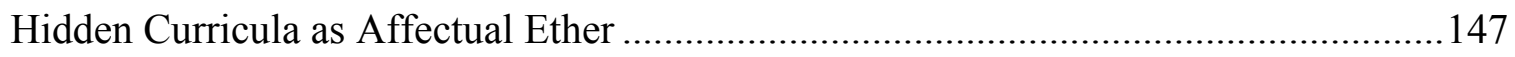

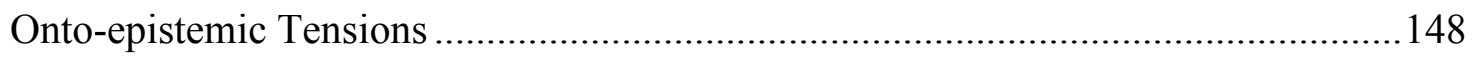

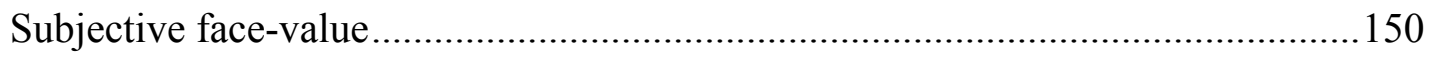

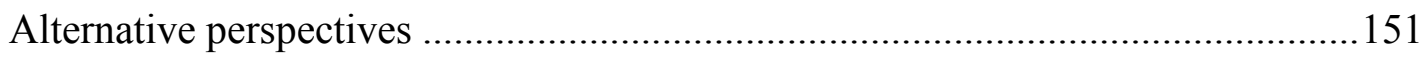

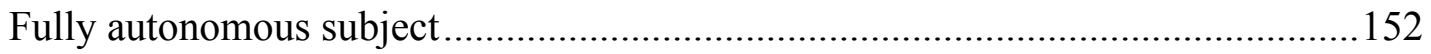

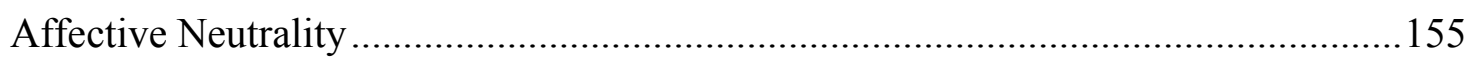

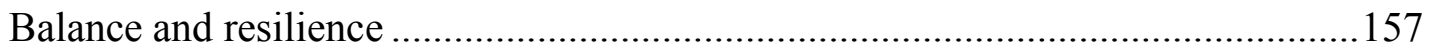

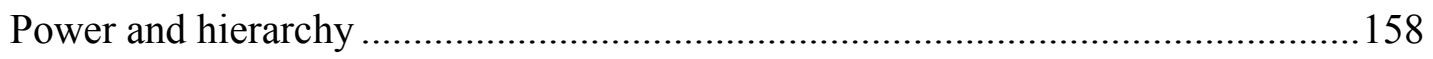

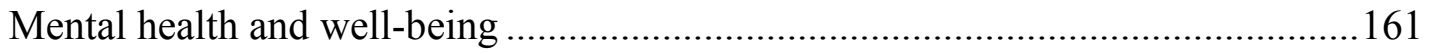

Freedom, Debt, and Hope/lessness ........................................................................ 163

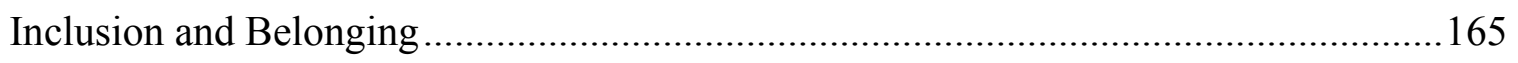

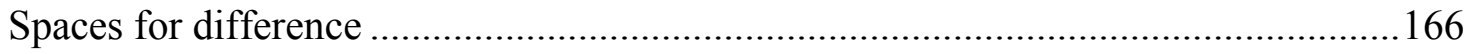


Affect/emotion

Social justice.

Possible Futures

For Research 169

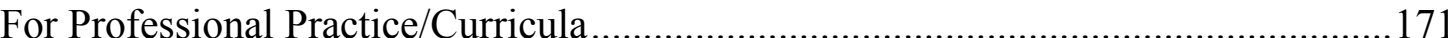

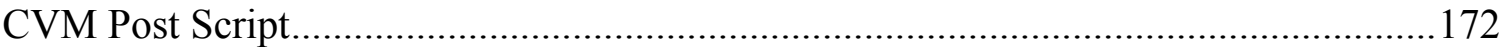

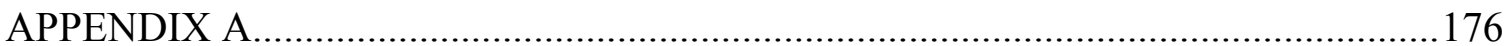

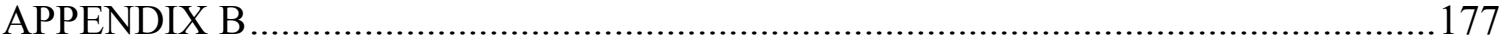

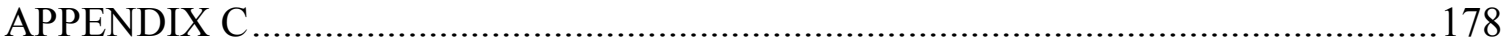

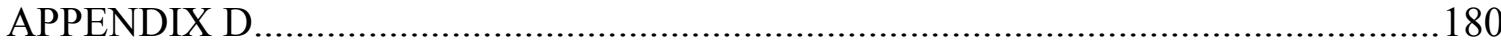

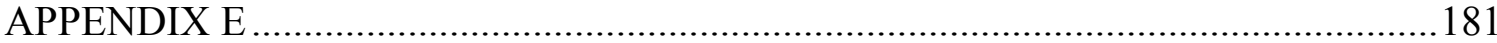

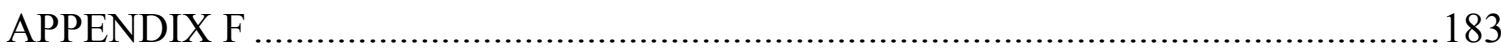

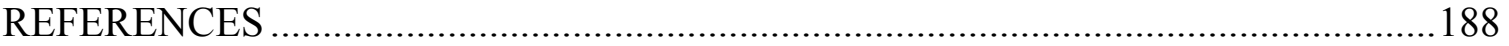

VITA 


\section{List of Tables and Figures}

Table 1. Jeffersonian transcription markings derived from Jefferson (2004) .................181

Table 2. In-process example of side-by-side merging of data and writing and thinking in

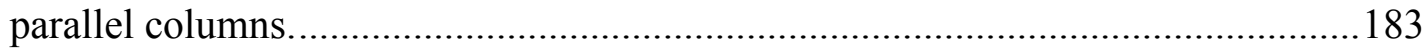

Figure 1. Mixed media artwork by Edward G. Hancock, dated February 17, 2018, titled

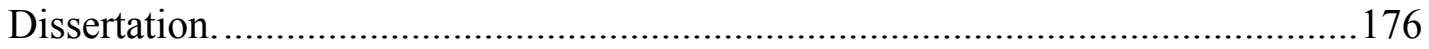




\title{
GENEALOGIES OF AFFECT AMONG A YOUNG VETERINARIAN'S PUBLIC
}

LETTER: AN EXPLORATORY STUDY OF HIDDEN CURRICULA IN A COLLEGE

OF VETERINARY MEDICINE

Tamara S. Hancock

Dr. Troy D. Sadler, Dissertation Supervisor

\begin{abstract}
Contemporary research in veterinary medical education indicates alarming rates of depression and anxiety among veterinary students. Yet, the focus of this scholarship is primarily on mental illness as effects of a social and relational process, rather than interrogating the affectual nature of the process. Medical education has a long history of interrogating various facets of socialization as largely embedded in the hidden curricula - the tacit culture of a social entity, and repository for values and norms of conduct. Unfortunately, scant scholarship explores the hidden curricula of veterinary medicine. Recently, an anonymous letter signed Young Veterinarian was published on a public website, and opened an electronic dialogue regarding the nature of affects imbedded in professional socialization. Many themes of the letter referred to issues imbedded in the literature. This study followed this online dialogue, and initiated one in a College of Veterinary Medicine. Centering this letter, object-focused interviews were conducted to explore how members of this community are affected by the anonymous letter. Analytical insights suggest three broad areas of affects related to the hidden curricula: Onto-epistemic tensions; affective neutrality; and freedom, debt, and hopelessness. Implications for research and professional practice/curricula are discussed and deliberated.
\end{abstract}




\section{CHAPTER 1: INTRODUCTION}

Not long ago, an Open letter from a disillusioned veterinary graduate (henceforth The Letter) was published on a public website, dvm360.com (dvm360.com staff, 2017). The Letter reads:

Recently I had an interesting conversation with a technician at work. She's bright, motivated, diligent and interested. She wanted to be a veterinarian when she was younger, but those dreams went by the wayside due to life circumstances and finances. Her father asked her if, since she's now working in a veterinary hospital, her old desires have been rekindled. Did she still want to be a vet?

"I think you would make a good veterinarian," I told her. "But I don't think you should go to vet school." The other recent grad and the fourth-year extern standing nearby immediately echoed my sentiments.

Why did we offer this advice? And why are veterinary students so

unhappy? Why do they suffer from anxiety and depression at alarming rates? It's a multifaceted problem, but everything boils down to incredible anger about our experience in vet school.

Anger because we worked hard with little reward. Anger because we had to sacrifice our hobbies, social lives and emotional wellbeing to study, do grunt work and write volumes of paperwork no one would ever read.

Anger because we were at times mistreated, yelled at and punished for things we didn't do. 
Anger because we were bombarded by statistics and articles that say vets are overpopulated, vets make salaries that are not consummate with the time and tuition they put out, vets are to blame for killing animals or practicing pseudoscience and are crucified on social media — with career- and life-ruining effects.

Anger because we watched animals suffer and die needlessly, were witness to errors we didn't have the power to fix and slogged on daily through injustice and mismanagement.

Anger because of the cumulative effects of massive, unrelenting stress. It's true that veterinary medicine attracts Type A people - the overachievers and the perfectionists. But I'm not referring to stress from internally driven motivators. There's a prevailing attitude in veterinary medicine that people need to "put in their time"—work like a dog for years, suffer, slave away, and slowly crawl to the top of the pile through copious blood, sweat and tears. I disagree.

This field needs collaboration, camaraderie and healthy competition. Instead, it has backstabbing, gossip and cutthroat antagonism. And at the university, I saw efforts to sabotage careers out of personal vendettas. I saw great attempts to discredit and embarrass clinicians in front of their students and peers. I saw patient care go by the wayside, a casualty of intra- and interdepartmental quarrels. And I saw - and even received - unjustified, over-the-top criticisms and punishments in order for someone to maintain a façade of undeserved authority.

At school I also had to follow orders I didn't agree with. On one occasion, I took part in a euthanasia for an ailment with a treatable solution, though the 
client hadn't been apprised of this fact because the head clinician refused to acknowledge its possibility. Those of us in the opposing camp were vindicatedtoo late - at necropsy. Obedience and fear of consequences kept our mouths shut. But such cases continue to haunt me.

I can't wave a magic wand and make the outlook better for graduating vets. But I can offer some guidelines to serve as counterpoints to some of the negative behaviors I observed as a clinical student.

Be realistic. If the head clinician is overwhelmed, the house officers probably are, too, and the students are probably running around like maniacs trying to keep the whole thing afloat. Each person should try to recognize when someone is in over their head and help out accordingly. There were many times when I witnessed technicians sitting around gossiping or snacking while students juggled menial patient care and other pressing responsibilities—or when senior clinicians vanished to an office hideout while underlings were left to clean up messes, both literal and figurative.

Furthermore, 15-hour days, five days a week, plus emergency shifts, nighttime patient medication and walking, and weekend care just isn't sustainable for a student who's also trying to study for a block exam, prepare for boards, take care of responsibilities at home, read up on upcoming cases, finish paperwork and more.

Be respectful. The Golden Rule still applies, even behind closed doors when superiors aren't watching. I've witnessed some utterly heinous behavior from respected "professionals," directed both at students and at fellow doctors. 
This is demeaning, stress-inducing and morale-killing. It seriously contributes to workplace dissatisfaction, which leads to further pent-up anger, tensions, inefficiency and ultimately bad service for animals and clients.

Be receptive. Sometimes good ideas come from unexpected places. Sometimes clients can diagnose their pets before the doctor can, because they know the animal better. Sometimes students are armed with more up-to-date knowledge on their cases than the clinician, since the classes are fresher in their brains or because they took the time to comb through PubMed looking for a solution. Don't discount these ideas just because they didn't come from an "expert."

Be relevant. I've seen bad or outdated science touted as unquestionable fact. We must grow and change with the times. Universities should be at the forefront of medical progress, not stuck in the Stone Age out of stubbornness and reliance on "tradition." We have to challenge our dearly held beliefs daily if we hope to grow, remain current and be good doctors. Our patients and clients deserve nothing less.

There are certainly some excellent individuals serving as clinicians and teachers at universities. I hope these people who still value teaching high-quality medicine and the pursuit of scientific knowledge will remain in academia so future students can benefit from their knowledge and altruism.

This is how dialogue in the veterinary community ought to work. Please don't forget this.

\section{Sincerely,}




\section{A Young Veterinarian}

The website that published The Letter is a veterinary news aggregator and publisher. Their twitter profile touts a bio which positions them as, "The definitive source for veterinarians and team members for veterinary news, medicine, business, hospital design, events, and community" (dvm360, 2017). They publish several glossy magazines (e.g., $d v m 360$, Firstline, and Vetted) as well as offer up numerous email newsletters either associated with the magazines or geared to keep veterinarians in-the-know about news topics aggregated around interests such as business, products, or hospital design. In this regard, The Letter represents a contribution to the profession. It introduces experiences, ideas, and then suggestions for moving forward. It opened a dialogue and exchange of ideas in comments sections of this post and other shares where people from in and outside the profession remarked, responded, or rejected what was written by the Young Veterinarian or other commenters.

Many themes evident in this dialogue with The Letter have percolated in scholarship of veterinary medical education, such as poor mental health/well-being, professionalism, and the hidden curricula. For instance, Young Veterinarian, The Letter's author, makes claims that "veterinary students [are] so unhappy" and "suffer from anxiety and depression at alarming rates" (dvm360.com staff, 2017). Indeed, the prevalence of poor mental health in veterinary medical students is well-established and staggering. Many studies have found at least one third of veterinary students are experiencing symptoms of depression that are above the clinical cut-off (Cardwell et al., 2013; Hafen, Reisbig, White, \& Rush, 2006, 2008; Siqueira Drake, Hafen, Rush, \& 
Reisbig, 2012; Sutton, 2007) with some reporting up to two thirds (Killinger, Flanagan, Castine, \& Howard, 2017; A. M. J. Reisbig et al., 2012).

Scholarship to date has illuminated staggering prevalence of depression and anxiety in the veterinary profession (e.g., Siqueira Drake et al., 2012) and a majority of this work highlights individuals and mental illness or poor well-being as an unintended effect. Yet, little attention is paid to the interrelated nature of well-being, reflectivity, and tolerance of uncertainty with clinical performance (Benbassat, 2014). This indicates negative patient outcomes are also elaborated when doctors or trainees suffer with mental illness or poor well-being. The connection among the profession as a social entity, although implied, is largely absent in much of this work. A shift in attention to the social and processual nature of such unintended and deleterious effects is a dire need among veterinary medical education scholars.

Over the past several decades there has been a rapid and dramatic gender shift in the veterinary profession, from predominantly men to predominantly women (Association of American Veterinary Medical Colleges (AAVMC), 2017). The process of professional socialization and general structures of curricula in the veterinary profession have not changed much since they were established. The history of mental illness is grounded in social norms that often follow gender lines. Moreover, the sociology of emotion, whether performative, cultural, or otherwise, is gendered (Jaggar, 2009). Feminist accounts of exclusion on the basis of emotion could contribute to an inquiry of this nature (Boler, 1999). Prohibition of discrimination on the basis of gender has been outlawed, and accordingly it is not expected that any formal curricular plans or practices should reveal discrimination. However, hidden curricula represent a repository of 
embedded value systems that circulate among professional communities and schools, and could provide insight into practices or systems of exclusion. Unfortunately, very few studies in the veterinary medical educational scholarship explore or illuminate hidden curricula.

On the other hand, Young Veterinarian speaks their truth to issues of professionalism, and its reciprocal relationship with the hidden curricula, and makes several claims,

And at the university, I saw efforts to sabotage careers out of personal vendettas. I saw great attempts to discredit and embarrass clinicians in front of their students and peers. I saw patient care go by the wayside, a casualty of intra- and interdepartmental quarrels. And I saw — and even received — unjustified, over-thetop criticisms and punishments in order for someone to maintain a façade of undeserved authority.

The hidden curriculum, the tacit culture of an institution which socializes students in normative ways to be a professional, is evident in The Letter. Research has demonstrated that hidden curricula become apparent when students are affected by it —in experiences that deviate from what is expected or espoused in curricula and tensions and/or surprises emerge (see Hill, Bowman, Stalmeijer, \& Hart, 2014; Jaye, Egan, \& Parker, 2006; MacLeod, 2014; Monrouxe \& Rees, 2011; Phillips \& Clarke, 2012).

In this particular passage from The Letter, attention is called to a hidden curriculum, to what behaviors were/are permitted or not regarding relationships among other professionals - among colleagues. The relationship among, and primary responsibility to, professional colleagues and the profession, defines professionalism 
(Goldberg, 2008). In The Letter, the author implores the profession to embrace "collaboration, camaraderie and healthy competition" as tenants of professionalism, rather than "backstabbing, gossip and cutthroat antagonism" (dvm360.com staff, 2017). Remarkably, both exist in the comments that follow. Many commenters provided support, understanding, and acknowledgement, and just as many provided the same "cutthroat antagonism" and categorical disdain such as, "I could go on about you Millennials" or, "listen here little lady." This suggests a critical need for continued civil dialogue "in the veterinary community" that is, as Young Veterinarian requested, realistic, respectful, relevant, and receptive (dvm360.com staff, 2017).

In consideration for these stories, histories, and current findings regarding mental health, feminization, and hidden curricula, and in operationalizing a shift in attention to veterinary medical education as a socialization process, questions are raised. What, if anything, of the process of professional socialization contributes to the inclusion of individuals living with and recovering from mental illness or under unproductive distress? What norms of affect might contribute to exclusion which further fragments and compounds distress and/or mental illness?

This study brings together well-being/mental illness, hidden curricula, and gender for the study the professional socialization process and associated inclusion. As little scholarship exists to orient the research into this area, a theoretical perspective that can encompass many and uncertain findings was needed. Investigation into such matters, and to do so in a way which highlights and interrogates these as relational processes, a mechanism to "cast previous work in a fresh light" was sought (Hardt, 2007, p. ix). 
Affect is a theoretical orientation that casts this fresh light. It helps scholars to both "grasp the changes that constitute the social and to explore them as changes in ourselves, circulating through or bodies... yet irreducible to the individual, the personal, or the psychological" (Clough, 2007, p. 3). That is, as an impetus for research, affect encourages us to enter the realm of causal relationships with complexity in mind, simultaneously exploring both sides of the relationship (Hardt, 2007). In these ways, affect is a theoretical means to investigate the power to affect the world while at the same time being affected by it. In these powers are equal considerations of and among body and mind, reason and emotion.

Given the profound lack of scholarship that could guide a study of process and affects in the veterinary medical profession, The Letter was introduced as an object to anchor this exploratory study, which followed the guiding question: How does The Letter affect members of a College of Veterinary Medicine (CVM) community? Throughout the study, additional, analytical questions were developed and used to explore data and produce insights. These analytical questions were: (1) How did these affective values come to be for this person? (2) How do these affects produce (dis)connection? and (3) How do affects delegitimize The Letter as an account of hidden curricula?

This research involved continued conversations centering The Letter with fourteen participants of a CVM community in the Midwestern United States. Participants included faculty, students, and house officers. Analysis involved interrogating data with theory and producing insights related to affects as values, as relational forces, and as sociopolitical forces. I hope this scholarship affects those who come into contact with it 
the ways Young Veterinarian hoped for-in ways that are realistic, respectful, relevant, and receptive.

\section{Significance of Study}

As previously articulated, little work exists in veterinary medical educational research which explores well-being/mental health in relationship to the socialization process. Furthermore, scant research articulates or explores facets of hidden curricula in the veterinary profession. In considering the nested and affectual relationship among well-being/mental health and curricula, this study is an expedition into an important unknown. In this regard, these results lay the groundwork for additional work with hidden curricula, professional socialization, and veterinary medical education as a social entity - in particular, those social, political, and relational processes as associated with mental health and well-being.

\section{Summary of Chapters}

This introductory chapter provides orientation to issues of mental-health and wellbeing in veterinary medicine and offers windows into the vast gaps in scholarship. In addition, it introduces The Letter as a public offering to the professional community which explores some of these gaps and more well-known issues. Chapter two provides reviews of relevant literature. Chapter three addresses the theoretical orientations of the study. Chapter four explains data, methods, and methodologic rationale used. Chapter five elaborates the insights derived from this research. Chapter six is the discussion and deliberation of the insights in conversation with relevant literature. This final chapter concludes by offering avenues for additional research, introducing implications for 
veterinary education and practice, and offers a few cursory suggestions for the partner CVM this research was situated in. 


\section{CHAPTER 2: LITERATURE REVIEWS}

Several literature bases are reviewed for this study. First, the scope and magnitude of issues related to mental health and well-being of veterinary students are reviewed. Next, as mental health and well-being are necessarily related to emotion or affect, these topics and associated constructs, such as empathy, are discussed in relationship to the profession. Lastly, hidden curriculum scholarship, with attention to that of veterinary medicine, is also reviewed. These three literature bases are put in conversation and illuminate a focus of scholarship in need of attention.

\section{Mental Health and Well-being in Veterinary Medicine}

The corpus of scholarship regarding veterinary student well-being represents multitudes of dichotomous and overlapping vantages - positive/negative, individual/social, values, priorities, and emotions - with research primarily concentrated on the individual and negative. A focus on stress, depression, anxiety, and related predictors predominates. Mental health is regarded as the lack of serious psychological distress (Nolen, 2018), and well-being is more holistic and related to overall life satisfaction which encompasses both positive and negative dimensions of physical, social, and emotional health (Mastenbroek, 2017). To begin, I define several related concepts and how they are commonly investigated and reported.

Stress is productive and associated with a range of outcomes. On one extreme, the outcomes are wholly positive, such as being able to "respond effectively in times of trauma" or increasing our "performance or efficiency" when needed (Gelberg \& Gelberg, 2005, p. 173). On the other end, stress becomes distress and is associated with negative consequences that damage performance; increase anxiety and depression; reduce 
efficiency; and generate physical, emotional, behavioral, and cognitive health problems (Gelberg \& Gelberg, 2005). Most studies on mental health and well-being seek to define or validate certain stressors related to the production of stress and/or associated distress.

Depression is a clinical disorder that manifests as a "lack of interest or enjoyment in daily activities" (Hafen et al., 2006, p. 433) as well as a constellation of various cognitive, affective, and behavioral symptoms. Individuals who are living with depression often express feeling sad and hopeless. Depression arises from a constellation of factors including those that are personal, familial, and environmental. Most studies of depression in veterinary medical professionals refer to depression as "depressive symptomology a participant reported to have experienced" (Reisbig et al., 2012, p. 343), rather than a clinical diagnosis. Anxiety is "characterized by an apprehensive anticipation of future danger or misfortune that is accompanied by emotional disruption or physical tension" (Hafen et al., 2006, p. 433). Like depression, studies typically referred to anxiety as reported anxiety symptomology, not a diagnosis.

\section{Depression and Anxiety}

At least one third of veterinary students are experiencing symptoms of depression above the clinical cut-off (Bakker, Lyons, \& Conlon, 2017; Cardwell et al., 2013; Hafen et al., 2006, 2008; Karaffa \& Hancock, 2018a; Siqueira Drake et al., 2012; Sutton, 2007). Where the clinical cut-off indicates a threshold where it becomes likely that symptoms are affecting academic, psychological, and social functioning. Some studies report even higher prevalence, Killinger et al. (2017) reported a depression prevalence of $66.4 \%$ in their sample of 1,245 veterinary students across North America. Likewise, Reisbig et al. (2012) report across three semesters, 49 to $69 \%$ of students reported depression 
symptoms at clinical levels. It is worthwhile to consider these data with other prevalence, such as medical students (23\%), undergraduate students (23.7\%), and the general public (21.5\%) (Reisbig et al., 2012). It is unsurprising, then, that veterinary students have reported a lower quality of life when compared with their medical school peers (Labbafinejad, Danesh, \& Imanizade, 2016).

Anxiety is also common among veterinary students with up to $84 \%$ of students reporting feelings of anxiety as a significant part of their previous year (Sutton, 2007). Yet, only a small proportion of students are aware of a history of living with an anxiety disorder (Kogan, McConnell, \& Schoenfeld-Tacher, 2005) which suggests their experiences while in veterinary school affect them in ways which produce these feelings of anxiety. Like depression, anxiety scores increase over time (Hofmeister, Muilenburg, Kogan, \& Elrod, 2010; Siqueira Drake et al., 2012) and peak in the second and third years of study (Siqueira Drake et al., 2012). During this state of heightened anxiety, the average scores were above the clinical threshold, indicating it is likely their symptoms are affecting their academic, psychological, and social functioning. Many findings regarding anxiety are interrelated to those of depression, which indicates and reinforces the relationship between depression and anxiety.

Over time, depression and anxiety scores of students increase and peak in the second and third years of study and during these peaks, scores are above the clinical threshold (Siqueira Drake et al., 2012; Reisbig et al., 2012). Miller et al. (2015) corroborated this 'sophomore slump.' They found second year students had the lowest scores of self-esteem compared with all other years of study in a veterinary program. The sophomore slump is a known phenomenon "characterized by personal issues of self- 
confidence, uncertainty about the purpose of their studies, academic pressures, and struggles with engagement in learning and motivation" (p. 358).

\section{Stressors}

There are a host of academic and non-academic stressors correlated with or predictive of depression and/or anxiety. Reisbig et al. (2012) elaborate four common themes of stressors in veterinary students: Academic stress, transitional stress, familyhealth stress, and relationship stress. Academic stress included concerns regarding heavy workloads, difficulty understanding course material, and feeling uncertain about what is expected. Transitional stress referred to stress associated with finances, fitting in with other students, and homesickness. Family-health stress relates to family illness or the death of a loved one, and relationship stress relates to relationship conflicts and balancing relationships with school-work responsibilities. Each of these categories have significant impacts on students' well-being.

Transitional stressors are correlated with increased depression and anxiety and decreased life satisfaction (Bakker et al., 2017; Hafen et al., 2006, 2008; Kogan, McConnell, \& Schoenfeld-Tacher, 2005; A. M. Reisbig et al., 2012; Siqueira Drake et al., 2012; Strand, Zaparanick, \& Brace, 2005; Weston, Gardner, \& Yeung, 2017). Similarly, relationship stress is correlated with increased depression and/or anxiety stress (Kogan et al., 2005; Reisbig et al., 2012; Sutton, 2007). The role of care-taking responsibilities (pets or humans) can also be significant in the development of depression and/or anxiety (Kogan et al., 2005; Strand et al., 2005). Academic stress impacts depression and anxiety symptoms, overall life satisfaction, general health, and GPA. Several specific academic stressors are known to correlate with or predict depression 
and/or anxiety across all years of study: general 'concerns' about academic performance including GPA (Hafen et al., 2006, 2008; McLennan \& Sutton, 2005; Miller et al., 2015; A. M. Reisbig et al., 2012; Williams, Arnold, \& Mills, 2005), workload or heavy burden (Siqueira Drake et al., 2012; Sutton, 2007; Weston et al., 2017), unclear expectations (Bakker et al., 2017; Reisbig et al., 2012; Siqueira Drake et al., 2012), and lacking study skills and/or time management techniques (Laakkonen \& Nevgi, 2014; Moore, Truscott, St Clair, \& Klingborg, 2007; Strand et al., 2005; Sutton, 2007). When directly asked, students reported three themes of academic concerns: intensity of the program, lack of clinical relevance, and academic preparedness (Sutton, 2007). The intensity of the program was described as "unforgiving" regarding quality and quantity of content in relationship to time available to survive (e.g., commute, sleep). When this lack of time for simple sustenance are considered in conversation with the myriad non-academic stressors, it is no wonder many veterinary students do not reap the positive academic benefits of stress and find themselves distressed. Indeed, academic and non-academic stressors are inextricably linked to the poor mental health in veterinary students. What it is about the connection between an individual and their constellation of known and unknown stressors that precipitates distress during their training remains mysterious.

Given the complexity of these constellations, longitudinal perspectives on the topic of anxiety and depression are welcome, yet few studies use repeated measures or longitudinal design. On average, most veterinary students experience a decline in wellbeing as indicated by depression and/or anxiety (Bakker et al., 2017; Hafen et al., 2008; Hofmeister et al., 2010; Miller et al., 2015; Moore et al., 2007; Reisbig et al., 2012; Siqueira Drake et al., 2012). Two trends which aggregate similar patterns of depression 
scores, adaptive and struggling, have emerged (Hafen at al., 2008). Adaptive includes decreases in scores to non-clinical levels or scores that remain below the cut-off over two time periods. Struggling includes those scores that increase above the cut-off over time, increase to clinically significant, or increase greater than or equal to one standard deviation. Students with concerns about physical health or persistent academic concerns puts them at greater risk for categorization into the struggling category (Hafen et al., 2008). Further, students who score significantly higher in measures of psychological capital (PsyCap), which are individually focused resources related to "who you are" rather than "“what you know' (human capital) and 'who you know' (social capital)," are more often considered adaptive (Bakker et al., 2017, p. 57)._The PsyCap resources related to being adaptive includes self-esteem, optimism, hope, and resilience.

\section{Positive Psychology}

As previously mentioned, there are fewer studies which focus on positive dimensions of well-being. Positive Psychology as a movement represents a move from deficit models of well-being and psychology (Compton \& Hoffman, 2013). Positive psychology advances that what is good is more than the converse of pathology, it requires its own explanation. The focus for action is on what is going well and capitalizing on it, rather than focusing on what is not. In this regard, some schools and scholarship have opted to focus on constructs of positive psychology for a different vantage on mental health and well-being.

The work which emphasizes the interrelationship between positive psychology, greater well-being, and an inverse relationship with depression and anxiety (see Bakker et al., 2017; Gardner \& Parkinson, 2011; Moore et al., 2007) is interpreted with caution. 
The metrics used to evaluate the presence of positive and pathologic psychologic variables likely do not independently vary and covariance is not considered in analyses. For instance, Gardner and Parkinson (2011) reported that students with greater optimism and self-esteem were less stressed and had higher life satisfaction, yet the predictive relationship between stressors and depression has already been established (see Bakker et al., 2017; Hafen et al., 2008; Hofmeister et al., 2010; Miller et al., 2015; Moore et al., 2007; Reisbig et al., 2012; Siqueira Drake et al., 2012).

Citing the link between mindset ${ }^{1}$ and resilience, a few scholars have centered these constructs in their inquiries. In a cross-sectional sample across six veterinary schools in Australia, only $6 \%$ of students were at or above a threshold that indicates 'highly resilient' (M. McArthur et al., 2017). Even more, approximately one third were classified as having low levels of resilience. They further considered the relationship between mindfulness practice and resilience, and demonstrated higher nonjudgmental and nonreactive mindfulness, and self-compassion were related to higher resilience scores. Yet, Root Kustriz (2017) results refute an easy link between mindset and resilience. They investigated a small cross-sectional sample of students from a single year, and found that mindset was not correlated with GPA or perceived stress. Further, $70 \%$ had a growth mindset or a growth mindset with some fixed ideas. Whittington, Rhind, Loads, and Handel (2017) indicated students with a fixed mindset scored significantly lower in autonomy, personal growth, positive relations with others, purpose in life, and self-

\footnotetext{
${ }^{1}$ Mindsets are based on much of Carol Dweck's research, which articulates two mindsets regarding intelligence. A fixed mindset sees intelligence as just that-fixed. Prompting learners to see setbacks as failures and themselves as incapable of doing better. In contrast, growth mindsets see intelligence as malleable and capable of growth. Setbacks are forms of feedback and these individuals tend to approach challenges as opportunities rather than setbacks. See Dweck (2006).
} 
acceptance. McArthur, Andrews, Brand, and Hazel (2017) demonstrated that autonomy is inversely related to burn out, suggesting that the "significant time commitments and rigid structures that may largely dictate the personal life of the student" add to a lack of autonomy and in turn contribute to burnout (p. 15). Together these findings suggest students with growth mindsets report more positive experiences in veterinary school, though these positive experiences most likely do not translate to changes in GPA (positive or negative). Further the relationship, if any, between mindset and resilience is complicated and poorly understood. Indeed, dimensions of positive psychology may prove to be important targets of interventions, yet the complexity and persistent ambiguity of these constructs and their relationships to others (e.g. depression) should not be underemphasized.

The focus on resilience has drawn critiques in medical education (Baker \& Sen, 2016). Proponents of resilience purport its necessity as a fundamental skill of clinical practice and training, both of which are inherently stressful (Cake, McArthur, Matthew, \& Mansfield, 2017; M. McArthur et al., 2017). Indeed, stress is beneficial in times of trauma and can lead to increases in productivity (Gelberg \& Gelberg, 2005). Many specialists who work in academic settings have likely harnessed this stress in their preparations for an impending board examination. Yet this brings to light a contributing factor to the perpetuation of a culture that dismisses its contributions to the issue at hand. Those who are in academic veterinary medicine are likely "supernaturally resilient" (Baker \& Sen, 2016, p. 605). Successfully navigating the rigors and demands of veterinary school, an internship(s), residency, and likely a graduate program while remaining psychologically and physically resilient is no doubt a source of pride for many. 
Baker and Sen (2016) ask, "in harboring this ideal and reinforcing it throughout training, do we create a culture in which [future colleagues] easily lose sight of the fact that we are also human beings subject to illness vulnerabilities" (p. 605)? Arguably the focus of scholarship on the inability of others to "successfully" be resilient in the ways others have suggests to some degree yes.

Medical students also have reportedly high levels of depression and anxiety (Benbassat, 2014). Benbassat (2014) emphasized, in total, the sum of findings consistently indicates "medical training causes emotional distress" (p. 597). Importantly, well-being, moral development, reflectivity and tolerance of uncertainty are interrelated and associated with clinical performance. All together, these results indicate not only is training deleterious to those who undertake professional school, but also has negative outcomes for patients.

\section{Promise Among Peril}

Developing relationships and identities outside veterinary medicine have been shown to have a protective effect against depression and anxiety. Although, there are no statistical differences in depression levels between groups of students in romantic relationships and those who are not, when groups of higher functioning and lower functioning relationships were compared, there were significant difference. Higherfunctioning relationships provided protective effects against depressive symptoms, lower stress of work/life balance, less relationship conflict, better physical health, and improved ability to cope with the expectations of veterinary school (Hafen, Ratcliffe, \& Rush, 2013). Further, higher-functioning and satisfying relationships require time and effort (Siqueira Drake et al., 2014), which emphasizes the tensions associated with the inverse 
relationship of attending to the rigors of study in and out of the classroom and maintaining high-functioning relationships in veterinary school. Regarding colleagues and friendship, most students identify peer support as the most important resource for ongoing stress associated with their studies (McLennan \& Sutton, 2005) and when burnout is assessed, living with a fellow veterinary student is significantly associated with decreasing burnout (Chigerwe, Boudreaux, \& Ilkiw, 2014).

Greater than $90 \%$ of veterinary students and practitioners surveyed agreed wellbeing is necessary for success as a veterinary student and in the profession (Pickles et al., 2012). Fifty percent of U.S. schools and $40 \%$ of international schools have on-site faculty or staff to provide counseling services. In North America, approximately $70 \%$ of those providing services are designated to provide for veterinary students specifically. Although most schools offer counseling free of charge and do not have limits on the number of free sessions, roughly one fifth impose some limit on the number of sessions (Kogan et al., 2012). Yet, despite awareness of poor mental health and easy access of services, many students do not seek help (Cardwell et al., 2013; Karaffa \& Hancock, 2018a; Kogan et al., 2012; Pickles et al., 2012). Ninety-four percent of veterinary students agreed anyone can suffer from mental health problems, but then a much smaller proportion suggested if they were suffering with poor mental health they wouldn't want anyone to know about it (Cardwell et al., 2013). This indicates stigma is a barrier to seeking services. They reported participation in counseling, and being associated with, having poor mental health may affect their future school and career opportunities because of lapses in confidentiality (Cardwell et al., 2013; Kogan, Schoenfeld-Tacher, \& Hathcock, 2012; Winter, Rix, \& Grant, 2017). So, despite increased awareness and 
availability of services, significant social and cultural barriers exist that prohibit the help seeking behaviors of veterinary medical students. This emphasizes the need for community, culture, social, or relationally oriented inquiries around well-being.

\section{Emotions in Health Professions Education}

Emotions are imbricated with well-being (Alexandrova, 2014), professionalism and competence (Dornan, Pearson, Carson, Helmich, \& Bundy, 2015; McNaughton \& LeBlanc, 2012) and gender (Jaggar, 2009). They are implicated in, and integral to, a variety of cognitive processes such as decision making and memory (Doyle \& Zakrajsek, 2013; McNaughton \& LeBlanc, 2012), which highlights foregrounding emotions as a necessary for matters related to professional practice and training.

This review and associated scholarship spans multiple disciplines and the languages of emotion are varied. Briefly, I will explain the various, and interrelated, terms of emotion, namely: Emotion, feeling, and affect. Although emotion refers to socioculturally labeled and inscribed linguistic and paralinguistic expressions, the term feeling is often colloquially used interchangeably with emotion. Scholarship separates the two, with feelings referring to sensorial experience of a given emotion, e.g., heart-racing, sweaty palms, and butterflies in your stomach the feelings you might associated with being anxious. Expressing feeling as an emotion, you might state, "I feel nervous," or shake, wring your hands, pace, or fill the space with rapid speech. Emotions as discretely defined categories are constrained and created by the culture or social group they originate within. Although feelings and subsequent emoting are both doings, they are both originating within an individual. 
Affect is sometimes used to encompass and/or approximate feeling and emotion, and is defined as an action; a social process. Affect is the social movement between and among feeling and emotion and other affective capacities. Theoretically, this study is rooted among affect. As a theoretical study of process, the term affect will primarily be used, yet the terms emotion or feeling may also be used. At times, this will be to represent the terms used by another scholar, participant, or as interchangeable. The discourse and positioning of affect, emotion, and feeling are discussed in several other sections ahead.

\section{Philosophical Roots of Emotion}

Writing on emotion dates to the Enlightenment period in Western Philosophy where philosophers such as Descartes, Hume, Spinoza, and Kant. These philosophers made contributions to how we think and reason about emotions which are still evident to date. Hume positioned emotion as central in moral deliberation and Kant rejected Hume's position, and instead emphasized how we must 'do away' with emotion (drawing on Stoicism) to become rational. One of Descartes biggest legacies is his concept of dualism - the mind as spiritual and the body as material. That is, the mind and body as separate entities. His statement, "I think therefore I am," signals thinking is essential to being, which leaves the body as a material substance, or simply put, a vessel which follows the mind. Descartes positioned emotion as the integral node between the mind and body, but not of either. Since the mind is the only substance capable of clear perception, certain knowledge can only come about a priori (through reason alone) and any knowledge that comes through the body is unreliable. 
Spinoza, on the other hand, opposed dualism and instead suggested a dual aspect monoism with passions and affects. This considers mind and body two "attributes of a unified substance" rather than two distinct entities (Ellis \& Tucker, 2015, p. 56), marking a move away from Descartes' dualism. With Spinoza, affects and passions are related to flows of power and are relational. He positions that nothing can be characterized by a distinct essence. Rather, affects are relational patterns dependent on different configurations that increase our powers to act (to affect or be affected) or decrease our powers. More specifically, affect depends on the relationship bodies have with other external objects and these object affects do "not have a single mode" (Ellis \& Tucker, 2015, p. 57). Rather, affect(s) "will always depend upon the specifics of the relationship [among the] interact[ion]" at the moment (p. 57). Spinoza positions external factors as the sole source for enacting affective change ${ }^{2}$ in contrast to Descartes theory where the mind has total control. Passions were conceptualized as passive affects that are deemed 'inadequate' because their causal and relational emergence is unclear.

These philosophical understandings undergird much contemporary thought on emotion and affect. Descartes positions the mind and its capacity to reason as separate from the body, connected through emotion, and having total control. On the contrary, Spinoza philosophized affects, which encompass emotion and passion, are external to the unified substance of mind and body. Kant positions emotions as unstable oppositions to reason and thought and Hume makes clear emotions are keys in moral deliberation. These four stake out diverse and, at times, contradictory views on emotions and affect, which

\footnotetext{
${ }^{2}$ Spinoza positioned a pantheist view here that supported a single external source, God. More contemporary interpretations position these external sources as all-inclusive - that is, all that is intangible.
} 
come to affect the ways in which emotions and affects are researched and discussed.

From this mire, with a social and processual inquiry in mind, I position my study with the philosophical tradition of Spinoza. Where affects, including emotion, are social and mind and body are unified in the capacity to act and be affected.

\section{Scholarship of Emotion and Affect}

Given these philosophic roots, the relationship between emotion and affect is complicated by more contemporary scholarship. Briefly, I will cover some of the big distinctions made across research traditions. Namely, emotions broadly conceptualized in three categories: neuroscientific, cognitive, and sociocultural. Where the sociocultural view establishes a nested relationship, with emotion as an affect, but not all affects as emotions.

The neuroscientific view places emotion as a pure construct of brain structures, e.g., the limbic system, amygdala, and other "older" and more "primitive" areas of the brain that connect us with other animals (McNaughton \& LeBlanc, 2012). Cognitive concepts of emotions and subjective experiences, are interrelated and play an important role in cognitive processes such as "attention, perception, memory, and decision making" (p. 80). Much neuroscientific research supports this cognitive view of emotion. For instance, the amygdala is implicated in the "interpretation of emotional social information and memory of emotional information" (p. 78). The prefrontal cortex is integral to decision making and planning has a role in emotions - research on individuals with irreparable damage to the prefrontal cortex show they consistently and without cessation make decisions that lead to significant social, financial, interpersonal losses. These results position emotion as indispensable to human functioning, which undercuts the 
neuroscientific views of emotion as "primitive and antithetical to reason and higher order cognition" (p. 77).

The neuroscientific views have a clear connection to Descartes' views of emotion — as a node between an individual's mind and body. The cognitive view, like

dualism, leaves the body behind, focusing solely on the role of thinking and knowing as a property of the mind alone. Although these biologic and cognitive views of emotion are important to round out our understanding of emotion, social relation is the fundamental way we connect and communicate. Ignoring social constitutions, overlooks "a vast swathe of human experience and activity" (Ellis \& Tucker, 2015, p. 3).

Sociocultural to poststructural, postmodern, and/or sociomaterial theories of emotion conceive of it as socially, culturally, and materially constituted and distributed. This directs research and attention to what emotion does - its function and "role as social, political, and cultural mediator" (McNaughton \& LeBlanc, p. 84). McNaughton and LeBlanc caution competency-based approaches, even when informed by socially-oriented theories of emotion, inadvertently shift the focus back to cognitive views for reasons that, "viewing emotion as simply another set of skills in our cognitive tool kit, although practical, does not go far enough in recognizing the need to move beyond explanatory models that put all the responsibility for managing, controlling, and explaining emotion on the individual" (p. 89). Despite the philosophical roots of affect positioning such emotive capacities as social entities, discussions continue to use emotion as a synonym for affect, which shifts the focus onto what is produced for an individual.

\section{Emotions as Gendered}

The challenge remains for medical educationalists and clinical teachers to create a learning environment that encourages medical students to become a certain kind of 
doctor that maintains and strengthens the positive attributes they bring to their medical education, and offers opportunities to grow and develop professional personas without losing sight of the person who is the doctor - Jaye, Egan, and Parker (2006, p. 151).

Veterinary medicine surpassed all other professions in proportions of women enrolled in 2008 (Irvine \& Vermilya, 2010). Moreover, this increase is best characterized as a rapid 'feminization' of an originally masculine profession. For instance, between 1980-1990, there was a 104\% increase in female veterinarians, and between 1991-2000, an additional 27\% increase and another 30\% increase between 2001-2010 (AAVMC, 2017). Mossop (2012) takes an etymologic eye towards a history of professions by defining it as "an occupation in which a professed knowledge of some subject, field, or science is applied; a vocation or career, especially one that involves prolonged training and formal qualification" (p. 93). She points to the awarded privileges of the men who entered these professions, e.g. self-regulation or status, in exchange for their trustworthiness and body of knowledge. Women were traditionally excluded from professions, particularly veterinary medicine since, "male veterinarians [in the late 1800s] argued that [veterinary practice] required an unsentimental attitude that women did not possess" (Irvine \& Vermilya, 2010, p. 59). Communications in 1939 from Kansas State’s Dean Dykstra extends this,

We do not encourage women to enroll in the curriculum in veterinary medicine. In fact, we try to discourage them, our reason being that we must refuse admission to many worthy young men, and to accept a young woman with the chances that she will not remain in the profession and to deny admission to a young man, does not seem logical (Association for Women Veterinarians, 1997, p. 11). 
Throughout the 1950s, only 139 had women graduated from veterinary schools in the United States. The relationship between the history of professions, particularly that in veterinary medicine, and gender, warrants a sociocultural processual perspective to interrogate social and political determinants of experience (e.g. race, gender) and those historical remnants of a gendered and exclusionary process. Many of these historical remnants may still be housed in hidden curricula, the (un)intended learning through value-laden systems and institutions.

Emotions (Jaggar, 2009) and affect (Ahmed, 2010) are similarly positioned as congruent with values evident in choices, and reflective of dominant social values. Dominant norms typically produce the privilege of emotional neutrality and suppression as strength, as rational and preferred (Jagger, 2009). On the contrary, women are permitted and required to express emotion more openly (Jaggar, 2009), and have different socialized expectations for communicating emotions (Underman \& Hirshfield, 2016). Both have consequences for how women are evaluated as doctors or doctors-in-training. An early woman pioneer of the veterinary profession, Margaret Sloss (1939) documented women's history in the profession using reports from early graduates of veterinary programs who were women. In particular, she documented how women felt the expectation to both express and suppress emotion to be successful member of the profession. This because dominant social norms expect and demand women to be kind and gentle, and in order to maintain group pleasantness, needing to suppress emotions, likely in the face of sexism or harassment.

Social norms within the profession are those characteristics that produce and congeal the group identity-solidifying the local definition of professionalism. These 
norms, as self-determined and value-laden, are determined by and circulate within social entities. To the point, social groups and norms are co-constitutive. These social group, e.g. professions, set and police certain values they deem inclusive (Ahmed, 2010) of being professional. Such that, in acting, being, doing, and/or practicing as a certain professional, e.g. veterinarian, one defines through those material-discursive practices what constitutes a certain professionalism (e.g. veterinary professionalism). Of particular interest here, is what affects and expression constitute professionalism. How do certain affects constitute legitimate belonging?

Although these gendered perspectives and feminist critiques of professionalism, affects, and emotional expression are important, at this time they do not represent a primary focus of my inquiry, whether theoretically or analytically. They will, however, remain in consideration as I see myself necessarily entangled in this inquiry and as a woman, a feminist, and a veterinarian, they remain factors that cannot be separated from my process.

\section{Onto-epistemic Tensions of Becoming}

The bioscientific methods and objectivity of knowledge emphasized in medical curricula are not sources of compassion, communication, and social responsibility. As such, these do not typically receive prominent attention (Wear \& Castellani, 2000). In exploring these epistemic tensions, Wear and Castellani (2000) identify, when medical students are taught, explicitly and implicitly, that the only true medical knowledge comes from empirical, objective, quantitative inquiry, they naturally distrust all knowledge that is gained from other methods. Factors such as gender, race, education, social class, ethnic identity, the political climate are often 
viewed as outside or secondary to "proper" medical knowledge, the assumption being that both the product and the process of making "proper" medical knowledge exist independently of these factors (p. 605).

These onto-epistemic tensions extend to considering and devaluing emotion and affect as real, legitimate, or important to the practice of medicine. Thereby further reifying Cartesian dualism of mind/body. Indeed, historically curricula have been structured and biomedical knowledge constructed in such ways to indicate both explicitly and implicitly affective neutrality and distance is ideal (see Fox, 1998; Good \& Good, 1989, Smith \& Kleinman, 1989). The implicit messages are those communicated via the hidden curricula and tensions are felt as the process of professional education, of becoming a doctor, is affectual in nature.

\section{Hidden Curricula}

The hidden curriculum emerged in the late 1960 s as a construct that represents the "norms and values that are implicitly, but effectively, taught in schools" (Apple, 1971, p. 28). P. W. Jackson (1968), through his ethnographic work in elementary classrooms, is credited with coining the term, and defined it as "the crowds, the praise, and the power that combine to give a distinctive flavor to classroom life which each student (and teacher) must master if he is to make his way satisfactorily through the school" (pp. 3334). Martin (1976) extends the definition of a hidden curriculum as what is "learned yet not openly intended" (p. 137) "of some setting, at some time, for some learner" (emphasis original, p. 138). In particular, this contributes to the maintenance of similar world views and is reified in systems of rules and assumptions. Scholarship prior to Jackson (1968) involved the investigation of professional socialization into medical 
school, and elaborated many similar facets to implicitly taught/learned norms and values (e.g., Becker \& Geer, 1958; Becker, Geer, Hughes, \& Strauss, 1961).

These tacit features of a social process serve to organize and legitimize the activities of social paradigms can be broadly organized into: Basic and preferential. The basic rules are the broad parameters, such as the rules of a game that determine which moves can be made and in what order. Preferential rules are a matter of personal choice, those patterns of work which are preferred. For example, the game of chess. The basic rules state which pieces are capable of types and patterns of movement, but preferential rules more readily dictate the order to which a player enacts basic rules. Although social paradigms and these norms and values which serve to legitimate them are constantly changing, reifications of these are left behind and crystalized in patterns of common sense, tradition, and at times codified in institutional policy or procedure. Importantly, this claim is not that values are passively received, nor passively transmitted, nor actively created. The importance lies within the vulnerable awareness and analysis of values. In seminal essays on the hidden curriculum and the nature of conflict, Apple (1971) asserts, without an analysis and greater understanding of tacit values and assumptions, educators "run the very real risk of continuing to let values work through them" (p. 39).

The emergence of the hidden curriculum as a concept coincides with a period of social revolution in the United States, marked by conflict among social paradigms. In understanding the social milieu integral to conflict and with which curricula operate, Apple (1971) laid the charge there must be "continual attempt[s] to bring to a conscious level those epistemological and ideological assumptions that help structure the decisions" made and the social learning environments designed (p. 38). An important contribution 
here is the notion that "'happy cooperation' and conflict are two sides of the societal coin" and neither is wholly positive or negative (p. 36). Meaning, having conflict is not the problem, however seeing conflict as problematic is inherently problematic.

Early hidden curriculum scholarship which sought to examine or elaborate on values and the relationship among conduct within schools was conceptually difficult. Although it was commonly agreed that social structures, like schools, impart values and norms and those "concern what people should do, or have a moral or normative obligation to do" (Dreeben, 1976, p. 112), the correspondence among these values, norms, and conduct is also situational, constrained by local, temporal, social context in addition to values. A distinction is sometimes made between values specific to situations, namely values, and those which transcend situations, norms. In studying the hidden curricula, considerations for institutional norms in the form of policy or historical precedent, is valuable. The pre-determined and intended outcomes such as skills, habits of thought, knowledge, or beliefs are assumed to be a natural product of content and pedagogical process. However, these curricula and pedagogical practices are in part influenced by values (e.g., Apple, 1971, 1999; Gudmundsdottir, 1990). That is, curriculum has always been a contested and political and to be sure, has never been objective. Therefore, the study of values nested within relationships among conduct and institutions and systems that establish norms can provide meaningful insights on contemporary issues with a historical basis.

These distinctions of values and norms conjures a connection among the scholarship of the hidden curriculum where it connects to ideology. Scholars insist upon interrogating whose knowledge and ideology are represented in curricula, rather than 
what knowledge and ideology (see Apple, 1971; Apple, 1999, 2013; H. A. Giroux, 1990; Giroux \& Penna, 1979). Ideology is a "manner or the content of thinking characteristic of an individual, group, or culture" and more these are "integrated assertions, theories, and aims that constitute a sociopolitical program" (Merriam-Webster, 2018). This connection gives rise to interesting questions about the connections among ideology and the professions, of the hidden curriculum of (veterinary) medical education. That is, whose knowledge and ideology are represented in contemporary professional curricula?

\section{Traditions of Hidden Curriculum Scholarship}

Studies in the hidden curricula, like other areas of inquiry, are contested and filled with much philosophical debate. Giroux and Penna (1979) carved out three philosophical perspectives and traditions guiding studies of the hidden curriculum in social studies education at the time, namely: Structural-functional view, phenomenological view, and neo-Marxist or critical view. Briefly, the structural-functional view posits students as passive recipients of unquestioned "beliefs, rules, and dispositions fundamental to the functioning of the larger society" (p. 23) and "stresses consensus and stability rather than movement" (p. 24). This view downplays the role of social conflict and positioning conflict as a "function of faulty socialization" which shifts the cause of conflict outside the context and instead labels the "individual as deviant" (p. 24). To the point, meaning and values are transmitted and conformity is adopted or not. The phenomenological view places reality and meaning as socially constructed through interaction which brings together the past, present, and future. However, critiques of this view suggest "it lacks a theoretical construct to explain the role ideology plays in the construction of knowledge" (p. 25) and ways discordant meaning between individuals and the experienced structures 
are reconciled. To the point, Giroux and Penna (1979) state this view "has succumbed to a notion of cultural relativity" (p. 25). The neo-Marxist or critical view is a "recognition of the relationship between economic and cultural reproduction" at the intersection of theory, ideology, and social practice (p. 26). Some scholars note that the critical lens casts a "conspiratorial light" (Dreeben, 1976, p. 112), when no offense nor bias was intended.

\section{Hidden Curricula in Medical Education}

Mention of the hidden curriculum arose in health professions scholarship in 1974. Here two conference lectures were published in medical education journals (Drucker, 1974; Marinker, 1974). In an invited lecture given in 1972, Drucker (1974) positioned the hidden curriculum from a critical standpoint. Arguing,

[medical] schools have become an agent of assumptions and models so deeply embedded in their style of operation that most participants are not even aware of their presence. As life and family and social structures have changed, the schools plod on, more dedicated to obsolete values than ever. As these values come into increasing contradiction with the reality of the student's lives, the system is stressed and ceases to function as an educational experience (p. 267).

In his critique of the health care system, he suggested reform in the admissions practices so institutions might decrease the number of candidates from privileged backgrounds in order to be responsive to the needs of communities it serves. In contrast, although demographic factors were not considered, research with medical students demonstrated over time, they self-reported lower agreement with items that indicate a 'socially-liberal perspective' (e.g. "there is a need to admit substantially more black students to medical schools even if admission standards are a little different") (Coe, Pepper, \& Mattis, 1977, 
p. 95). The authors speculate the so-called activist student (see Lucas, 1969) or 'new' medical student with 'liberal perspectives' were a passing "product of transitory forces" since the liberal views peaked in 1970-1972 (p .89). Coe and colleagues indicated the socialization process embedded in the curriculum will ensure these "new students will not be very different from their predecessors when they graduate because instutionalized processes of professional socialization have been little affected by the relatively modest curricular reforms of the last decade" (pp. 89-90).

Research investigating the these reforms was reviewed by Rezler (1974), whose synthesis indicated the medical school environment fosters cynicism, and special programs or interventions to counter this resulted in temporary attitude changes, at best, since otherwise unsupported by the medical school environment. Like Coe et al. (1977) and Drucker (1974), Rezler (1974) suggested alterations to the selection (admission) practices to admit students who have certain desirable attitudes since they are unlikely to be otherwise changed. In contrast, Marinker (1974) calls for sunshine as a disinfectant to behaviors and covert objectives residing within the hidden curriculum, instead suggesting the culture is open to change and has more fluid characteristics.

Implicit curriculum and professionalism. Consistent scholarly inquiry into hidden curricula in medical education began to emerge in the 1990s in what is described by some as a revolutionary time when there was finally a mechanism to "[identify] and [categorize] these "hidden" aspects of education [politics of gender, race, and social class]" (MacLeod, 2014, p. 539). Prior to this, scholarship was sparse at best.

The construct was initially taken-up by bioethicists (Hafferty \& Franks, 1994) and medical humanities scholars (Wear, 1998). These scholars identified the construct as a 
powerful challenge to their aims to teach, research, and affect medical student and school ethical and professional practices. That is, a hidden curriculum interferes with even the best intentions of a written curriculum.

Frederic Hafferty was highly influential, and much of his work was devoted to medical ethics and hidden curricula. In his most widely cited piece, he notes of curricular change without difference, and points to the hidden curriculum as a source of resistance to change efforts (Hafferty, 1998). He defines three components of a medical curricula: the formal, informal, and hidden curricula and calls attention to the hidden curricula in terms of critical examination of institutional policies, evaluation activities, resourceallocation decisions, and institutional slang. This distinction among the hidden and informal curriculum, the influences at the level of institutional structure and the interpersonal and ad hoc interactions that constitute the enactment of teaching/learning, is challenged by some (see Wear \& Skillicorn, 2009), but Hafferty maintains together, the hidden and informal curricula are what contrasts what is written and formal—in ways that are both good and bad. His distinction is not to move away from critique or a critical stance, more to parse the nuance between structures and people. He ultimately also adopts the discourse of professionalism, yet maintains the nuanced separation between informal and hidden curricula.

At the same time Wear (1998) was also influential, taking a more critical stance in her scholarship on hidden curricula. Wear and others represented a divergence in hidden curricula scholarship, adopting a discourse of professionalism and professional socialization and enculturation, and commonly operated from a critical standpoint that drew from Apple (1971) and other critical theories (e.g., feminist). This positioning was 
in response to other scholarship of the time. Wear insisted a focus on the hidden curriculum does not allow for active work with and against disrespectful behaviors. Moreover, both the hidden curricula and informal curricula work in tandem, in ways that codify and permit certain behaviors in reinforcing ways. In this regard, this emphasizes the necessity of a holistic perspective.

Cribb and Bignold (1999) called for more reflexive, interpretive, and humanized medical education scholarship. They note that, to date, regardless of research tradition, many studies have elaborated on the notion of emotional socialization in tandem with socialization into the medical profession. Studies consistently indicate emotional talk is taboo and hidden curricula demand detachment, affective neutrality, and emotional marginalization (e.g., Smith \& Kleinman, 1989). What would more widely be considered culturally normal emotional responses are inappropriate and the normal response becomes one of non-response or a maladaptive strategy to objectify the patient or procedure, joking, blaming patients, or avoiding sensitive contact (Smith \& Kleinman, 1989). They argue that this emotional socialization is associated with the "worryingly high levels of stress and mental health problems, such as depression” (Cribb \& Bignold, 1999, p. 200).

Phillips and Clarke (2012) concluded Canadian medical students had four characteristic responses to their experiences with the hidden curricula: dissociation (e.g., keeping quiet), role confusion (e.g., I don't know enough yet, I'm just a student), resistance (e.g., questioning authority), or transformation (e.g., adjustment of goals). Except for resistance, each of these responses suggest students "believe that the profession expects them to be resilient and not to have values, traits or needs that 
interfere or are at odds with the ability to practice medicine as modeled" (p. 892). Many participants in this study suggested they were aware of the hidden curriculum but they believed it to be benign. However, results suggested otherwise, "[the hidden curricula] appears to have a very real impact on their learning to be doctors" (p. 892). In essence, these results indicate students internalize and attempt to meet an unwavering social and professional demand of affective neutrality, perhaps to their own peril.

Hidden curricula of veterinary medical education. The field of educational research in veterinary medicine is still growing, and generally, there are small quantities of scholarship in veterinary medicine and the field is far outpaced by medical education. Given the low numbers of studies overall, the small numbers of studies on hidden curricula are unsurprising. The focus is primarily on professionalism, rather than hidden curricula. To begin, I explore the base of professionalism research and then conclude with the scant amounts of research on hidden curricula.

Veterinary professionalism. Professionalism is the socially constructed embodiment of curricula. It is grounded in the local, social understanding of what it means to be and become a professional within a certain profession (Goldberg, 2014). “The strength of a profession as a social unit lies in its members' assertion of a distinct and consolidated collective identity" (p. 716) — it is the ties that bind and are defended by its members. Professionalism is, then, the ideology of a program of professional veterinary practice for which all members strive to achieve and embody.

In embarking in scholarship and curricular practices related to professionalism, Mossop (2012) positions the lack of a cohesive and intersubjective definition of veterinary professionalism as problematic. Yet some critique the professionalism 
movement as mere discourse without attention to the hidden curriculum, which then in effect recursively defines what constitutes acceptable, i.e. professional, behavior (Wear \& Kuczewski, 2004). Further, that producing checklists of skills and behaviors will perpetually fall short of explanations or supports for the depth of meaning necessary for embodied professionalism. Mossop (2012) adds to this perspective, how some see the efforts as generating auditable skills with little regard for the skills of those performing the audit. In acknowledging these barriers and critiques to adopting an intersubjective definition, Mossop (2012) contends it is time to formalize definitions so that we may make it a focus in our formal curricula. However, given the idiosyncratic nature of affects associated with professional encounters, it is questionable whether a formalized definition could be arrived at. This is particularly relevant when the hidden curriculum remains a powerful contradictory power in constituting and contesting professionalism.

Mossop and Cobb (2013) articulated connections between theory and practice in teaching and assessing professionalism and caution that both formal and hidden curricula must be considered. They suggest that "discussion and reflection between students and [faculty or staff]" will contribute to progress of aligning and mitigating the effects of the hidden curriculum (p. 224). In presenting an array of learning theories to consider appropriate for teaching and learning professionalism (i.e., situated learning theory, social cognitive theory, adult learning theory, experiential learning and reflective practice theory, and constructivism) all frameworks emphasize reflective practices and/or meaning making as essential. Considering the time offered to students for other nontechnical practices that could support them in process (e.g. developing relationships), the 
emphasis on this lack of time to develop more holistically suggests this is not currently a priority.

Yet, despite these findings and perhaps what appears to be a push to collectively define professionalism, it is worth considering: Is this even possible? Considering the tensions that exist between idiosyncratic experiences, the likelihood that we might converge on a shared ideology anytime soon is unlikely or even impossible. Perhaps, instead, we ought to pursue scholarship which considers how embracing innate differences is what makes the profession vital. In this work, we could advance ideologies that emphasize new ${ }^{3}$ definitions of professionalism — a duty to one another in our differences as well as our similarities.

Given this conceptual definition of professionalism, the author of The Letter, the corpus of work pathologizing veterinary students (Hafen et al., 2013; Killinger et al., 2017), many comments to The Letter, and the research with veterinary medical hidden curricula (Greenhill \& Carmichael, 2014) suggests student depression and anxiety as well as their ties to stressors presents a rupture in the definition of professionalism. That is, the ties that bind and are defended by some but not by all. Specifically, some see being negatively affected by a veterinary medical program serve as a criterion of exclusion from the profession. This fundamental connection between what constitutes criteria of professional inclusion and group identity in addition to well-being and/or negative affects is new for the field, and worthy of exploration.

\footnotetext{
3 I use the term new here, not as an announcement of a concrete something 'not in existence ever before.' But rather as an "alert that [I am] determined to try to think [and do] differently" (St. Pierre, Jackson, \& Mazzei, 2016, p. 100).
} 
Veterinary hidden curricula. Scant research on the hidden curricula in veterinary medicine exists. Whitcomb (2014) makes note of this and positions a greater awareness alongside a call for more research. Mossop, Dennick, Hammond, and Robbé (2013) aimed to validate the use of a cultural web as a framework for data collection in interviews as well as an analytic tool to interrogate salient, professional identityinfluencing dimensions of the hidden curriculum. The cultural web is a series of overlapping domains that produce a central paradigm. The domains consist of: Symbols, power structures, organizational structures, control systems, rituals and routines, and stories. They used an image of cultural web as a centerpiece of conversation with seven different focus groups of faculty, staff, and veterinary students. Their analysis consisted of coding transcripts using a priori codes derived from the framework as well as emergent codes. Ultimately, they organized their data back into the seven domains, i.e. symbols, routines, rituals, control systems, organizational control, power structures, and stories which produced a central paradigm, i.e. core assumptions, with emergent codes representing sub-dimensions identified through axial coding. Although they found the tool to be useful, meeting part of their aims, the ways in which they sought to 'validate' the existence of the hidden curricula were unusual. The fact that a priori validation was necessary to prove the existence of experiences of departures, tensions, or surprises was an interesting facet. This reveals epistemological assumptions and tensions in exploring the sociology of training and power. That is, what constitutes knowledge of the hidden curricula and how that knowledge is or can be legitimized.

Roder and May (2017) examined messages of professionalism communicated via the hidden curricula on intramural veterinary medical services at a teaching hospital. 
Nested with important facets of professionalism in accord and under dispute, they identified important moderators and mediators of the hidden curriculum. Moderators of the hidden curriculum are identified sources that buffer the unintended effects of the hidden curriculum messages. Within this study, moderators identified as individuals. On the other hand, mediators were structures and systems that communicate messages, yet the students remained unaware of their affects. The relationships as moderators were most important for students to navigate and maintain the strength of personal and professional values such as work-life balance or empathy. Peer support was often ad hoc, and associated with their rotation group, however the cultivation of role-models who served as moderators was active and purposeful, students looked for and selected “individuals who exhibited characteristics they already deemed important” (p. 547). Independent of these few studies, inferences are necessary to look across veterinary medical educational scholarship to derive what values and presuppositions support certain findings. On behalf of the Association of American Veterinary Medical Colleges, Greenhill and Carmichael (2014) deployed a culture and climate survey to all 28 veterinary programs in North America and had 5,268 responses. This survey discovered overall, although there are high degrees of comfort and low rates of harassment reported within professional veterinary medical programs, certain underrepresented groups do not corroborate this. Almost one third of students of underrepresented race/ethnicity reported hearing racist comments from their peers occasionally to very frequently and over $20 \%$ of lesbian, gay, bisexual, transgender, queer, and questioning (LGBTQQ) students reported homophobic comments from fellow students occasionally to very frequently. Although student peers were most commonly 
cited as voicing these comments, faculty were also cited with some frequency, particularly regarding sexist comments. Approximately $21 \%$ of women and $23 \%$ of transgender students reported hearing faculty making sexist comments occasionally to very frequently. Comparatively, all students reported faculty making sexist remarks occasionally to frequently $12 \%$ of the time, each. Indeed, students characterize identity/self-expression and spontaneity/freedom as unwelcome in the curriculum (Meyer-Parsons, Van Etten, \& Shaw, 2017). These findings indicate the hidden curricula devalue and harass identities, behaviors, and values deemed to be non-normative, which includes self-expression, and simply existing as a member of an under-represented minority group or a woman.

\section{Other Dimensions of Hidden Curricula}

Here my focus will shift to situate on dimensions of hidden curricula scholarship of interest for this study. In particular, those related to power and accountability, mental health, and related interventions. Professional students often find they are "expected to be the kinds of doctors that their teachers are not" (Jaye et al., 2006, p. 150), which produces two separate worlds they must simultaneously inhabit and perform in. One world where they act in a way that is in accord with assessment criteria, which is often incongruent with the behaviors of those judging their competence. Another where they are performing to those "normative practices of the working environment" (p. 151), i.e. the hidden curricula.

In these sections, I will draw on both medical and veterinary medical educational scholarship and use terms with caution to ensure findings are contextualized. The field of educational research in veterinary medicine is still new and unmatched to medical 
education. This being said, the structure and process of the veterinary medical profession was built on the traditions of medicine and largely mirrors it. Without problematizing the thirst for generalizability of situated knowledge, I suggest the parallels among the professions are enough that, as a community, we can and should conclude the findings from medical education are reasonably applicable within veterinary medical education.

Power and accountability. Power is a productive relational force and circulates socially (Foucault, 1983). Within the realm of what is produced with power, harassment and abuse are two emergent products from powered relationships (Angoff, Duncan, Roxas, \& Hansen, 2016). Accountability, or the lack therein, refers to the socialized mechanisms people enact to endorse or punish certain products of power. For example, sexual harassment is now receiving heightened attention given recent allegations of several high profile powerful men, such as Bill Cosby, Harvey Weinstein, Matt Lauer, or Larry Nassar, engaging in repeated acts of sexual harassment, abuse, and/or assault, which were socially "accepted” or ignored. An important intersection of these contemporary events is at gender and power. Much scholarship in medical education establishes similar issues of longstanding student abuse and harassment, abuse of power by physicians and faculty, and student concerns regarding professional repercussions of reporting abuse or harassment and/or norms surrounding whistle-blowing. Although over time, issues have lessened in frequency, they persist. Questions of the hidden curricula remain and are articulated in the paragraphs that follow.

Humiliation is the most commonly cited form of abuse medical students report, however other forms of abuse based in gender or race are also reported (Wilkinson, Gill, Fitzjohn, Palmer, \& Mulder, 2006). Kassebaum and Cutler (1998) examined exit surveys 
from graduating medical students across 6 years, sampled every other, and found abuse reports are primarily situated in the clinic and perpetrators equally represented among men and women. Nearly a quarter of women graduates report one or more incidents of sexual harassment while only $3 \%$ of men do. In addressing the issues of deviation from (hetero)normative practices, Richman, Flaherty, Rospenda, and Christensen (1992) data showed when students deviate from gendered norms, they were more likely to experience abuse. Greenhill and Carmichael (2014) substantiate these findings in veterinary medical students. They revealed although there were high degrees of comfort and low rates of harassment reported within professional veterinary medical programs, certain underrepresented groups, such as racial and ethnic minorities or LGBTQQ students, did not corroborate this. These underrepresented groups reported much higher levels of discriminatory comments. Likewise, Grant, Genero, Nurius, Moore, and Brown (1986) indicated "women who do not conform to traditional value orientations of physicians will be defined as "unprofessional" and will face limited opportunities for advancement" (p. 99).

In focus groups discussing a gendered climate, most students initially report all positive things (Wear \& Aultman, 2005). Yet, despite these positive claims, participants readily pointed out and described problematic issues of harassment. Harassment often goes unreported do to myriad reasons, including comments or behaviors seen as less serious, because they are considered normative or routine. Moreover, this resistance maintains the status of the victim as tough enough to handle the environment, built on the role of the physician historically modeled on masculine ideals. Many believed nothing would be done to perpetrators, "I think the overall consensus is to keep your mouth shut 
and not rock the boat" or "Don't bring it up because it's going to hurt you in the end, it's better to stay quiet, not say anything, let it happen, take your grade at the end, be thankful that you passed... Basically it's just lie down and take it." (p. 5), indicating serious concerns about retaliation, increased stress or ostracism, or hostility. Findings indicated women who label or report sexual harassment violate gendered rules and norms for "what a trustworthy colleague looks like" (p. 7). Because whistle-blowing is socialized as the unprofessional behavior, rather than the harassment.

Consequences for students and implications for professional learning environments are many. Kassebaum and Cutler (1998) concludes the clinical learning environment is imbued with a power-driven authority which uses aversive reinforcement to drive behavior and learning, and produces "a style of education and supervision that often is insensitive and punitive" (p. 1157). This also serves to socialize students into a culture of abuse which is inconsequential, leaving a "transgenerational legacy" of "future mistreatment of others by those who themselves have been mistreated" (p. 1157). Overall, all abuses are tied to diminished learning outcomes, and most students do not report them (Wilkinson et al., 2006). Richman et al. (1992) demonstrated students who report at least one abusive experience were "significantly more likely to experience depressive symptoms or to drink for escape purposes" (i.e., maladaptive coping) (p. 693). These results were independent of mental health prior to matriculation and both genders experienced distressing consequences. Approximately one sixth considered leaving the profession/school because of the abuse (Wilkinson et al., 2006). Medical and veterinary students are shown to have precipitous declines in attitude scores (Woloschuk, Harasym, \& Temple, 2004) or empathy (Benbassat, 2014; Brazeau, Schroeder, Rovi, \& Boyd, 
2010; Calderon-Amor, Luna-Fernandez, \& Tadich, 2017) throughout passage through professional curricula.

Creating a welcoming atmosphere that promotes belonging is important for mental health, as well as the development of a professional identity (Cardwell \& Lewis, 2017). Other ramifications of the hidden curricula include impacts on these feelings of being welcome in the learning environment. Medical student narratives on clerkship showed a preponderance of negative stories on respecting colleagues/learners from lower hierarchies (Karnieli-Miller, Vu, Holtman, Clyman, \& Inui, 2010).

These findings illuminate how the hidden curriculum helps to protect the status quo of harassment, and maintain a culture that does not deter nor punish offenders. Research exploring implications for those who label and report behaviors is lacking, since students who report are often labeled as less trustworthy or troublemakers, and often suffer damage to their mental health and well-being. In short, many studies highlight the processes by which students are victims of power-based abuse and harassment, and implicate the hidden curricula of normalized responses as the structure which permits such processes to continue. This calls attention to the powered dynamics embedded in questions of who can know and label abuse or harassment and why. Who and what is served when victims are professionally ostracized? Interpretations of these modern-day common-sense practices in relationship to the historical structures and processes as necessary bedrocks of hidden curricula are imperative. Who and what was served in the foundational processes and structures of the explicit curricula? How are they related to what is now hidden? 
Mental health and burn-out. The distinction between depression and burn-out or compassion fatigue is necessary. Burn-out and compassion fatigue are both related to stresses of working in a care-giving field. Compassion fatigue is "an emotional and physical burden created by the trauma of helping others in distress" (Scheidegger, 2015) and notably specific to the work performed, while burn-out is related stresses in a work environment such as "problems with coworkers, loss of economic security or position or diminished control" (Scheidegger, 2015). Neither are forms of depression, but both can lead to or co-exist with depression - a defined clinical state that interferes with your social functioning.

Professional programs of medicine have demonstrated impacts on attitudes and beliefs about mental health/illness. In a cross-sectional study of nationally represented medical students, approximately $23 \%$ of medical students report recurring abuse or harassment by faculty or residents(Cook, Arora, Rasinski, Curlin, \& Yoon, 2014). Recurring abuse, occurring several or numerous times, was associated with significantly higher burnout. Attitudes towards depression and burn-out or compassion fatigue differ. Depression, although considered a psychosocial illness that arise from differing constellations of individual and social factors, is often thought to be a personal problem and is associated with stigma and self-stigma (Karaffa \& Hancock, 2018b). On the other hand, burn-out or compassion fatigue are associated with "work" and thus the source of an issue is more readily external. Given the training medical students receive regarding development of mental illness and associated psychosocial factors, Korszun, Dinos, Ahmed, and Bhui (2012) examined medical students' attitudes to mental illness and compared with attitudes toward other medical illness. Their findings indicate students' 
gender, culture and direct or indirect experience of mental illness influenced stigmatizing attitudes. Over time, students' attitudes towards depression, psychosis, or illicit drug use were unchanged. The authors conclude, "this would imply that we are making little impact at medical school in improving attitudes toward mental disorders" (p. 202). This aligns with other findings which indicate some humanistic value persistence through medical school, but that this is largely dependent on gender with women entering and leaving with higher humanitarian scores rather than efforts within a curricula which tend to foster extrinsic rewards (Grant et al., 1986). Grant et al. (1986) speculate "medical school does impact values," yet "internship, residency, or early-career years are perhaps more influential in establishing values that affect careers choices and practice style" (p. 106).

Indeed, $14 \%$ of veterinary practitioners surveyed in the Netherlands met the criteria for burnout and $27 \%$ and $22 \%$ scored above the clinical cut-off for emotional exhaustion and cynicism, respectively (Mastenbroek, 2017). Regression analysis indicates small but significant effects for gender and years since graduation, indicating that younger women practitioners are more vulnerable to burn-out than older men.

Interventions targeting hidden curricula. Wear, Zarconi, Aultman, Chyatte, and Kumagai (2017) advises, "faculty members must resist the temptation to avoid explicit discussion of topics that are not directly related to health care" (p. 316). In elaborating on mechanisms to build a curriculum for social justice, Wear and colleagues (2017) offer descriptions of the successful course offerings and mechanisms employed at their institution for addressing health disparities and social justice. Their successful fouryear course, Human Values in Medicine, comprises a mixture of film, poetry, critical 
reflection in small-groups "in which issues of power, privilege, identity, and oppression may be safely and productively explored" (p. 315). In addition, they suggest pedagogical strategies employed at elsewhere: antiracist pedagogy and structural competence.

The review of students' comprehensive portfolios is noted to be a source that revealed the hidden curriculum (Weiss Roberts, McCarty, \& Obenshan, 1999). In these reviews, faculty noted expedience and misrepresentation of data superseded accuracy in discussing and documenting patient histories. This was uncovered because of multiple perspectives garnered in the comprehensive portfolio were conflicting and this conflict was explored, this emphasizes the importance of multiple perspectives and sources of feedback to document and explore the hidden curriculum and its products.

Angoff et al. (2016) calls attention to the lack of attention to "institutional and professional structures that can lead those in positions of authority to compromise the agency and dignity of trainees" (p. 204) which contribute to inhibitions around whistleblowing. In evaluating their intervention to address this issue as successful, they describe the process by which they attempt to affect structural changes through the implementation of two "Power Days." Power Day I is an inter-professional day which brings together medical and nursing students to develop awareness of power dynamics in the clinical environment though storytelling and self-reflection. Power Day II is the discussion of student narratives produced while on clinics in small, facilitated groups. They report this intervention has had many positive effects on training including helping students feel less alone. Further, the use and abuse of power has become a more open and legitimate topic of discussion both on rotation and in departments with faculty awareness 
increasing. These faculty report concern and attention to their role modelling responsible uses of power.

A year-long personal resources development program was successful in preserving the well-being of recent veterinary graduates (Mastenbroek, 2017). Participants in the program indicated developing personal resources to mitigate symptoms leading to burn-out and promoting work engagement. They also "developed other important personal resources, namely, self-acceptance, self-esteem, awareness of own influence, and responsibility" (p. 89). As with other studies (e.g., Binyamin, 2018), reflection was a key to these developments. Mastenbroek (2017) argues "increases in personal resources affects [veterinarians'] perception of job demands and related coping strategies" (p. 90).

\section{Vulnerable Awareness ${ }^{4}$ and Emotion}

Professional curricula are largely based on the Flexner Report (Flexner, 1910) which recommended an intensified focus on biomedical science as the gold standard. Curricula were reformed in response and typically offered two years in basic sciences and then two in clinical sciences. The model was based largely on a German system which also emphasized a hyper-rationality (Duffy, 2011). In addition to this hyper-rational emphasis, at this time in history, the practice of medicine was by and for white men which layered gendered expectations for the performance or experience of emotion. Ultimately an imbalance between the art and science of medicine was instituted and persisted. Medicine was thought to be best practiced with detached concern (Fox, 1988),

\footnotetext{
${ }^{4}$ Apple (1971) asserts a vulnerable awareness of tacit values and assumptions is necessary, otherwise educators "run the very real risk of continuing to let values work through them" (p. 39).
} 
affective neutrality (Smith \& Kleinman, 1989), objectivity and emotional neutrality (Good \& Good, 1989).

These emotionally-uncharged histories are unexplored in the scholarship of veterinary medicine, but insights can be gleaned from historical accounts from veterinary students who were also members of historically underrepresented groups (e.g., women). Sloss (1939) documented an emotional double bind for women in veterinary medicine. She analyzed reports from early graduates of veterinary programs who were women, and several quotes from her reporting, in particular, the expectation to both express and suppress emotion to be successful member of the profession were present. "[Many] feel that a woman will give kindly and gentle attention to their beloved pets, and therefore is the ideal person to whom to go" (p. 5). Yet, "during all of my time in school, I attempted to make myself just one of the group. This, I think, tended to increase the pleasantness of my stay in veterinary school" (p. 3). That is, "a woman has to be willing to do her share of the work, as well as not let anything 'get under her skin'”' (p. 3). The emotional norms are intertwined with dominant social norms, both of which are gendered. Where the dominant social norms expect and demand women to be kind and gentle and to suppress her other emotions in favor of maintaining group pleasantness. It is clear they were prohibited from affecting others in ways which might disrupt group pleasantness. It is a wonder what sorts of behaviors, harassment, or overt sexism these women could not let 'get under their skin' for fear of professional exclusion or further unwanted harassment?

Given recent attention to more humanistic qualities of practice in (veterinary) medicine, such as empathy and client communication, "medical sociologists' focus on emotions has largely disappeared" (Underman \& Hirshfield, 2016, p. 95). Moreover, the 
hidden curricula, given the history of socialization, gendered expectations for emotional performance and labor, the rapid shift in women in the professions, and known effects of affective neutrality, scholarly attention to emotion and affect of the hidden curricula are desperate needs. In examining student narratives on the hidden curriculum, (KarnieliMiller et al., 2010) note the "relative paucity of language in these narratives that explicitly records the students' emotional responses to the events they have seen unfold" (p. 130). Perhaps it is because they are being socialized to not feel.

\section{Empathy}

Indeed, several studies demonstrate staggering declines in empathy over the course of a veterinary medical education process (see Calderon-Amor et al., 2017; Pollard-Williams, Doyle, \& Freire, 2014; Schoenfeld-Tacher, Kogan, Meyer-Parsons, Royal, \& Shaw, 2015). This decline is alarming because "social relationships are based on our ability to put ourselves in the place of others, and from there be able to react appropriately and logically" (Calderon-Amor et al., 2017, p. 179) and practice, professionalism, teaching, and learning are social relationships. Pollard-Williams, Doyle, \& Freire (2014) state, "it would appear that veterinary students undergo a hardening of attitudes that coincides with exposure to practice, perhaps as a mechanism for coping with the distressing events and frequent conflicts of interest that manifest in veterinary practice" (p. 256). On the contrary, perhaps the hardening of attitudes reflects a mechanism to navigate belongingness - an event of professional enculturation and emotional socialization. This explicit reciprocal perspective, the one which considers the profession as an entity capable of affecting newcomers as much as newcomers affect it, is missing from studies. Rather, most work pathologizes the individual veterinary students' 
affected states and well-being as roots of a problem rather than leaves produced from a structure by a process.

\section{Relational Professionalism}

Austen (2016) suggests "as the weeks of grueling work blur into months and years, clinical detachment may lead to numbing not only the emotions of our patients, but also the emotional resonance of colleagues, friends, and those we love most" (p. 377). Yet little research exists that interrogates the community, cultural, socially, or relationally oriented ways in which veterinary students are affected by their experiences. This is important work since social supports and organizational resources are two of several factors described by veterinary students that function as 'protective' against the persistent stressors they experience in school (Weston et al., 2017). Social supports include positive interactions with people around them in the school community and those that are specifically valuable include: student interactions regarding study groups or materials, with other professionals who shared "their own difficulties and mistakes" (p. 23), and with academic staff who shared their own experiences as students. Organizational resources are materials regarding non-technical skills and staff allocated for mentoring or formal support (e.g. counselors).

Perspectives that advance scholarship regarding how resources work in relationship with the educative process in veterinary school show a sense of belonging and navigating this belongingness is crucial (Cardwell \& Lewis, 2017). Student social cliques and friend groups that form early, usually along with orientation activities in relationship to normative characteristics such as 'interest in sports' or 'alcohol-based activities,' are a barrier to feelings of belonging and a tension to work around for some 
students. Additionally, perceptions of competition versus camaraderie among these peers contributes to students' positive or negative feelings about academic belongingness. Further regarding academic belongingness, veterinary students experience shifts in their perceptions about their academic abilities and skills and often must renegotiate/redefine success, competence, and confidence. Those students who are not aware of, seek out, or feel supported during these challenges are often stuck in a place of managing enormous risks and anxiety associated with failure alone. This undercuts the development of professional belongingness, which is having "feeling[s] of being taken under the wing of the profession" (p. 33). Cardwell and Lewis (2017) urge the profession to consider this notion of professional belongingness in relationship to individual well-being, particularly how fostering it within the veterinary academic or professional community might affect "collective interest in, or responsibility for, individual well-being" (p. 35).

Several relational possibilities exist. Research with occupational therapy students shows that collaborative reflection on relational dilemmas with role partners helps bridge the gap between theory and practice in addition to supporting student development of their professional identity (Binyamin, 2018). In her exploration of a pedagogy of discomfort for closing the relational gap between physician and patient, Aultman (2005) suggests its utility for the hidden curriculum. As a strategy, it offers possibilities to develop a mutual awareness “of each other's dynamic beliefs and values” (p. 271). Yet this is not without caution, she goes on, "while educators are carefully working to uncover the hidden curriculum, what is revealed may be too difficult and complex to understand, e.g., students' emotional reactions to the discomforting content of the curriculum" (p. 272). Despite this challenge, the stakes are dire and perhaps a pedagogy 
of discomfort is necessary in order to share space and witness what and how we have been taught to (un)see or (un)feel.

\section{Conclusion}

The focus of veterinary medical scholarship is on professionalism, student development or "deficiencies," and the attributes therein. While not problematic to focus on positive dimensions to improve education and professional standards (Jaye, Egan, \& Parker, 2005), inattention to the numerous negative aspects of the hidden curricula suggests the field is unwilling or does not value the necessary vulnerability nor emergent accountability derived from uncovering hidden curricula in veterinary medical education. By not examining the forces at play in the hidden curricula, the structures and processes, we remain complicit in the perpetuation of "hidden" power abuses at many levels, nested in tradition and common sense.

Given the mental health and well-being concerns in the profession, the relational complexity of emotion and historical influences, and hidden curricular influences on emotional suppression — what is happening in veterinary medicine? How do we respond to affect or emotion? What do our responses do? This study is a move beyond explicit traditions of phenomenological or critical accounts of hidden curriculum to that of shared vulnerability in exploring the value-laden structures and processes embedded in the responses to a certain, public curricular affect. In the next chapter, I introduce a theoretical perspective that provides concepts to attend to this complex array of intangible forces that move among, move with, and move us. 


\section{CHAPTER 3: THEORETICAL PERSPECTIVES}

Steering through the issues of the profession encompassing mental health, wellbeing, and feminization this exploratory study was guided by the question: How does The Letter affect members of a CVM community? Interrogating hidden curricula as a process, guided by this central question, and given those contemporary concerns, there is a need for theoretical perspectives of relationships among, of affect, beyond emotion or feeling. This allows for a more open and fluid—participant determined—source of affect, being affected, affective, or affectual. It also allows the opportunity to trace the absence of emotion or feeling in genealogies of affect.

Affect, as a theoretical perspective, provides conceptual mechanisms to explore the complexities of causal possibilities among social relationships without reducing them. Affect is a theoretical means to investigate the power to affect the world while at the same time being affected by it. In these powers are equal considerations of and among body and mind, reason and emotion. Yet, this particular theoretical vantage of affect is not alone. For clarity, I will briefly touch on some other theories and/or uses of affect in education before articulating my theoretical concept of affect.

\section{Affect as a Learning Domain}

Traditional domains of learning, informed by scholarship by Bloom and colleagues (see Bloom, Engelhart, Furst, Hill, \& Krathwohl, 1956) include affect, behavior (i.e., psychomotor), and cognition. These domains of learning are positioned as separate and distinct categories and often operationalized in curriculum, lesson, or outcome/assessment planning. The affective domain is the learning of values, feelings, emotions, appreciations, or attitudes (Krathwohl, 1980; Légaré et al., 2015). Although 
these taxonomies have proven to be useful tools for many educators, when it comes to inquiries involving growth of professional practice, these categorical analyses have failed to approximate representations or explanations for the many ways people are moved to act or act differently (Légaré et al., 2015). A shift in how these learning domains or models are used is unlikely to resolve this disconnect. This is because the relationship between taxonomic classifications and action or practice are singular are fundamentally flawed. Further, establishing connections between theses domains and my theoretical use of affect and associated concepts would serve to further enamel these flawed connections. Instead, I suggest inquiries into social practices and processes demands an intentional awareness and interrogation of the teaching and learning environments that surround and affect us like water surrounds and affects a fish. ${ }^{5}$ Rather than an analysis of or comparative to learning domains informed by a cognitive model.

\section{Affect as Emotion}

In many ways it has already been demonstrated how affect is used as a term to signal congruence with, or as a synonym to, emotion (Linnenbrink, 2006). However, some scholars make further distinctions, suggesting that affect represents a general affective state, which encompasses moods or attitudes, and/or emotions. Here, another distinction is sometimes made, positioning emotions as short and intense contextual responses, and moods as longer lasting and persistent across many contexts. Some

\footnotetext{
${ }^{5}$ This is inspired by the opening paragraph to David Foster Wallace's (2005) commencement speech at Kenyon University. It is, as follows,

There are these two young fish swimming along, and they happen to meet an older fish swimming the other way, who nods at them and says, "Morning, boys, how's the water?" And the two young fish swim on for a bit, and then eventually one of them looks over at the other and goes, "What the hell is water?"
} 
scholars consider beliefs and attitudes on a sliding scale with emotions, where emotions are the most intense and least stable and beliefs are the most stable and least intense (Hannula, Evans, Philippou, \& Zan, 2004).

I suggest this emphasis on affect as an emotional and psychological constitution can limit the vantage by which we, as scholars and researchers, might consider how people are affected and can be affectual. That is, affective relationships have always been embedded in practices and constitute a complex enmeshment with relational, social activities (Zembylas, 2014). Broadening the scope of affect-engulfing emotion, moods, and beliefs along the way-scholars turn to a more generic sense of affect, where affect is cause and capacity. This enlivens and evokes more complex causes (i.e. affects) and capacities (e.g., associated affects, affected states, affects) than a singular response (e.g., emotion or effect). This broadened scope of affect is a means to theorize and research the complexity of experiences in a tangled social-material web, that offers up possibility, rather than a categorical foreclosing through singularities. In this sense, affects produce affects rather than effects. The latter suggests a terminus, while the former keeps forces on the move.

This study is grounded in theory and as theory is at times dense, through my own sense making and production of theoretical concepts related to the study at hand, I attempt to use analogies and similes to illustrate these concepts in accessible ways which interdigitate the more theoretical discourse. Although this language (i.e., affects produce affects) and others may seem, on the surface, to be unnecessarily theoretical. I contend the intentions are not to obfuscate. Rather, this and other theoretical language is out of 
respect to the theory the study is rooted in, and intended to maintain emphasis on conceptual or processual significance.

\section{Affect as Cause and Capacity}

The use of affect in this study is a theoretical means to unravel complexities among the relationship of affects as causes that produce affects as capacities. To be sure, these definitions are complex and although this broadened sense of affect is intended to problematize the concise definitions therein, attempts at clarity are helpful. As an example, a cast around a limb which contains a fractured bone. The cast affects the limb in its application and proximity. The limb, as affected by this relationship with the cast, has muscle wasting, decreased circulation, and fracture reduction and stabilization. These affected states correspond with capacities enabled by being affected in certain ways. There is the capacity to heal the fracture in both optimal (e.g., aligned) or suboptimal (e.g., maligned) ways. There is also the capacity to produce or inflict new harms or discomfort by inducing swelling because of decreased venous return, or even worse, loss of limb due to dramatic reduction in vital blood supply. The leg as affected by the relationship with the cast has the capacity to dermatologically react to it from an allergic standpoint or simply from developing sores or chafing. The capacity to feel bored, frustrated, or limited in ability in association with the affect (i.e., cast) and the capacity to express those feelings as emotions or behaviors or not. The capacity to feel connected to others when they sign and draw on your cast. These capacities, complexly, can or will affect the ways the limb heals, functions, is vital (or not). They can or will affect the ways a person heals as a whole person — more than a broken bone - as a social being with 
desires, plans, relationships, dreams, and wishes. This is to say that these capacities with an affect, produce affects.

This circuitous milieu of affect and associated capacities (to affect) requires a theoretical orientation to think with this messy middle, this in-between-ness. Although affect theory as I have elaborated in the 'generic cause and capacity sense' offers this, this is not to say that affect theory offers a single theoretical framework, but rather that it provides concepts and approaches helpful in researching how people affect and are affected by what surrounds them. Not interrogating for a singular way, but rather the many ways people, animals, materials, ideas, structures, and more, come together in encounters as vital forces that affect one another. Forces, however, may be misleading as these encounters do not need to be forceful per say, but rather, like in physics, forces may push or pull, keep us grounded or not (i.e. gravity) and are more likely than not invisible. Moreover, like in physiology, the hydrostatic and capillary pressures which constitute Sterling's Law and thus affect the capillary and perivascular spaces. Like physiologic pressures, affects are cumulative.

This theoretical concept of affect is indeed broad; however, it is important to the study at hand. Current scholarship points to an individualized view of (negative) emotion or affective states, while professional skills interventions and curricula target individual learners in such a way that suggest affect and emotions are additions to, or pathologies of, rather than integral components of education and pedagogy. That is, the current scholarship minimizes and silences the historical and current contexts relevant and necessary to issues raised in The Letter and in contemporary scholarship. It focuses to the individual and competence, rather than a focus on social processes as elaborations of the 
social-historical context that is and always has been present. In order to interrogate complex social processes and causal relationships, broader theories and concepts of affect are necessary.

Considering, then, what this broader, more generic sense of affect can do, it offers a means to theorize "in the midst of in-between-ness: in the capacities to [affect] and be [affected]" (Seigworth \& Gregg, 2010, p. 1, emphasis original). When considering where to biopsy a tissue — that is, how a practitioner might gather a sample from a lesion (e.g. lump or bump in the skin) — the lesion context and borders can be helpful to understand the process from a histopathologic point of view. For large, poorly demarcated lesions, these borders can be difficult to locate and perhaps remain forever hidden. One risks taking a sample of the middle which has been cut off from vital blood flow, where the tissue and constituents therein have become necrotic, poorly defined, and lacking architecture or adjacent tissues to orient it. This pathologic vignette is important here: With little work to-date on any parts of veterinary medical education as a social process, this inquiry is like taking a biopsy in the middle of a lesion. This emphasizes using The Letter as a place to start. Importantly, The Letter does not represent a beginning or end, but rather a middle. This middle is among many - the middle of the process of affecting and being affected by the profession. In the middle of the process of affecting and being affected by the partner CVM.

Many, varied, and entwined processes of cause and capacity/ies are produced in conversation, and in part, comprise the embodiment and production of professionalism at this partner CVM. Here, the emphasis is on how local histories of specific relationships among something affectual (e.g. hidden curricula), how one is to be affected by it, and 
which capacities to act and behave are deemed 'normal'. These local histories, or genealogies of affect, when embodied, can mark a body as belonging to a world of particular affects. Much like professionalism marks the belonging of a body to a particular professional world. Thus, embodied movements and interactions produce everyday life, and affect is concerned with collisions and what those collisions do.

\section{Affect as Sticky}

Regarding the ways in which affects circulate and are cumulative, producing norms and making distinctions of inclusion or exclusion, Ahmed (2010) positions affect as "sticky," where "affect is what sticks, or what sustains or preserves the connection between ideas, values, and objects" (p. 29). This sustained relationship among values, the worthiness or desirability of a certain something, and affect, the capacities induced and affects produced from contact with-, produces "affective communities"-not unlike professional communities bound by professionalism. That is, the ways in which people come to value the worthiness of certain affective relationships and associated objects, people or ideas, acts as an aggregating force that brings communities of people together with their shared affective orientations with ideas, objects, others, and so forth.

In conceptualizing affect as sticky, the "genealogy of expectation" (Ahmed, 2010, p. 41) is the historically determined valuation of certain affects, which produces expectations in the present. These expectations of particular affects associated with encounters or proximal associations, are historically and socially informed - they are derived from a genealogy of expectation. For instance, connecting back to the genealogy of expectation associated with a cast and a limb. If within your social sphere, the historic affects and capacities shared with you narrate a manageable experience of healing and 
connecting with others around you with little to no complications associated with the cast, that represents the genealogy of expectation for how your limb and life will be affected by a cast. Connections via affect establish lines of distinction which curate and create ourselves, our worlds, and our orientations. This is not to say that the connections are a "simple correspondence" (p. 32), rather they are complex, contingent, and accumulate affective social value. These social values, such as orientations towards affects, i.e. genealogies of affect, produce social markers reproduced through habits that become history and then connections and orientations of inclusion or exclusion. Meaning, the "sticky" nature of affect congeals group identities through similar affects—not unlike professionalism.

Professionalism encompasses local socialization into a 'profession' and aims to strengthen the group identity (Goldberg, 2008). Thus, the primary duty of individuals is towards the 'profession' and behaviors are judged and policed through comparison to the accepted social norms. These professional norms are established, in part, through collective productive "sticky" forces that trace professional norms. Considering affects as collective productive forces is a means to open-up what is produced with The Letter in ways that speak to local issues of, and scholarly work in, hidden curricula/professionalism. In particular, with a bend towards supporting mental health and well-being.

Sticky professional affects of exclusion. In this section that follows, I use several comments which responded to The Letter as a specific example of affects at work-in ways that are sticky, informed by genealogies of expectation, and make distinctions of inclusion or exclusion - resting on the basis of Young Veterinarian's publicized affects. 
That is, these comments enumerate the ways in which these people were affected by The Letter.

"I was sorry to read that the "disillusioned young graduate" had actually graduated. Veterinary medicine, especially clinical practice, is not for this person" (mardigras1, 6/20/2017). “Oh, I could go off on your millennials, however, my generation retains some decorum. I say to you, [Vet School Grad], our profession requires sacrifice, the giving up of hobbies, etc. You graduate with the title of "Doctor" and with that comes blood, sweat and tears. You've got a lot to learn young lady" (drkelly, 5/31/2017). "Sounds to me like you chose a school with a bad cultural fit. Everyone I know who chose this field for anything other than personal satisfaction/passion for the work has been sorely disappointed. I am amazed that during the time you might have been studying and looking for ways to better yourself, you were instead engaging in the "drama" of your surroundings. (I don't hire people who are into drama.)" (DocSara, 5/31/2017). "You are a typical sounding millennial that believes the world owes the[m]. You should buy some lawn mowers and work at your appropriate level” (Doc, $5 / 31 / 2017)$.

The author of The Letter is not considered a member of the profession because of the way they described being affected, which stands in contrast to the genealogies of affect described by these commenters. Many make the claim that the Young Veterinarian simply does not and cannot belong in the profession because of the way the profession affects them. Professional socialization demands new-comers "embrace a common culture that is already given" (Goldberg, 2008, p. 47). These commenters, as representatives of the 
veterinary medical profession, position the Young Veterinarian as an "affective alien" (Ahmed, 2010) since they did not embrace what they saw as a given — what they see as true from a genealogic standpoint. Alienation is "when we do not experience pleasure from proximity to objects that are already attributed as being good" (p. 37). Sharing this narrative, in some ways, diminishes Young Veterinarian's capacity to connect with members of the profession, such as Doc, or mardigras1. For the purposes of this study, alienation is exclusion from a professional community in relation to affective difference. It is an action which counters belonging. An action which delegitimizes Young Veterinarian's affects as self-evident and true. A delegitimizing action to dismantle Young Veterinarian's status as a member of the profession.

Affect theory and sticky affect have the capacity to produce meaningful insights and new thinking regarding many of the common themes currently in The Letter as they theorize around the movements amid social connection, and (the capacity towards) action. In the next section, I expand on the data, methods, and methodologies employed in this exploratory study. 


\section{CHAPTER 4: DATA-METHODS-METHODOLOGY}

This study is nestled in a College of Veterinary Medicine at a university located in the Midwestern region of the United States. The present moments tangled, untangled, and explored are knotted up with a local history and more global history in relationship to the profession. I briefly explore both of these genealogies before describing data, methods, and methodology.

\section{Histories of Exclusion 6}

The history of the veterinary profession, like other professions, is marked by exclusion and discrimination. As veterinary student demographics changed to reflect greater diversity, Robinson (1978) noted beliefs, fears, and resentments of men and women, alike, are areas for further inquiry. Moreover, the "increasing numbers of women students in college of veterinary medicine in recent years, all actors in the processstudents, faculty, administration, and support staff-have had to redraw the old concept of 'the average veterinary student"' (p. 21). The average veterinary student represents a common-sense definition of experiences and practices established over time.

Women were barred explicitly and implicitly until close to the passage of the Civil Rights Act Amendment of 1972, which contained what is now commonly referred to as Title IX. This amendment prohibits sex discrimination in educational programs or activities which receive federal assistance. In the decades preceding, the percentage of women graduates ranged from $0.1 \%$ to $4.6 \%$ (Association for Women Veterinarians,

\footnotetext{
${ }^{6}$ I acknowledge there are many other stories and histories of exclusion, many of which involve people of color, some of which are also women. The telling of gender exclusion is not a move to minimize other accounts of exclusion, rather they are to maintain a focus of this particular scholarship.
} 
1997). Unsurprisingly, the percentage of women graduates quadrupled to $16.8 \%$ in the 1970s. The 1980s saw a ten-fold jump in proportions of women graduating, encompassing $44.3 \%$ of all graduates of programs in the United States and Canada. In 1986, the gender split was approximately 50/50 and since the proportion of women graduates has steadily increased. Today the percentage of women graduates is $80.5 \%$ (AAVMC, 2017) and the applicant class of 2022 is approximately $85 \%$ women, $15 \%$ men, and less than $1 \%$ non-binary. ${ }^{7}$

Prior to prohibition of discriminatory practices, few women were admitted and for those who were, it was implied "women do not carry the full and regular class work" (Sloss, 1939, p. 7). However true, it is not the full story, Sloss (1939) clarifies, "in no case of any modification of, or omissions from, the standard curriculum, are the women students themselves responsible... half of the veterinary colleges bar their women students from certain courses" (emphasis added, p. 7). These exclusionary practices expanded to include a rationale that women would 'waste their education' by not finishing or not practicing after graduation (Robinson, 1978; Association for Women Veterinarians, 1997). In particular, objections to training women were they get married and do not stay in the profession and accordingly, do not make contributions. ${ }^{8}$ Dean R.

\footnotetext{
${ }^{7}$ The AAVMC expanded their gender identification question in 2017 to include non-binary and transgender options.

${ }^{8}$ In my clinical years of study at Iowa State University in 2010-2011, I was told these exact things by a young male intern I was working under. Women who have children are wasting someone else's spot and should not be admitted because they are wasting everyone's time. I was stunned and did not respond nor did I report this. The veterinarian I worked with prior to matriculation and past president of the American Animal Hospital Association, commonly expressed such sentiments in our day to day interactions at his clinics, saying that women were fat-assed and ugly, especially so after they had children. To me, at the time, it was not unusual to hear and perhaps that is why I did not report it.
} 
Dykstra of the Kansas State College of Veterinary Medicine makes this clear in his correspondence to Sloss (1939).

We do not encourage women to enroll in the curriculum in veterinary medicine.

In fact, we try to discourage them, our reason being that we must refuse admission to many worthy young men, and to accept a young woman with the chances that she will not remain in the profession and to deny admission to a young man, does not seem logical (p. 11).

In her informal inquiry of the 21 women graduates of veterinary colleges, Sloss (1939) found that only two were unemployed. Robinson (1978) again refutes this 'commonsense' belief in her dissertation, which realizes none of the 230 women surveyed "withdrew from her period of professional study due to pregnancy or child care duties" (p. 69). Moreover, of the women not retired at the time of study, only $4 \%$ reported they were not presently active in the profession, citing reasons which included: "taking care of small children, pregnancy, surgery, looking for a job, and obtaining a state license to practice” (p. 74). In Waddell (1982), Dr. H. Watkins elaborated many of the tensions which still bear on this gendered inequity, which affects the ability to practice, "since I still feel that I am for the most part responsible for the rearing of the children, I must admit that problems do arise. There are times when the duties of the profession will conflict with the duties of a mother" (p. 155). ${ }^{9}$

\footnotetext{
${ }^{9}$ Dr. Watkins goes on here to offer an example, "as I write this article, I am constantly being harassed by a four-year old who wants my assistance at coloring" (pp. 155-156). While this may not appear, on the surface, germane to the topic at hand, it most certainly is. Importantly, as a mother writing a dissertation who knows this tension all too well. My son, Edward (almost three), frequently works on his various "dissertations" whether they be artwork or some other imaginative play. I've included one such dissertation in Appendix A. This work deserves parallel recognition.
} 


\section{Local Exclusion?}

Veterinary medicine at the partner CVM has a long history dating back to 1884 where the first course in veterinary science was established. In examining archival documents, no explicit exclusionary practices were documented, yet several findings, when contextualized with broader history, bring about questions of gate-keeping. Two cases are explored.

In a Bulletin (1963), the Dean's welcome letter includes a passage about selfreflection and continuing in the profession.

When the student elects to enter veterinary medicine it is clear that satisfying the requirements of the institution is only one part of the process involved. More complex is the process of self-examination. Each student first satisfied himself that a profession has been selected which will be stimulating and challenging, as well as gratifying and rewarding. Satisfactory "passing" of this self examination is the most important factor in the entire process of preparing for a profession. Testimony of this truth is provided by noting that graduates in veterinary medicine traditionally continue in the profession throughout their lives.

To be sure, self-reflection on how one might fit within a profession and how this fit might be gratifying is not in itself questionable. Self-reflection would be helpful for anyone embarking on the challenges of a veterinary program and professional life. However, given the prevailing ideas of women in the profession at the time - that they would leave the profession, wasting not just their time, but that of individuals engaged in their training, and disrespect the profession as a whole — the message of self-reflection could be read with a different subtext. Perhaps it serves as a warning to women given their 
perceived or real social pressures outside the profession, they might not be welcome. To the point: to be welcome, you can never leave, and since women will leave, they are not welcome as professional students. On the other hand, women who were wives were always welcome and encouraged to join the Women's Auxiliary.

Nested in this passage, it is noteworthy to draw attention to "each student has satisfied himself' (emphasis added, 1963). Historically, the standard practice is to default to masculine and male pronouns to describe more encompassing and diverse gender populations, however it can be a source of reification of exclusion or discrimination. Alternatively, you could contend the vast majority of the student and graduate veterinary population was at the time, in fact, majority male. Yet if the argument is sound, we should include only feminine pronouns in all contemporary and future publications given the gender shift in the profession. In other areas of archive materials, masculine pronouns are commonplace as are descriptions of appropriate dress for professional students. In 1965, The Handbook for Students in the School of Veterinary Medicine outlines professional dress as,

A white shirt and conservative tie is required as basic dress during all four years of the curriculum. It is expected that everyone will realize the significance of this matter and conduct themselves accordingly (Missouri Chapter of the AVMA, 1965, p. 19).

In 1973, the requirements lessened somewhat, to state, "professional dress includes dress shirts and ties for all lecture classes" (University Partner, 1973, p. 11). The inclusion of what would be expected for a woman to wear was not added until 1974, stating "Women students must select appropriate skirts and blouses, or dresses" (p. 11). Around this time 
and shortly thereafter, some of the other language shifted to gender neutral pronouns, such as themselves, or named a veterinary student as such.

It is of utmost importance to emphasize these contextual histories of the CVM in no way make claims the program directly engaged in discriminatory practices or is discriminatory to date. Rather the emphasis is elaboration of the social histories and genealogies inherited. The profession, as a whole, was built on discriminatory practices. These histories infuse local histories and social systems that guide policy, practice, and perception. To be sure, it is an emphasis on the fact that curricula, policy, and practices are not constructed nor carried out objectively in a vacuum. They are social enterprises affected by the value-oriented people who build and carry them out. To this end, they are not and never have been neutral, in fact "school curriculum has always been the result of past conflicts and compromises that are themselves the product of wider social movements and pressures that extend well beyond the school” (Apple, 1999, p. 38). I contend we have a social and moral responsibility to inquire, understand, and face these in order to do and be better until we again know better. I discuss my value orientations later.

\section{Recent Events}

In 2016, a staff psychologist was hired through the counseling center to offer services to the CVM, primarily focused on students. They have an office in the main classroom building and offer extended or non-traditional appointment hours in order to accommodate the schedules of veterinary students. Although seen as vital, and met with enthusiasm by many, is also a source of mixed reviews. Some believe experiencing mental illness during the program suggests one is not fit for the profession and/or that we 
should effectively screen for histories of or current mental illness, and not admit those who are living with or recovering from mental illness.

\section{Study Context}

Currently, approximately 120 students are enrolled each year, and in the class of 2019 was $81.7 \%$ women and $18.3 \%$ men with an average age of 22 at matriculation (University Partner, 2016). Their average GPA was 3.70, average GRE score was 307, a slight majority (49\%) majored in Agriculture while barely fewer (46\%) majored in Arts and Sciences. Overall, most students applied for the first time with $11.4 \%$ having applied two times.

To apply, students must have a minimum overall cumulative GPA of 3.0, a minimum combined score of 285 of verbal and quantitative portions of the GRE, and a minimum of 1.5 on the analytical writing section. Although the CVM requires applicants to have obtained a minimum of 40 observation hours with a veterinarian in their normal work environment, they indicate successful applicants usually have more than 300 hours with multiple species. There are 60 prerequisite credit hours required for eligibility, which includes 6 hours in English or communication, 3 in college algebra or more advanced math, 3 hours of biochemistry which requires organic chemistry as a prerequisite, 5 hours of physics, 10 hours of biological science courses for majors, 10 hours in social sciences or humanities and 23 hours of electives. In addition, the "admissions committee expects applicants to demonstrate certain abilities and personal traits" including: "Experience working with a variety of animal species, familiarity with the veterinary medical profession, community engagement with demonstrated leadership 
abilities, effective communications, time and stress management skills, sincere

motivation, [and] realistic plans for financing their education" (p. 22).

The four-year curriculum at the CVM blends 11 eight-week long "semesters" in the classroom or laboratory, with nearly two years in a clinical learning environment. The curriculum culminates in the Doctor of Veterinary Medicine (DVM) degree.

\section{Data}

To explore hidden curricula affects, I centered The Letter in semi-structured object-interviews with peer groups of veterinary community members as well as semistructured individual interviews. Additional data sources were used in conjunction with the interview transcripts, including The Letter and associated comments; memos, jottings, and journaling; correspondence with participants; and archival data. These data sources and how they were produced are explained in greater detail next.

\section{Participants}

Participants were recruited by means of email through a mail filter service of the CVM (CVMMailFilter). Solicitations for participation were sent out three separate times via the CVMMailFilter to the CVM Faculty, Students, Residents and Interns (i.e., house officers), and Veterinary Technicians on October 30, November 20, and November 27 of 2017. The email is included in Appendix B. In addition, flyers were placed on bulletin boards and on the door to the CVM's Library near the end of November 2017. In total, ten faculty, four students, and three house officers contacted me and eight faculty, three students, and three house officers consented to participate. The loss of three participants was due to various reasons including being "on clinics" and unable to attend a group interview as planned, travel interfering with interviewing timelines, and lost to follow-up. 
Overall, 14 community members consented and participated. There were eight faculty, six are women and the remaining are men. All three college departments were represented (i.e., Biomedical Sciences, Veterinary Pathobiology, and Veterinary Medicine and Surgery). Half of the participants were tenure track and all ranks in the tenure and non-tenure track were represented except for assistant professor. Each participated in an interview, two of which were individual at the participant's requests. There were three house officers (i.e., interns and residents), two men and one woman. The Veterinary Pathobiology and Veterinary Medicine and Surgery were represented. Three veterinary medical students consented to participate, one in the pre-clinical curriculum and two clinical students. All student participants are women. All students participated in individual interviews, one of which was specifically requested. One participant engaged in the alternative response option. ${ }^{10}$

In participant groups of mixed genders, e.g., faculty and house officers, gender neutral pronouns (i.e., they/them/theirs) are used. For students, since all participants were women, feminine pronouns are used (i.e., she/her/hers). Otherwise, participants are cited or called by their generic identifiers to protect their anonymity as much as possible. Faculty participants are: faculty 1 , faculty 2 , faculty 3 , faculty 5 , faculty 6 , faculty 7 , faculty 9 , and faculty 10 . House officers are: house officer 1 , house officer 2 , house officer 3. Students are: student 1 , student 3, student 4.

Ethical considerations. The interview space is inherently powered. In initiating interviews, choosing questions, choosing follow-up questions, and actively engaging in

\footnotetext{
${ }^{10} \mathrm{I}$ acknowledge these descriptions of the people who participated are truncated and thin. This is intentional to protect their anonymity as much as possible while offering some details of their positions and relationship to the college and various functions.
} 
an active assembly of discourse I am most likely to be permanently perceived as the researcher rather than a collaborator. This positions me in ways that are powered through authority over the research project and process. However, my approach to research with participants is how they see what counts as legitimate ideas or experiences for them is their authority.

Yet, as conversation unfolds in the interview space we enter ambiguous territory. I do not approach research or interviewing as a passive collector of data—of embodied stories shared to pick-up and carry back to my office for interpretation. I am entrenched in the production - the making and unmaking of moments and stories in process. This is a territory that becomes an active assembly of connections and disconnections. In here, I have an ethical responsibility to honor the sometimes ambiguous and/or transformative processes that occur within and beyond these shared interview spaces. Particularly because considering those articulations of a lack of time for reflection offered to students or scholars (see Sutton, 2007; Ulmer, 2017), it does not often seem like an encouraged practice to slow down, to think, to reflect, which positions the interview space as an opportunity to do so and in these ways, has been described as having the potential to transform (see Marn \& Wolgemuth, 2016; Wolgemuth \& Donohue, 2006). This capacity is particularly one in relationship with those interviews which are active and grounded in an inquiry of discomfort. Where the inquiry of discomfort involves an acknowledgement to the inherent tensions and emergent ambiguities of the interview space and relationships. In particular, those interviews which are anchored in commitment to, compassion for, and an ability to respond to the research process as relational and transformative (Wolgemuth \& Donohue, 2006). Because of this potential to transform, 
Wolgemuth and Donohue (2006) insist “the researcher's role in that transformation should be carefully considered and made explicit" (p. 1028). Engaging in an inquiry of discomfort and in conversation that is realistic, respectful, receptive, and relevant follows The Letter. With this move, I embody research-I enter into what I propose as an action, as a process, as a transformation.

\section{Interviews}

Interviews were object-centered, meaning The Letter was the spark for the discussion and intended focal point. Nordstrom (2013) describes her process methodology of object-interviews in which she puts to work theoretical concepts and objects together with people in interviews. With this, objects are non-static and open to resignification within the interview. Specifically, objects "refuse permanence" and the information about them and what is produced with them has "shifting meanings that defy order and focus" (p. 243). Nordstrom (2013) used participant-selected objects in her study as a means to "keep participants focused on a topic" (p. 243) and to then analytically focus on the "verb-rich connections" materialized in conversation with participant-objects (p. 244). To this end, object-interviews can be generative and produce many connections. However, unlike Nordstrom (2013), I begin the object-interviews with a researcher-selected object: The Letter. The Letter is a common-yet uncommon-place to enter conversation and those encounters with it, associated affects, and what was produced are comprised of uncommon milieus of affects and connections inside and outside the interview space.

As the focus of this inquiry are affects, group interviews were sought for their ability to promote interactions among individuals and objects present. In particular, how 
folks who are involved can use the time "to interact... challenging and questioning each other's ideas or positions, exchanging stories, and thinking out loud with others who have similar experiences” (Wear \& Skillicorn, 2009, p. 452). In some instances, group interviews were not possible or not desired, so individual interviews were also performed. Both group and individual interviews were grounded in the same semi-structured protocol (Appendix C), where the language was adapted depending on the individuals and topics of conversation. The semi-structured protocol was a series of open-ended questions designed to prompt thinking and reflection on The Letter and associated reactions. Follow-up questions and prompts were designed and enacted impromptu to make space to explore ideas, feelings, emotions, or stories. Intentions were grounded in a desire to stay with the ambiguous and shifting affects among The Letter. Relationships within this constellation may include associations with veterinary school, with the profession, with others (e.g., people, animals, places, spaces, objects). I performed all interviews and wrote about how my physical presence and yet unchecked assumptions were imbricated. In this regard, I kept a research journal, which is another data source described later.

Group interviews. The group interviews were comprised of three peers and arranged according to the availability of the participants. The peers were individuals from the same hierarchy of power in the community, meaning students with students, etc. Peer groups, over heterogeneous groups, were selected to encourage comfort and trust for participants. Students were considered in particular, because they are at the mercy of grades to remain viable in the community and may feel threatened sharing a space with faculty or house officers who have, can, or will be grading them. Although this 
hierarchical homogeneity could serve to reify distinctions between these groups in the community, this was preferred because complicating and troubling the hierarchy had the potential to produce a more tense and unwelcome space. This could undermine efforts to build an interview space of trust where participants feel their ideas, thoughts, affects, and stories are valued and valid.

Prior to beginning the semi-structured protocol, I read a statement of expectations for the space and conversation. Intentions here were to set tone as well as delineate some boundaries for disagreement. The guidelines were developed from discussion notes I took while participating in a discussion session not directly related to the study at hand and are included in Appendix D.

Group interviews were conducted in a conference room. The room is long, filled with a long table and bookshelves filled with old textbooks along one wall — the wall facing you when you first walk in the room. The chairs that surround the table are black pleather, large, and comfortable. They are equipped with many optional settings including recline, adjustable height, and swivel. There is a screen to the right when you walk in, which functions as the computer screen for the nearby computer tower. The room is in the basement, has no windows and even with all the lights on, is dim. It's comfortable, yet feels old and powerful in certain ways - powerful in a way that speaks through unspoken history, old bound books, and tradition. There are chairs along the entire perimeter of the table.

Individual interviews. Individual interviews were conducted in either a small room on the second floor of the building with lecture halls and more traditional classrooms (Small Room), or an individual faculty's office on the third floor of the 
teaching hospital, or in my office on the first floor of the building with lecture halls (My Office).

Small Room is what appears to be an old break room of a research institute formerly housed at the CVM. It is small, has a window that nearly fills the wall to the left when you walk in, and two white boards which fill the walls perpendicular to the window. Across the from the window sits a small countertop space and cabinets, a sink, and even a drip coffee maker. From time to time the white boards are filled with jottings of studies - most recently neuroscience. I make it a point to open the mini-blinds when I enter the room, even if the sky is overcast—-having an extension of the outdoors that projects in, I feel is important. The overhead fluorescent light otherwise keeps the room bright and the air handling seems to never shut off, though the space is typically comfortably heated or cooled. Most folks I take to this space comment on how nice it is, away from everything and everyone - tucked in a quiet corner with a window to the outside. The long corridor that leads to the room is also lined with windows and potted plants. Perhaps this brightens each step along the way and lifts the mood, welcoming the sunny solitude.

My Office is an expansive room underneath the large, tiered classroom. It houses many open-air cubicles filled with graduate students and post-docs. The cubicles are smaller than what seems normal. There are L-shaped desks that fill approximately half of the cubicle and the open space is consumed by your chair when you push away from your desk. There are no external windows and only overhead fluorescent lights. The 'corridor' spaces between cubicle modules are often filled with trash or recycling bins-both overflowing with trash. My cubicle is not overly messy, but not necessarily neat either. I 
have several pictures of wild birds from a calendar pinned on the wall (a goldfinch, a redwinged blackbird, and a cedar waxwing), a coloring book page tastefully colored in purples and black by my young son, Edward, several checklists, and many notes from friends, colleagues, or past students. In one corner sits a pile of paper-there's a legal pad, clip-board, who knows what else. A small Kerr jam jar is filled with pens and highlighters. The shelf is filled with pathology textbooks and paper copies of journals sprinkled in with a few binders and Communities of Practice (Wenger, 1998). It's quaint, cramped, and eccelctic.

Thirteen hours of conversation were recorded and transcribed verbatim. One recording was sent to an external service for transcription and the remainder I personally transcribed using Express Scribe (NCH Software) and select Jeffersonian markings (Jefferson, 2004). Express Scribe is foot-pedal controlled transcription software with various features that assist in transcription, such as augmenting the speed of audio. It was used in tandem with word processing documents to produce transcripts. The selected markings (Appendix E) were used in an attempt to record some paralinguistic features of the conversations. Because the production of transcriptions and decisions therein are political and theoretical acts of research — they are not neutral nor inconsequentialtherefore, my decisions were to contribute to the thick and rich affective data produced for analysis. Those selected markings were attempts to approximate affect - use of silence and other embodied movements and sonic qualities (Daza \& Gershon, 2015).

Ochs (1979) positions transcription as theory. Rooted in theory, the use of transcription markings was informed by theoretical concepts of affect. In ways that affect, being affected, and affectual are embodied experiences and embodied experiences are 
present in linguistic features, paralinguistic features, other feelings and noticings, and also present in their absence. Those markings used include annotations of silences in seconds and micropauses, background noise influenced by the bodies present in the room, influenced by The Letter or other materials related to the letter. When utterances became hushed or sped up or slowed down or emphasized, this was noted. Throughout transcription, I cross-referenced my intra-interview jottings and post-interview memos to impart affectual qualities of the interview in the form of notes in the transcript to account for non-sonic, non-discursive affects.

\section{Additional Data Sources}

Several other data sources were used in process to develop interpretations in conjunction with interview data. These sources included The Letter and associated comments, research journaling and analytical memos, email conversations with participants, and a creative response one participant embarked on. These data and how they produced and used are described next.

The Letter. On May 26, 2017, Open letter from a disillusioned veterinary graduate (The Letter) was published on a public website, dvm360.com (dvm360.com staff, 2017). The Letter was centered in the object-focused interviews. Paper copies were made available to all participants, however some participants arrived with their own annotated copies. In each recruitment email, links were included. Some participants had previously read The Letter and comments on social media and were familiar with the content before working with me in this project. Additionally, The Letter and associated comments were data sources used and analyzed in conversation with the interviews to produce theoretical interpretations. 
Journals and memos. Approximately 80 pages were written in a research journal in and around the time of active data production with participants. This writing included jottings during interview sessions, analytical insights, and journaling to explore tensions through writing. Additionally, post-interview memos were typed or audio-recorded after each session. These data were used and analyzed in conversation with the interviews and other data sources to produce theoretical interpretations guided by analytical questions made possible through thinking-with-theory (Jackson \& Mazzei, 2012). Thinking-withtheory and analytical questions are explained in greater detail in forthcoming paragraphs.

Participant correspondence. I engaged in an ethic of care while working with participants, keeping in mind the words of Kim (2016) who urges scholars to be "clear how participants' perspectives were respected and honored" (p. 89). I was upfront on how I would be interpreting data, and how I would share bits of my analysis with them. I did my best to keep them up to date on perceived timelines. After the development of participant synopses, which I discuss later, I shared these with participants. Thirteen out of 14 participants responded and offered endorsement of the summaries. A few engaged further, offering comments regarding the process and/or the intermediary product. For instance, one participant wrote, "It's very interesting to see how you've put a casual conversation into something coherent!" and another wrote, "That's a great synopsis and really illustrates how I feel about the article and the broader aspects." I responded to each confirmatory message, and in some instances the conversation continued. In one instance a participant, despite participating in a group discussion, was curious of how they fit with others, "I would like to know if my thoughts were also shared by others." We discussed in several messages, and I was able to clarify the relationship among responses. 
Two participants took the response to their synopses further. One participant took up the opportunity to engage, reflecting on and expanded notes and ideas in their synopsis and sent it back. Another participant wrote back and forth regarding these interpretations, endorsing them but continuing to engage in curious questioning, and then further engaged in producing a creative response. This creative response was a sevenpage word document comprised of short personal narratives that synthesized responses and reactions to contents of The Letter or anonymous comments with song lyrics. They paid special attention to the meaning of those lyrics, personally and in response, and how they affected them. This participant also provided a two-page word document that synthesized personal responses to their life's circumstances and challenges. It was a personal, in-depth offering of what is happening for them and how it relates to music above and beyond their responses to The Letter and to the profession. These data were used in the interpretive processes, like other additional data sources.

Archival documents. With the help of the Veterinary Medical Library head librarian, archival documents and texts related to curricula, teaching, and learning were identified and reviewed. Those documents reviewed were the school's official bulletin, published approximately every other year. Bulletins, announcements, or college catalogs were the various names attributed to this document which primarily serves recruitment purposes by way of organizing information in a visually appealing glossy magazine or pamphlet. Bulletins from 1963 to present were reviewed. In addition, Student Handbooks, as publications of the state Chapter of the American Veterinary Medical Association, which outline the Student Chapter constitution and by-laws in addition to codes of student conduct were reviewed. Also, all available Curriculum Committee 
memos and correspondence available on file from 1980-2000 were reviewed. These data were used to produce a contextual history and interrogate institutional and historical contributions to interpretive findings of affective norms.

Ethical considerations. Using someone's personal experiences, disclosures, hopes, and dreams published in a letter online produces many ethical questions. Whose Letter is this? Can I research (with) it? What does it mean to "use" it as an object of and for research? Who is the Young Veterinarian and would they consent to my use of their Letter? What about the anonymous commenters? Do any of these people have a reasonable expectation of privacy?

Researchers who primarily use social media sites as data are highly active in debating questions such as how to deal with content produced and shared on websites (Georgakopoulou, 2017; Rüdiger \& Dayter, 2017), what are the copyright limitations (Pihlaja, 2017), what are users' expectations about their own content (Pihlaja, 2017; Zimmer, 2010), and what to do about consent (Zimmer, 2010). These scholars raise important questions about how to think about their data. First, Georgakopoulou (2017) elevates online 'data' and digital information to a respect of individual persons even when it is not apparent "how and where persons are involved in the research data" (p. 174). They suggest reflexive engagement focused on data as people and an attention to shifting ethical needs as research unfolds. Where data are considered with the same ethical regard as a person standing before you. Zimmer (2010) advanced a case study of social media data use gone awry to pose new questions of online research ethics and in doing so brought to light some salient details of supreme importance in this study. In the case study, several unique identifiers can put together a social and cultural fingerprint which 
may threaten anonymity. Considerations for this College of Veterinary Medicine are of paramount concern because curriculum is somewhat unique, having multiple unique identifiers, e.g. an unusual specialty_-backyard poultry—and graduating class, could pose a significant threat to anonymity.

Still, some questions about Young Veterinarian remain. They took care to remain anonymous as the author of The Letter and may not have considered their writing might be academically scrutinized and analyzed, or put into conversation at a local level. Pihlaja (2017) suggests that "the same could be said of much copyrighted material in books and newspapers" (p. 220). That these authors or creators might not foresee these circumstances, but that academic analyses are "not unreasonable or unethical" (p. 220). AERA Council (2011) goes on to support this, "education researchers may conduct research in public places or use publicly available information about individuals (e.g., naturalistic observations in public places, analysis of public records, or archival research) without obtaining consent” (p. 151). Kim (2016) encourages (narrative) scholars to be “clear how participants' perspectives were respected and honored" (p. 89). Yet, as a "found" story—I cannot enter into a conversation about desires and respect. I believe I have found a space of what Kim (2016) calls "ethics in practice" which come to bear on moments in research practice without clear guidelines. Here I am reminded of St. Pierre, who suggests that ethics "calls us to be worthy at the instant of a decision" (Richardson \& St. Pierre, 2005, p. 972). Centering The Letter, I am continuing the conversation-as realistic, respectful, receptive, and relevant-Young Veterinarian started, or aimed to generate, with their piece. Ethically, I have bound myself to those principles suggested in 
The Letter, as well as those proposed in the institutional ethical review process and other standards for humanities and social science research ethics (AERA Council, 2011).

\section{Researcher Diffraction ${ }^{11}$}

I have mentioned previously of my embeddedness and imbrication in this research. I am a woman, and a veterinarian. I am a pathologist who trained at the institution where this study is situated. Additionally, I am a graduate fellow there and have participated in the freshman orientation program for many of the years that constitute my tenure. I have accepted a position there, which I will assume on June 1 following the completion of my Ph.D. Being in and of the context is a blessing and a curse. Knowing some participants beyond the research encounters was helpful in interpretation, and in other ways it challenged me. Like the thin descriptions of participants, I will leave explorations of these to my research journal to protect anonymity of participants. I think and worry about who I work with and who will read this, what they will think and who will want "results." How I will marry another's definition of results with my own, and simultaneously contribute to necessary fields and engage in necessary duties. I find myself questioning what is essential? What is necessary? I believe these questions, and the negotiations that follow often affect how impactful we can be as change agents. I would like to think these worries do not embed themselves in the ways I conduct research, but undoubtedly, they do.

\footnotetext{
${ }^{11}$ Barad (2007) discusses how reflection and reflexivity are based on the assumption that light takes on certain patterns in relationship to an object that is there prior to their intersection. Davies (2014) calls attention to these categorical differences as documentation strategies and names diffraction as "itself the process whereby a difference is made and made to matter" (p. 734). In this section, I intend to surface some differences I bring to this scholarship as matters of importance and use the term diffraction, rather than reflection, reflexivity, or positionality to call attention to these matters of difference.
} 
I have lived with depression and states of poor mental health on and off my entire life. The awareness of gendered expectations percolated during my time in veterinary school, subsequently simmered during my residency, and then boiled over when I was pregnant as a Ph.D. student. I finally felt my subjectivity as a woman with every fiber of my being(-as-vessel). Post-partum brought about a new storm of anxieties in conversation with my doctoral studies, some of which I still face. The weight of much of this is it never fully leaves, you simply must figure out how to sit more comfortably with it given the furniture at hand, while still performing tasks at hand as if you are just like everyone else. This is not to say that everyone else does not have fears, worries, down days, or is sad-it is that these elements of their life are not or do not become all encompassing, leaving little to no room to sit with them. Rather, folks, like me, coping/living/recovering with mental illness are occupied pacing around, or worse yet, hopelessly laying down on the cold bare floor, wondering where and how to get along in the tiny threads of existence not already consumed by worry, fear, intrusive thoughts, or despair. I bring all this, and more, with me in my conversations, in my experiences, in my research. It is my genealogy of affects and it is borderless.

Within this study is an examination of values that circulate and are embedded. This study is one of hidden curricula. As I am necessarily embroiled in this research, one might ask of my values that underscore my response to The Letter, and perhaps, just as importantly, those which underscore this scholarship.

\section{Community and Social Justice}

I find a sense of community and collegiality to be a highly regarded element of my daily life, which includes but is not limited to personal, professional, and scholarly 
endeavors. The converse, a lack of this sense, is a stressor and this sense of belonging as an important feeling to buffer stress.

Veterinary medicine, like many other facets of the social landscape, is a diverse array of folks that embark on a diverse array of professional endeavors. We each bring our values, interests, hopes, and fears to the table day in and day out. Many of these overlap, and many are divergent, yet we purport to hold dear similar ideals of a professional — of professionalism. There are historical antecedents to the idea of a monolithic professional identity — a time when veterinary medicine was more explicitly exclusionary, consisted of white men who were financially solvent and the profession consisted of general practice defined by seeing a mix of animal species. Apple (1999) calls this a "collective memory," where

we look nostalgically backward to a time when teachers, administrators, parents, business leaders, federal and state government officials, and others all sat up and paid attention to our words of wisdom. In many ways, this is just as mythic a past as that found in the conservatives romanticization of the perfect school, family, and community where we all shared the same values, and pastoral settings reigned supreme (p. 37).

Importantly, some may look back to this collective memory, where 'everyone got along' and there were not 'these issues' we have today. The collective memory is shaped, in part, by the reality that certain practices were systematically built to maintain certain homogeneity. Importantly, those discriminatory practices have been outlawed since. When we look past those histories, we fail to see how there are remnants still present as relics of an institution, as traditions. 
Sherwin (1996), quoted in Wear and Castellani (2000), offers an appropriate take on homogeneity and the consequences therein, Homogeneity among participants in debates has consequences in any field. One important effect is that it allows most practitioners to remain oblivious to the significance of their own location and perspective for their work. As in other disciplines that are dominated by a well-educated, white, male elite, the fact that most of their colleagues share the same perspective makes it easy... to lapse into false generalizations from their own experience. It is all too easy to mistake oneself for a neutral "ideal observer" when no one is present to point out the specificity of one's actual stance by countering with direct experience from a different vantage point (p. 609).

The "bedrock" of the profession — a sense of collective professional identity-is untenable, and is a historic cache of inequity that dates back to the origins of veterinary medicine. Although some basic humanistic values might underscore a connection between us, a shared embrace of difference and all its vibrancy must diffuse among us all if we seek to sustain a sense of community among the vegans and the feedlot veterinarians, the government meat inspectors and the exotic animal oncologist.

Importantly, this value is not that everyone else share my value - more of an underscoring acknowledgement and acceptance of difference as foundational. Without this, our false sense of community will continue to divide us. The Letter and the comments it garnered offer a window into the fractures that emerge when homogeneity is offered a desirable status above difference. 
I have written previously about my stance as a feminist in the literature reviews. Although this is not a feminist study, I cannot claim feminist sentiments will remain "silent" in this work simply because it is not framed as a feminist study. Nested within the comments were all the evidence one needs to see the social disparity women, people of color, or other under-represented minority groups face day in and day out. Many (if not all) issues, including those addressed in this study and The Letter, are social issues. Social issues are complex, multifaceted, and unstable — on the move. The way language shifts over time, is erased, and the voices of those on the fringe are erased in the process. I see social justice as important and interlocked with a sense of community. If we do not value diversity, if we do not reconcile past injustices, we will continue to repeat them.

\section{Emotions}

We all feel. Many of us feel we should not feel or there are certain ways we ought to feel or can feel about certain things. That is, normalized sentiments shape the way we judge ourselves and each other in how we respond to anything in life.

The harsh judgement of how we express ourselves as affected, our feelings, through emotion is quizzical and isolating. As a woman who is deeply affected by many things and often moved to tears, ${ }^{12}$ I must surveil and censor myself in what feels like extreme ways because I fear may face glares, eye rolls, exclusion, and/or judgement. I fear people, feeling strongly about the Cartesian split, will think poorly of me as a person,

\footnotetext{
${ }^{12}$ I often provide the example of frequently getting choked up and/or crying in the last half- to quarter-mile of a long road race. As a runner who has trained and endured and likely endured a lot along the race route on race day, I find myself moved to tears and breathlessness - almost asthmatically so — in ways I cannot describe. This is at times when I have nothing left in the tank, when I otherwise vomit after crossing the finish line, I am profoundly affected by the cheers, shouts, and musical pageantry of the finish line area, of my own efforts, and tears emerge before it is over. Tears emerge in anticipation and in participation at the intersection of such intensities.
} 
a scholar, a pathologist, or academic, simply because I feel-and-think. Because I am whole. It is a troubling bind shared, I am sure, by many others—in particular, other women.

Young Veterinarian expressed strong emotion regarding their experience in veterinary school. Some folks agreed with this. Some folks vehemently disagreed. What is interesting, is people who feel strongly negative about their experiences are forced to repeatedly explain and justify their experiences because they are deemed invalid and they themselves are unworthy of the profession. Consider the comments, again. I would never hire you or people like you. Hysterical women. Whiney lazy millennial female. At the core is a sentiment that if you feel a certain way about something, if you express certain emotion, and are affected in ways that do not look like us, you don't belong. Which circles back to a sense of community and an orientation to social justice.

Free expression of emotion is seemingly a radical act. Many feminist scholars position emotions as political, insisting the views of women as emotional- "naturally nurturing and caring... also as tending towards an overemotionality" - serves "the interests of patriarchy and capitalism," and "justifies [women's] exclusion from the rational polis" (Boler, 1999, p. 7). This socialized pastoral control is psychosocial domination.

Here I am drawn to, and agree with the words of Boler (1999), I am not arguing that a pedagogy of emotions requires confession, that we must all bare our souls. I am arguing that we consider the reasons emotions have been systematically discounted, and develop more creative alternatives for emotions' roles in educational practices (p. xviii). 
I wonder, like Boler (1999), what we might gain by uncomfortably questioning our assumptions of emotion and learned ways of positioning, of doing gender, of doing doctoring.

\section{Analytical Strategies}

Thinking-with-theory (Jackson \& Mazzei, 2012) is a process methodology where data production, analysis, and thinking are merged as both method and methodology. This dynamic process refuses pre-set analytic methods or tidy schemes and instead is constantly unfolding. Thinking-with-theory brings together "philosophy, theory, and social life to see what gets made, not understood" (Jackson \& Mazzei, 2012, p. 3). This embrace of inventiveness is intended "to add to (rather than confirm) reality" (KoroLjungberg, 2016, p. 87). As experiences and affects are inherently complex and persistently ambiguous, qualitative methods and thinking with theory, together, provide means to highlight the multiple meanings that will emerge. Indeed, Nicolazzo (2017) described her thinking-with-theory process as a way "to expose the complex, shifting, and sometimes conflicting meanings that result from data analysis" (p. 7).

Engaging in thinking with theory research is moving into a space where "the divisions among and definitions of theory and data collapse" (Jackson \& Mazzei, 2012, p. 6). In this space, analysis is acknowledged to be always already happening (Jackson \& Mazzei, 2012, 2017; Ringrose \& Renold, 2014). This exploratory study was guided by the question: How does The Letter affect members of a CVM community? From here, using thinking-with-theory, analytical questions were produced in process to frame and focus analyses. These analytical questions were: (1) How did these affective values come to be for this person? (2) How do these affects produce (dis)connection? and (3) How do 
affects delegitimize The Letter as an account of hidden curricula? These questions are discussed alongside the analyses they emerged with and for.

Writing as inquiry (Richardson \& St. Pierre, 2005) was used while thinking-withtheory. Several scholars have advocated for writing as a process of inquiry, where data is (or can be) produced and analyzed (Richardson \& St. Pierre, 2005; St. Pierre, 2011). In this way, writing is treated as an uninhibited field of play, where data is produced, analyzed, and, importantly, where thinking occurs. In these ways, conventional definitions of data are troubled with this flattening of theory, data, and analysis. Which opens possibilities for new ways to imagine what constitutes data (Koro-Ljungberg, MacLure, \& Ulmer, 2017). This is not to say that customary conceptualizations of data, where data are produced through interviews with participants or field notes, are eschewed, but rather added to, expanded upon, and open to reinvention within the fluid process.

\section{Affects and Evaluations}

Affect (Ahmed, 2010) focuses data analysis on how responses and evaluations are formed, and then what those responses and evaluations, the affects, do. Evaluate is derived from the prefixes -ex (Latin) or -es (French) + value. Where -ex or -es mean "out, from," and value is the "relative worth, utility, or importance" (Merriam-Webster, 2018). Evaluations, then, are movements which emerge from values. Evaluations are affects in both cause and capacity. Evaluations determine the worthiness of matters and are the capacity to act in ways which would position matters as worthy.

Affects work, in part, through producing a space of expectation where affects stick and produce norms. In considering these theoretical concepts of sticky affect and 
spaces of expectation in conversation with the hidden curricula, there are many ways in which they speak to one another. In particular those in how hidden curricula materializes in departures from expectations or plans, and those plans or expectation are sticky affect in the space of expectation; they are the norms. To be sure, sticky affect produces the norms. Departures from norms are affects in spaces of expectation which constitute experiences of hidden curricula. The new responses and evaluations (new affects) emerging from spaces of expectation constitute markers of belonging in relationship to these affective norms. These theoretical concepts and associated analytics produced through thinking-with-theory are discussed next. In particular, how these analytics were used to explore affects through participant responses and evaluations via values. Then how these affectual values work to produce norms and departures in spaces of expectation are discussed next.

Affectual values. Affect is, in part, the glue that sustains and preserves the connections between values, ideas, and objects (Ahmed, 2010). Given this relationship, and the transient nature of affect, cultivating an instance of evaluation required interrogation for values, since evaluation is out from the designation of worthiness. In order to interrogate values, an initial analysis was produced to curate these value nodes around which affect sticks and works. This initial analysis is described next.

I read through each transcript for general impressions, making jottings in the margins or in a research notebook. Then, I engaged in multiple close readings to coalesce ideas of how participants are affected by The Letter in terms of their evaluations of it. Affect and evaluation, given the theoretical assumptions of this research, are necessarily enmeshed. Evaluations are affects which emerge from values. Being affected involves an 
evaluation (Ahmed, 2010). Although within the group interviews, participants topics of conversation ebbed and flowed with the various interests of people present, overall, the individual participant responses in relationship with others, and The Letter, was the focus of these close readings and subsequent analysis.

Next, guided by the analytical question, How did these affective values come to be for this person?, I engaged in writing as a method of inquiry (Richardson \& St. Pierre, 2005; St. Pierre, 2011) and produced narrative synopses for each participant that pulled together important themes and storylines as well as my theoretical interpretations of values associated with their affective responses. In this writing, I sought to describe how and why participants were affected by, and responded to, The Letter or to each other in ways which were underscored by a something personally held dear, a value. These synopses were both interpretive and descriptive, including written narratives that traced the genealogy of their affective values, including participant quotes and citations for data sources (e.g., lines from transcript).

Over time, some of these value labels changed and morphed as I stayed with the trouble of necessarily drawing such distinctions and placing labels among and across participants' responses. For instance, working the distinction between complexity and perspective was thorny. In some ways, they were similar in exploration of possible situations of other people, however with perspective, the quality of the affect was in affective affiliation with others and because of this deflecting judgement in favor of acceptance. On the other hand, complexity was an exploration and grappling with situations, yet the quality of this affect was to create distance and deflect judgement in favor of understanding. It was through iterative close reading of transcripts, at times 
listening to audio segments again, coordinating with memos, jottings, and journal entries, that these labels and distinctions were derived. In writing and comparing synopses, I kept track of areas of close overlap with other participants and with The Letter - of similarity among affects, conversations, and values. I made notations of these in each interpretative synopsis.

Enacting an ethic of partnership in the research relationship, I shared cursory interpretations with participants. In this way, it also served as check for mutual understanding and an opportunity to engage with data, provide reactions, and generate new affects. Thirteen of the 14 participants offered endorsement of synopses and values. A few engaged further, offering comments regarding the process and/or the intermediary product, or continuing conversations that explored and unpacked my interpretations. These new data were threaded back through the analysis, to ensure a mutual trustworthiness. Following this, interpretations did not change; however, extra quotes were added to two synopses based on this additional correspondence.

Spaces of expectation. Spaces of expectation are characterized by accumulation of sticky affect and represents affective norms, or the normative ways of responding in a given situation or under certain circumstances, for a given group. For instance, in veterinary medicine, given the highly competitive nature of admissions, the space of expectation regarding the notification of admission is one of excitement and joy. We expect others to be affected in this way, and likewise, others expect to be affected in this way. If not, we might be perplexed and wonder why something which should be-is expected to be-so joyful and exciting, is met with different affects. The space of expectation, in the establishment of affective norms, is relational and sociopolitical. 
Analytical methods to explore the relational and sociopolitical nature of affectof how it circulates and works - were developed thinking-with affect (Ahmed, 2010) and the hidden curriculum (Apple, 1999; 2013). The affect moving among values is like the enactment and experience of the hidden curricula, as hidden curricula are repositories of institutional, historical, personal, and political values. Often, hidden curricula are brought to light through departures from norms and expectations. Here, norms and expectations relate to sticky affect and spaces of expectation.

To unpack ideology, Apple (2013) offers conceptual and relational spheres wherein ideology works: economic, cultural, and political. They interact with one another and with other dynamic spheres of social life, such as gender, race, and class. Similarly, Zembylas (2002) produced and utilized three conceptual domains of emotions in science teaching: individual (intrapersonal), social (interpersonal), and sociopolitical (intergroup). In Zembylas' (2002) analytic, he sought to describe how emotions operate, circulate, and affect when how and why teachers use emotions. In drawing these theoretical and analytic parallels, individual, relational, and sociopolitical categories were developed and used for the purposes of tracing how affect was moving and sticking among values. The movements made evident in evaluations in participants' responses.

Caution is necessary, in naming categories, as the tendency with labeling is to produce discrete and easily identifiable and at times quantifiable categories, that is not my intention here. Rather, these distinctions operate together and in often overlapping and ambiguous ways. In this study, they are used to articulate a possibility, among many, of a genealogy of affect in relationship to The Letter. This is intended to explore the very fluid and ambiguous nature of affect and makes no claims that these distinctions are 
imperative; rather they operate as a tool to think-with and follow affect as it moves. In using these distinctions, it allowed for the introduction of policy and archival data to illuminate repositories of sticky affect and what it produces.

These three categorical spaces — individual, relational, and sociopolitical—where affects stick, circulate, and produce new affect were expanded using writing as inquiry (Richardson \& St. Pierre, 2005) and theoretical interpretations of participants' value synopses and archival data. Other data sources were also consulted and incorporated in this analysis. The individual interpretive concepts of affectual values were explored in the first analytical step, described previously.

The analysis of the relational space was guided by the question: How do these affects produce (dis)connection? As relational forces, affects constituted evaluations that marked connections and disconnections, or (dis)connections, among other affects and the people and experiences tangled with them. Here, I use (dis)connection to call attention to the connection necessary in the production of disconnection as well as the gradations between. Affects which seemed to circulate in similar, relational ways were then grouped. The traced genealogies of certain affects among The Letter were interwoven to protect anonymity and articulate difference among similar affective values.

As sociopolitical forces, affects are reified in larger systems and policy, further cementing them as institutional norms. In particular, as experiences of hidden curricula represent departures from expectations. Again, I used writing as inquiry and employed the analytical question: How do these affects delegitimize The Letter as an account of hidden curricula? I centered The Letter, on the whole, as a departure. Doing so is laced 
with hope that what the Young Veterinarian writes about would not be what was planned or expected.

Although these relational and sociopolitical distinctions and analyses are written as discrete analytic steps, they often happened in tandem. Through writing, I explored these affect groups, what they produce, and how they relate to belonging and well-being through writing. This process was engaged in word processing documents. First, bringing together all my writing around the various affectual values, and then writing to explore the connections among them, ultimately arriving at the groups of affects. Then, using a table with three columns, each labeled with the categorical spaces and associated analytical questions, I brought together other data and pieced together the genealogies of the affect groups via writing. Keeping the writing as inquiry in side-by-side columns was an intentional move to stay with the multiple analyses as mutually informing and reinforcing. An in-process example of this side-by-side merging of data and writing and thinking is included in Appendix F. 


\title{
CHAPTER 5: INSIGHTS
}

To begin, I insist these insights do not represent the affects, nested values, and associated responses to The Letter are representative of all community members at this CVM. Nor is this an attempt to isolate and characterize universal values responsible for all conduct and norms. Instead, these affects, values, and possibilities produced offer insights into the complexity of subjective beings in a complex and subjective community. My hope, like Zembylas (2002) study of emotion in science teachers, is this inspires further reflection and diffraction, and this brings about an interrogation of the many taken-for-granted ways we conduct ourselves in relation to one another and, in particular, relation to affect, emotion, or well-being. In this interrogation is an opportunity for vulnerability and transformation. It is my earnest hope, as a local and global community, we take advantage of this opportunity.

Many affectual values were related to affects arising from participant collisions with The Letter. Next, I explicate these affectual values, tracing their genealogy through stories. Then move to explaining how they are relational and sociopolitical affects which produce responses and spaces of expectation as they circulate and stick.

\begin{abstract}
Affectual Ether ${ }^{13}$
It's like how they interpret any rules or regulations is going to be based in their values. faculty 2

\footnotetext{
${ }^{13}$ Ether has several meanings, all of which are applicable and productive in this use as an organizing principle. In a philosophical sense, ether is an unknown element that fills space and the heavens - an unknown surround. In medicine, ether is a historic anesthetic solvent used to intoxicate and produce anesthesia for surgery. Scientifically, æther is a wave theory of light which permeates all space in transmission (Merriam-Webster, 2018). In these ways, the ether is that which is around us, constantly transmitting and potentially intoxicating, like affects and hidden curricula.
} 
The affectual values interpreted among responses to The Letter were as follows: Accountability, emotional neutrality, loyalty, self-reflection, responsibility, respect, complexity, positivity, helpfulness, balance, resilience, perspective, curiosity, social justice, gratitude, progress, agency, thoughtfulness, and freedom. An assumption of the hidden curricula is they are affective entities capable of producing certain learning or becoming as a result of interactions with it. Although these analyses and insights do not claim to, nor attempt to, approximate formal and quantifiable definitions of causality, consideration for connections across participants was taken. A majority of affectual values materialized with multiple participants. These connections may offer windows into potential relationships among participants, hierarchical relationships, or ways of learning and becoming veterinary professionals. On the other hand, several affectual values-self-reflection, progress, agency, and thoughtfulness-were identified as something held dear for one participant. Often, these seemingly singular affects were echoed in the responses of others, yet not interpreted as a primary affectual value representing a thrust of response.

In the sections that follow, all affects are discussed and explicated. The sections are organized through the grouping similar affects. The associations were based on how they work or were defined, not necessarily how they came to be. Each affect group includes extended narratives, which incorporate data from participant interviews to answer the analytical question: How did these affective values come to be for this person? Next, I present spaces of expectation. The purpose of this subsection is to trace many possible movements of the affects as relational and sociopolitical forces, capable of producing (dis)connections, and offering legitimacy, or not, to The Letter. In this 
subsection, narratives that incorporate participant and archival data are presented in ways to answer the analytical questions: How do these affects produce (dis)connection? and How do affects delegitimize The Letter as an account of hidden curricula? Across each section and subsection, quotes from participants or other data sources are cited, and quotes from The Letter presented in text are in italics for clarity. In areas where specific sections of The Letter are referenced, yet not directly quoted, the quote is presented in a footnote. Including quotes from The Letter in the footnote where they do not appear in the text is a means to anchor the multiple and overlapping responses and valuations of The Letter. On a larger scale, the anchoring represents how The Letter was centered in this study. The order of the groups in the following sections is of no intentional significance.

\section{Responsibility, Accountability, and Respect}

The affects responsibility, respect, and accountability primarily emerged in discussions with faculty and house officers. More broadly, these three affects relate to the powered structure of the teaching hospital and the "hierarchy of delegation" everyone depends on (faculty 5). ${ }^{14}$ Oftentimes, this emerged among passages in The Letter which begins, be realistic, and then expands on the dynamics of a teaching hospital, encompassing responsibilities of students, technicians, house officers, and clinicians. ${ }^{15}$

\footnotetext{
${ }^{14}$ For those unfamiliar with teaching hospital hierarchies related to training sequences of veterinarians, training is briefly explained: Teaching hospitals are where students spend a bulk of their clinical curricula, training on rotation with specialists and specialists-in-training. The latter consists of interns, typically veterinarians who just graduated, and then residents who completed an internship and are now in a 3- to 4year program to become a specialist (e.g., cardiologist). Students, interns, and residents have increasing levels of power, respectively, and all train/learn under boarded specialist clinicians and technicians are veterinary nurses.

${ }^{15}$ Be Realistic. If the head clinician is overwhelmed, the house officers [i.e., interns and residents] probably are, too, and the students are probably running around like maniacs trying to keep the whole thing afloat. Each person should try to recognize when someone is in over their head and help out accordingly.
} 
Emergent affects encompassed explanatory sentiments, which draw on the idea of "not the whole story" (faculty 2). Stories expanded on being responsible and being accountable, and how this works in tandem. Responsibility involved answerability, an accountability for the ability to choose and enact certain duties and ways of being. Accountability is the obligation to accept these willful acts or account for their enactment. Because responsibility and accountability are not individual efforts, they are also socially defined and outlined - these expectations entail certain hierarchies and are necessarily powered. With power and status comes respect. At times this respect is an expectation for special regard or certain treatment and at times it is expressions of humility out of respect or feeling 'less than.' It is both an act and an expectation. For one house officer, it takes a tone of humility and deference. In their discussions of interactions with other faculty, they note it is not the quality of the service this individual provides that impacts faculty collaboration, but the "just our services [themselves]" (house officer 1).

Stories that trace these affects are many, and often emerged among several connections in The Letter. One where the Young Veterinarian claims, "senior clinicians vanished to an office hideout while underlings were left to clean up messes, both literal and figurative." Or where a certain anger of veterinary students is articulated, in relationship with being "mistreated, yelled at and punished for things we didn't do." In another way, issues of responsibility arise from issues of competition. These issues of

There were many times when I witnessed technicians sitting around gossiping or snacking while students juggled menial patient care and other pressing responsibilities — or when senior clinicians vanished to an office hideout while underlings were left to clean up messes, both literal and figurative (dvm360.com staff, 2017). 
competition were articulated differently than what Young Veterinarian shared. ${ }^{16}$ In discussion, competition was positioned as "a competition to evade blame and the winner is the person who doesn't have to take responsibility for whatever goes wrong with that case" (house officer 2).

Reflecting on the complexity of the perception "clinicians are hiding in their office" one faculty expands on the " 10,000 other responsibilities" they have and how there are so many other related factors that can't be controlled such as caseload, staffing, and generating income, which weigh on time and availability on the clinic floor (faculty 2). For another faculty, their training as a resident and intern the hierarchy of delegation and nested responsibility and respect was tacit but unequivocal. When they were "in the clinic as a student, the faculty were always professional but people — even the residentswere afraid to talk to the faculty and ask for the help to come in" (faculty 5). When the faculty "said jump, you jumped" and "at that time the faculty, they could have an 8 to 5 job pretty much" (faculty 5). This leaves residents to cover for the interns, who both then cover for the students. Along the way to a certain success, a lot was given up and this faculty "made some family choices or personal choices because you couldn't have a child while you were trying to perform as a clinician and get through the tenure system" (faculty 5). If they didn't do what was, or was thought to be expected, "you knew there would be [or were] worried about retaliation."

\footnotetext{
${ }^{16}$ This field needs collaboration, camaraderie and healthy competition. Instead, it has backstabbing, gossip and cutthroat antagonism (dvm360.com staff, 2017).
} 
For a house officer, responsibility traced back to the time devoted to their specialty and the service unit, "we work our butts off" (house officer 2). Tracing to the dedication of some house officers to student situations, some of the house officers in particular who have gone out of their way to like email or have conversations about I think we might be putting students in an awkward position here, I think we may be asking them to pull between two services, I think we may be putting too much on them (house officer 2).

They also recall experiences as students. They discussed their role in shaping learning experiences of students from multiple perspectives, "let's take a step back, we were there not so long ago, this is a lot for students, let's see if there's a way that we can all get on the same page so it's not confusing for them, it's not detrimental to their learning experience" (house officer 2). This attention to the student learning experience is something this house officer saw as their responsibility as a teacher in the CVM. Nested in these responsibilities are the different layers of hierarchical power and delegation - the hierarchy of delegation.

In an alternative light, another faculty refers to this unspoken hierarchy of delegation as "pure chaos" (faculty 9), where order and mutual accountability is lacking. Expanding on accountability, another faculty recalls how there are individuals who don't exhibit civil behavior with their colleagues, with students, and you know I think those people are known. I think people generally know who those people are that don't behave well, that maybe yell at students or whatever, but the issue is that behavior is not addressed (faculty 1). 
They go on how interpersonal relationships and civil behavior is never considered in performance evaluations, "never in performance review is there any consideration of how I interact with my peers, or how I interact with students, it's not a criterion anywhere for me to advance" (emphasis theirs, faculty 1). Accountability for professional or civil conduct is not built into the system nor rewarded and so it goes unchecked and could contribute to Young Veterinarian's experiences. "You have to look at what are the rules and the written policies for advancement and promotion, and we have guidelines for that and so then it's not in there and if they are trying to address [incivility] do they even have a leg to stand on?" (faculty 1). In some ways, faculty saw themselves as solely responsible for being accountable for civil behavior as a personal matter, rather than social. Recalling how The Letter gave them pause and they wondered if they were sometimes "that horrible person that yells" (faculty 10).

One student held dear an affectual value of responsibility, and this was in some ways tied to loyalty and humanity as much as anything. She states, "I think it is our duty as humans (veterinarians or not) to be decent to each other," and as veterinarians, we have the added responsibility to be kind to animals and act as their stewards (student 3). She connects passages in The Letter, of student mistreatment, punishment, and yelling, ${ }^{17}$ to a story of a friend who recently received a nasty email from someone in radiology. She recalls how the message caused her friend to cry and be "really, really shaken up" (emphasis hers, student 3). This friend was volunteering for the CVM's raptor rehab and got a call in the middle of the night about a hit by car Kestrel who had a broken wing. As

\footnotetext{
${ }^{17}$ Anger because we were at times mistreated, yelled at and punished for things we didn't do (dvm360.com staff, 2017).
} 
a third-year student, her friend had the responsibility of assessing the bird and making diagnostic and treatment plans and she decided to take radiographs so had to put in a request. Unfortunately, this was her first attempt at requesting radiographs and the emailed response was "horrific." The student connects with a possible future, where she may be the brunt of this, "I haven't had a case yet that I've followed through so I'm sort of watching [my friend] go through this and like (1 second) she's wondering... she's wondering-I don't know I'm watching all this happen and then knowing that I'm going to do it next." She indicates she's not surprised by this "anonymous meanness," something expanding because of electronic communication. “I bet [they] wouldn't say any of that shit to somebody's face but like when you're at the end of your shift and you're pissed off and you can just sit and type whatever you want and send it," she goes on to say more specifically of experiences like this, "it's just part of it" (student 3). Kindness is one responsibility embedded in this story. However, the relationship between the responsibility to act and extending kindness, is complicated.

Spaces of expectation. Affectual values of responsibility, accountability, and respect constituted many (dis)connections for participants. The experience of mistreatment articulated by the Young Veterinarian resonated with many, but produced difference. For students, they both identify and move toward legitimizing the claims of abuse or mistreatment, and then produce space between them, a (dis)connection. Here students will claim "it is what it is" (student 3) and will "just grin and bear it" (student 1). They expect to accept certain mistreatment and unsurprised by The Letter, "like, it's just part of it. I don't know if that's right or wrong, but (1 second) it's not like I'm surprised by these things that are ( 2 seconds) coming about I guess" (student 3 ). 
In legitimizing the experience, they also work to delegitimize the emotional response. It is what it is - Young Veterinarian should expect to be yelled at and garner some mistreatment. It is all a part of the game and the process of belonging. To belong, we go with the flow and expect some bumps and abuses along the way. To belong, respect faculty even when they unapologetically yell. The expression of anger by Young Veterinarian is a departure from the affective norm. Emotional expression in relationship to mistreatment, yelling, perhaps even abuse, is of the hidden curricula because it is a departure from expectations.

The legitimacy of reports of abuse or yelling are reified in what some faculty described as an overarching lack of accountability. If faculty do not assume responsibility for their own civil conduct, the norm is no one else will hold them accountable. To this point, in conducting interviews and discussions, I adopted a responsibility for civil conduct and in several instances, remained silent in instances which seemed to transgress my ethos. These silences continue to endorse problematic behaviors as unproblematic, while at the same time, making distinctions of exclusion when mutual accountability is attempted.

These affects are not singular, nor do they operate in a vacuum. Knotted together with other affects, these produced different spaces of expectation. In tandem with selfreflection, faculty discussed how they reported themselves after conduct that would be considered uncivil. Others discussed how they worked to develop awareness of their own teaching practices, cultivating personal accountability for their pedagogy and conduct. For students, affective gratitude or positivity work to bolster this space of expectation. Whereby profound expressions of gratitude, "[a blessing] to be around clinicians with 
experience and wisdom to offer us" (student 3), or holding dear a positive outlook against all odds produce a (dis)connection among emotional expressions or anger. As if to say, these are mutually exclusive- I cannot be grateful if I am also angry-things cannot be both bad and good. All in all, these other affectual values collide and subvert some of these relational forces, yet do not appear to profoundly influence the norm of nonreporting, of enduring, and accepting incivility as part of daily life. The departure from this norm, the hidden curricula, is to feel and feel differently.

\section{Loyalty, Gratitude, and Thoughtfulness}

Loyalty emerged in faculty and house officer conversations, and gratitude was an affectual value of students. Loyalty as an affectual value was a dedicated faithfulness to an ideal, profession, or institution. Loyalty to a particular something was weighty undercurrent of a certain resilience, which buffered the impact of contradictions. Thoughtfulness encompassed a careful consideration of factors, in particular that which attended to the needs or feelings of other people. As an affectual value, it was strongly tied to a house officer and worked primarily in tandem with other affects. Gratitude was an affectual value emergent with students' responses to The Letter, and suggested an awe-filled or struck state of being grateful for experiences.

Stories among loyalty were multiplicitous. One house officer shared how they always wanted to be a vet and said, "[it was] all I can remember since I was a kid" (house officer 3). For them, however, considering the financial viability of the profession in relationship with student loans and competitive practice environments, brought about conflicting feelings, "this is stupid doing this, it's financially stupid. Like it's not viable and-but it was my passion" (house officer 3). This faithful dedication to becoming and 
being a veterinarian is what keeps them going when they think of quitting because the reality of it is "you hate your life" (house officer 3). In other genealogies, the ideals experienced at the CVM have strengthened some faculty's loyalty to the institution. The Letter articulated seeing "bad or outdated science touted as unquestionable fact" and many faculty rejected this. One stated, "that to me, is a complete, $100 \%$ polar opposite of my experience here" (emphasis theirs, faculty 1). Another faculty was perplexed, “it can't be that we are trying this hard to create a good learning environment ... and this is the perception. I just couldn't hold those two thoughts in my head at the same time" (faculty 2). Yet, when other faculty brought about knowledge pertaining to the origins of The Letter, making a claim it was written by a graduate of their CVM, these positive affects shifted to a defensive stance with loyalty, "I think that knowing it came from here, that helps me frame what I think... because I know that this isn't true” (faculty 1).

Similar to loyalty, stories of gratitude materialized in relationship with contradictory affects among The Letter. One student was first drawn to and affected by how The Letter stated, "hard work with little reward and sacrifice social lives and emotional wellbeing to study, do grunt work, and write volumes of paperwork no one will ever read." She tied this back to an endurance of "how vet school drags you down at times" (student 1). Although this student was quick to note she's not depressed and never has been, she has had times where she "dread[ed] going in" (student 1). Yet, a gratitude for the "many moving parts and [how] so many people are involved in one patient's care... it's incredible that so many great things can happen because of it," overruled her agreement with The Letter, and occasional dread associated with being bullied by a faculty (student 1). 
For another student, who responded to the Young Veterinarian's account of "mistreatment, yelling, and punishment" shared, "a lot of it comes down to being afraid we're going to fuck up and having someone there that you're not afraid to ask questions to" (student 3). She elaborates on hearing stories of a house officer "being mean and shitty to the students and leaving nasty voice mails even" (student 3). Elaborating on how just one person can ruin a whole rotation. She called this "toxic," toxic in how one person makes students afraid to ask questions and to learn. She goes on and explained, "we can choose to some extent, what stands out in our memories-at least in some situations" (student 3). For her, in grappling with the glut of "tears and sweat and blood" of veterinary school, she is grateful to "surround myself with animals and other people who love animals every day" that help her remember the good stuff (student 3). To remember they are here to learn. Despite all of this, she maintains "I think the environment at [this CVM] is very calm, like compared to other vet schools" and gets curious and reflective, “it would be interesting to know where they went to school because I don't feel this way that much at [this CVM] maybe it's just because I haven't been unlucky enough and my day will come" (student 3).

On the other hand, thoughtfulness was an affectual value of a house officer who positioned responses, in all communications, thoughtfully. Even in sharing their rationale for participating in the study, they comment, "I thought it was a good chance to really read [The Letter] in depth and then formulate ideas to it and reactions to it, as opposed to just reading and being like, Yeah, that's just, you know, one person's opinion on a bad day, maybe" (house officer 1). In some instances, where others were more direct and 
cutting with their remarks, theirs had a quality of more careful attention, in particular in regarding or speaking of other people.

Spaces of expectation. Many complex (dis)connections are produced with loyalty, gratitude, and thoughtfulness. For students, much like how other affectual values produce a connection through students' identification with and legitimization of several claims of Young Veterinarian, i.e. hard work and sacrifice with little reward, ${ }^{18}$ mistreatment, ${ }^{19}$ or shit rolling downhill. ${ }^{20}$ In these moves to legitimize with gratitude, there is a yes-and. Yes, these claims are true and gratitude is how I cope. Gratitude introduces a small space for affectual difference with acceptance and legitimacy for both. In contrast, the (dis)connections among loyalty are complicated. In one way, it constitutes a connection among the house officer and Young Veterinarian. A legitimization of their experiences and a knowing affirmation, "you hate your life," without qualification. The (dis)connection is difficult for the house officer, like the students, they seem to wrestle with opposing feelings, in this case of profession-oriented affection. This personal-professional turmoil does not interject and supersede the relational connection with Young Veterinarian, instead it pierces the personal relationship this house officer has with the profession in an uncertain way. This participant, though discussing how a certain life is hated, was jovial and riffed off these statements with chuckles and shrugs — an implied "what are you going to do?"

\footnotetext{
18 Anger because we worked hard with little reward. Anger because we had to sacrifice our hobbies, social lives and emotional wellbeing to study, do grunt work and write volumes of paperwork no one would ever read (dvm360.com staff, 2017).

${ }^{19}$ Anger because we were at times mistreated, yelled at and punished for things we didn't do (dvm360.com staff, 2017).

${ }^{20}$ If the head clinician is overwhelmed, the house officers probably are, too, and the students are probably running around like maniacs trying to keep the whole thing afloat (dvm360.com staff, 2017).
} 
Affectual institutional loyalty produced a large (dis)connection with Young Veterinarian. Many faculty grappled with seeing the affects articulated in The Letter as related to their CVM, in light of their own affects with it. (Dis)connections were produced before disclosures suggesting Young Veterinarian is a graduate of this CVM. Faculty wondered, maybe Young Veterinarian did not "have all the facts" (faculty 1) or they're just "stuck on the negative" (faculty 2). Some commented how if this were from a graduate of another veterinary school, "we wouldn't really consider it that much" (faculty 2). But, with the revelation, the (dis)connection moves from a place of gratitude because it does not match their reality and pity for those who it does, to a rejection of Young Veterinarian and The Letter on the whole. "I think that knowing it came from here, that helps me frame what I think about this person and their mental state because I know that this isn't true" (faculty 1). The (dis)connected space is one of whole sale rejection-their reality does not match mine, so they must be mentally unfit. In particular, a question was raised, "this was their experience ... but then you have to ask what side of reality do they live on?" Another question of mental health was extended, "is this a student who has significant mental illness that isn't being addressed, or maybe not successfully addressed, and this is the view that they see" (faculty 1).

The varying degrees of rejection of Young Veterinarian as a community member, the (dis)connection through discordant affect, were painfully apparent. Here, there was a palpable (dis)connection commanded by uncomfortable silence. The lack of agreement and affirmation of these personal rejections were the connectives among the (dis)connection. 
Mobilized institutional loyalty posed a new question which problematized the person, rather than the practices. It is a move not to delegitimize knowing these affects of hidden curricula, but to delegitimize Young Veterinarian as capable of knowing. Knowing is legitimized when it is congruent with knowing of others. This is reified in asking on how "representative" these statements are or when parallels are sought. Knowing is legitimized through a purported objectivity, and objectivity cannot be claimed if emotion is involved. The emotional knowing is the departure from the affective norm. Affective knowing in relationship to gratitude is legitimized, but works in tension as a delegitimizing force that provide opacity for conflicts. Conflicting facts, affects, feelings, emotions, and ways of knowing and being. Again, duality is visited and builds walls of inclusion/exclusion. You must be with us, and to be with us, you must reject your embodied knowing because it is wrong.

These stories and nested affects move toward legitimizing The Letter's accounts of "great attempts to discredit" people. In particular, relating to "unjustified, over-the-top criticisms and punishments in order for someone to maintain a façade of underserved authority." To be sure, I do not believe the affects and moves within the discussions were intended to harm or cause harm. The claims argued Young Veterinarian could not know - that they could not be an authority on their own experiences because their perspectives were not shared. The moves to delegitimize the account of hidden curricula actually served to legitimized the claim, through the attempt to delegitimize Young Veterinarian as mentally unfit.

'Mental fitness' as a concept circulates in various documents. The current admissions guide indicates personal attributes such as the development of "time and 
stress management skills" in addition to others are preferred (Partner CVM, 2017, p. 9).

Within the Student Handbook (1998) technical standards for emotional health are outlined,

The candidate/student must possess the emotional health required for full utilization of his/her intellectual abilities, the exercise of good judgment, the prompt completion of all responsibilities related to diagnosis and care of animal patients, and the development of mature, sensitive and effective relationships with clients. Candidates/students must be able to tolerate physically taxing workloads and to function effectively under stress. Compassion, integrity, concern for others, interpersonal skills, interest, and motivation are all personal qualities that are expected in a candidate/student (section II, article E).

Perhaps, then, Young Veterinarian's affective account amounts to an undesirable attribute or evidence of absent emotional health, which serves to further legitimize exclusion based on these accounts.

Thoughtfulness primarily legitimized The Letter affects, yet did so in ways which minimized the directness of the legitimacy in favor of more vague, indeterminate terms. This move is apparent in claims of core faculty driving culture and norms which minimize and delegitimize the voices of other members who are more transient (i.e., students or house officers) or who are forced out (e.g., junior faculty). Thoughtfulness affects this house officer's claim, tempering it. Folks "have tried and failed to move that needle somewhere and unfortunately get lost in the whole grand scheme of things in academia" (house officer 1). At times, this thoughtfulness was adjusted with affectual justice, in favor of more direct story-telling. Positivity and complexity collided with 
loyalty, augmenting the vantage from which (dis)connections were produced. That is, my experiences here do not match Young Veterinarians, because I see and look for the positive things. Or in a different way, things are inherently so complex, a search for understanding and knowing overshadows the Young Veterinarian's claims.

The Letter as an account of hidden curricula is legitimized with these circulating and sticky affects. The hidden curricula exist in a space of expectation where students need to build defenses to keep going, one such strategy is to use gratitude to temper harshness. The legitimization of The Letters affects were seemingly bolstered by ardent attempts to delegitimize the messenger. Distance, (dis)connection, and questions of mental fitness characterize these attempted delegitimizing movements among loyalty. Yet, it appeared this stance, the powerful questions of Young Veterinarian's right to know their own affects, was unshared. This constitutes an emergent and palpable departure from what is expected. The hidden curricula undermine personal authority and mental fitness of a whistle-blower in favor of institutional loyalty.

\section{Social Justice and Self-reflection}

As affectual values, social justice and self-reflection were highly personal in their genealogies, and largely produced connections and space for legitimacy of The Letter's affects. Social justice was attention to mechanisms or means to maintain what is just, in particular with regard to social matters of wealth, opportunity, or privilege distribution. This was evident in explicit accounts, claims, or through the pursuit of conflicting claims. Self-reflection was looking inward and considering one's roles and contributions to issues at hand and a critique of one's actions or inaction as contributing factors. This 
affectual value was related to power and accountability but at a depth and intensity that centers on the self as culpable.

Stories which trace the genealogy of social justice emerged for faculty and a house officer. Two traced issues of finances in relationship to opportunity. One faculty described how they were turned off by this CVM as a faculty candidate because of the lack of diversity, “when I came here to interview I almost didn't take this job, I said to my [partner] it's way too white there ... it made me really nervous" (faculty 10). Despite these misgivings they joined the faculty, and considers being a veterinarian and teaching to both be privileges. Further, with these privileges comes some humility and a need for intentionality in interactions. This faculty was concerned about their personal involvement in producing indebted veterinarians with potentially limited resources to generate income to pay it all back. "I feel complicit in setting them up for these problems later in life by being a faculty member" (faculty 10). Even more, they harbor a growing concern this might "skew who becomes veterinarians, so that only people who are wealthy and privileged [can]" (faculty 10). For this faculty, these are problematic on multiple levels. Veterinary medicine is already the whitest profession, and the financial issues work against diversity in a major way, from limiting access to social capital to managing debt load afterwards - "I have colleagues whose parents pay their mortgages so they could get started. A family with meager means cannot support the necessary financial burden of becoming a veterinarian" (faculty 10). For this faculty, keeping issues of social justice close produces a concern about potential diversity and the future of the profession. 
A house officer expressed frustration for their financial situation and its relationship to merit. They explain, a lot of my classmates and I worked a ton during vet school and [that pay is] just a drop in the bucket compared to, you know, interest and everything. But at the time it seemed like it was a good idea to do [to work and take out fewer loans]. But then you're devoting all that time and you're not potentially as involved in other extracurricular things, so then all of a sudden you're sitting there and you're like, 'How did this person get $\$ 30,000$ in scholarships?!' and they’ve basically devoted no outside time [to working a job], and it just gives them the perceived leg up to be able to devote that time that you're using to [financially] survive essentially, to devote to books [and extracurricular things] ... and then just boom, financially rewarded again and again and again (house officer 1).

The hard work of staying financially afloat and making, what they thought to be were, wise financial choices during veterinary school seemed to be a detriment for this house officer. The circuitous tangle of resources and certain pre-ordained merit, as they see it, privileges those who already have resources — time, money — rather than those without and this affectual value was quite moving for them.

Another faculty was quite explicit in their affectual value of social justice and the genealogy was quite personal. They articulated an unjust and fraught path through a rigid system of advancement and meritocracy in the academy, which pits your personal liferelationships, well-being, family_at odds with your professional "success." They agree with Young Veterinarian, 
there is a big sense of disillusionment... I'm associate professor and there's still this 'I did it this way, it's been done this way, and therefore it is the only way and this almost intractability of the senior people that is should be any different because you know I went back to when we had [our child] and we were pretty much told 'you've decided to not be a good scientist. You want a balanced life? You will not be a successful scientist (emphasis theirs, faculty 3).

This faculty connects with Young Veterinarian and how they challenge the assumptions of what our metrics and vision of success mean, what they do, and how they are arrived at. "[Being told that] has forever ticked me off — maybe they're right but I have had a balanced life" (faculty 3). This faculty shared song lyrics in response to The Letter, which were particularly meaningful for them regarding the tense relationship between self/scholar,

No matter the plaudits I earn

The whoring and scoring for points

To strive to be superficial

I'll live by your status

This is knowing your place beneath the ivory towers

Not a going concern

But a lowly beast of burden (Napalm Death, 2006).

This faculty sees a broken system and are hopeful they can, if nothing else, "make a real difference in the real world" if not in the system (faculty 3). There is an anger here"these bastards are leaving a broken world for my [kid] to fix in the future, just so they 
can be famous and/or rich in the present" (faculty 3). This affectual value is an impetus to act for them, producing an urge to "change this no matter how small my contribution may be" (faculty 3).

Stories tracing self-reflection were tangled in what one faculty described as an innate facet of who they are. Self-critical was the term they used, but rather than it being a harsh critique at all times, it represented varied intensities of sustained growth and introspection over time. They described being a Type A "perfectionist" (faculty 5). They divulged how at a different time, they held those same expectations of others, and it can be a challenge to not extend them into the environment. When those perfectionist ideals do leak out in the form of "being critical of those around you," they "internalize a lot of it" (faculty 5) in the form of profound regret. In recapitulating a certain story of this, they emphasize, "I regret it" (emphasis theirs, faculty 5). They go on to indicate they apologized to everyone who witnessed this incident and self-reported to the appropriate offices.

The self-reflection weaves their story through many facets of relationships: "You don't know what is going on at all-I'm guilty of this too-and we can be too quick to make judgements and you just need to talk to the person... when I read this article I was hurt but also I realized I was probably part of the blame" (faculty 5). They share how personally taxing this is for them, "for me it takes a tremendous amount of energy to be wear a smile on my face walk down the hall and say hello be -create an environment of civility you know" and contrasts this to others in the room. How other folks do not appear to carry this same burden. It is at times a lonely feeling, and when this faculty member 
looked outward, often wondered if they were not alone. Another faculty walked an introspective path of culpability with The Letter's affect

I work hard to empower students and teach them and do everything I can and give good service, and I felt lumped in with everyone else [in The Letter]. But maybe I'm not better than anybody else, we all want to think we're better than the people they're describing here and then as I read it a little bit... well, it made me stop and think. Do I behave that way? Do I behave that way consistently? Have I behaved that way in the past? Have I been self-aware that I've behaved those ways in the past and have I tried to change my behaviors at all? (faculty 10).

Many wondered if they were culpable or pointed to others who were culpable - the burden was unevenly distributed.

Spaces of expectation. For the most part, social justice and self-reflection worked to produce relational connections and legitimation of The Letter as hidden curricula. Social justice opens up a space for enacting difference through connection. Relationally, as an affectual value, it reserves judgement on The Letter or Young Veterinarian. It, at times, constitutes an intense connection without qualification that demands delivery of an understanding for another — an expectation for proof of validity. Self-reflection similarly establishes connections, yet often this seems to be through countering (dis)connections. Yet in other ways, the introspective intensity becomes space occupying, leaving little space for others, and fosters (dis)connection over connection.

As intersections with hidden curricula constitute surprises, again, many affects were legitimized in partnership with these affectual values. However, the instance of selfreporting and apologies articulated by one faculty (faculty 5) was seemingly a departure. 
No other faculty mentioned reporting, apologizing, or considering this as important. Even though many legitimized the affects, the apology and self-reporting of severe behaviors constitute the departure from the norms - the hidden curricula.

\section{Perspective, Complexity, and Curiosity}

As an affectual value, curiosity was a persistent inquisitive inquiry, a pressing and open-natured desire to know and engage with people as a precursor to action. Complexity was tackling and staying with the inherent complexity of experiences and/or affects in relationship to sense-making as a mechanism for understanding, arresting action, and/or withholding judgment. At times, affectual complexity affected in ways which produced an 'analysis paralysis.' A pressing urge to gather more information with more information providing the key to understanding and understanding bringing about an answer - as if a singular answer could be arrived at with such complexity braided in. In contrast, perspective was empathy-like and as an affectual value was the holding dear the many possible situations of others and offering them grace rather than harsh judgement. Also, maintaining a perspective of the bigger picture, of many moving parts, of a relationship among and responsibility towards other people, animals, even the world. Humility nested within a recognition of privilege. Perspective was an affect of panoramic qualities, expanding and adopting multiple vantages, while complexity was an affect of seeking closure. Perspective was an affect among students while complexity was an affect primarily among faculty.

The stories tangled with these affectual values were full of wonder, curiosity, and inquisition. One student traced stories of negative encounters on the clinic floor, weaving them in and of Young Veterinarian's as she wrestles with maintaining her positive 
attitude. In taking these perspectives of others, she offers a lot of grace in partnership with otherwise difficult interactions. She described this perspective, "someone might be in a bad mood and it might seem like it's getting taken out on you but it's probably not that but specific to the person and situation... we are all stressed and working really hard and everyone is there for really long hours so if someone does seem frustrated with you it's probably just because something went awry in their day" (student 1). She digs in further, reaching to see the positions of those around her and, “can't even imagine being an intern or a resident trying to teach and you might not have ever taught" (student 1). In addition to the role this affectual value plays in producing a positive attitude, she also positions it as one of coping, "you just have to be realistic about the emotions and the stress people are dealing with, at least that's the side I've decided to take with it" (student 1). Another student was curious and concerned with her perspective. She wonders how people got to be in a place to be so mean and rude, like the house officer who leaves "nasty voicemails" for students on rotation (student 3 ). Keeping affectual perspective close produces a capacity to maintain a belief that "people are decent" because "that person is just probably having a bad day" (student 3).

For one faculty, by the end of the discussion, and in wondering about the future, they bring an affectual perspective into play, "I think we can all put ourselves in those students' shoes, we've all been there" (faculty 5). They make some suggestions on becoming and relating, "people need to take the time when they're really seeing some obvious struggles ... to sit and talk to the person. You don't know what is going on at all—I'm guilty of this, too — and we can be too quick to make judgements and you just need to talk to the person" (faculty 5). In some ways, this statement of students seems to 
conjure a reflection of personal needs for this faculty, someone to inquire about their needs, the pressures they face, reserve judgement, and to simply listen. A different faculty participant reads aloud through The Letter, offering a point-by-point agreement with Young Veterinarian's affects.

Anger because we had to sacrifice our hobbies, social lives, and emotional wellbeing in order to study, do grunt work, and write volumes of paperwork no one would ever read. I agree... but, when you embark on something like veterinary medicine, law, these higher-level professions there is a degree of sacrifice.

Anger about being mistreated, yelled at, and punished for things they didn't do, completely justified, I see that—honest or harmless mistakes - I see it.

Bombarded by statistics and articles that say vets are overpopulated, vets make salaries that are not commensurate with the time and tuition they put out, vets are blamed for killing animals, that is all one hundred percent justified I think, and I agree that social media has exacerbated this problem for veterinarians tremendously... some client on a crusade can kill somebody's career and they're 100, 200 thousand dollars in debt. I can understand that" (emphasis theirs, faculty 10).

Even though this faculty admits the anger expressed by Young Veterinarian often rubbed them the wrong way, they open up space to explore, adopt, and validate the perspective with few additional caveats. 
The genealogy of curiosity was overflowing with experiences resonant with The Letter and produced movement, thought, action. These persistent inquiries pressed the group to wonder about and perhaps adopt an alternative perspective or explanation. For example, an interpretation of The Letter was shared indicating Young Veterinarian was imploring a stress-free working and learning environment. They pushed back, "I never got the impression [stress-free] is what she wanted" (faculty 3) and curiously explored this and other alternative vantages. Discussions around the validity of The Letter's affects brought about another instance of this insistence. Questions were raised, "so I'm curious as to now this is one person, ok, I would love to hear other perspectives from their classmates ... I'm sure they didn't think it was great but did they show this type of anger, did they see these-did they witness similar things, ${ }^{\circ}$ I'm curious ${ }^{\circ}$ " (de/emphasis theirs, faculty 6). In a move to press on this point differently, and deepen the intellectual immersion, the curious faculty wonders aloud about these classmates might "say, oh, [veterinary school] was fabulous, but it raises the question were they the backstabbing bullies? Because, of course, it was fabulous for them" (faculty 3). Curiosity affected in ways that pressed the present group. Pressed to be clear in expectations for 'resilience'. 'I keep hearing resilience — and that's fine, fair enough—-how do you teach it? The impression I get is 'they don't have it' which means we have to teach it. Equally, how do you teach it and what's your definition? Some people may not necessarily have resilience [as we define it] but that doesn't mean they are going to be a bad vet" (faculty 3 ). Pressed to imagine and marvel about an alternative expectation or path.

Stories with the tracings of complexity were assorted and mixed up with many relationships - including clinical decisions, client relations, and peer relationships. In 
response to the story of unwarranted euthanasia ${ }^{21}$ in The Letter, one faculty explored the inherent complexity of these situations in depth because to them, The Letter "seems like a very superficial assessment of a situation that was much more nuanced and deep" (faculty 2). In these difficult clinical scenarios involving euthanasia, everyone involved is dealing with their own end of life emotions and students may not have had access to all the discussions the clinician had with the owner which lead to the decision to euthanize. Yet, even in situations where students do have access to all the information, they may still find themselves disagreeing with the decision, but commented "it's not their call" (faculty 2). This faculty tries to anticipate what student concerns are and discuss them, but makes note of the inherent complexity as a place of pause. These discussions vary and are dependent on the clinician, the situation, and students. Moreover, students might not always find it comfortable to raise concerns if they have them. The lack of this complexity with the affects among The Letter are a major concern, "because there's not necessarily a lot of stuff out there then, it's going to make this perception more real because people only have access to a couple different views of something and this is going to have validity in their mind because there's nothing to oppose it" (faculty 2). This faculty is worried people will think this is real and the only reality of academic veterinary medicine. In some ways, they arrest among the tangled multiple realities and grapple with and are subdued by complexity. In particular, "when you hold people accountable for

\footnotetext{
${ }^{21}$ At school I also had to follow orders I didn't agree with. On one occasion, I took part in a [sic] euthanasia for an ailment with a treatable solution, though the client hadn't been apprised of this fact because the head clinician refused to acknowledge its possibility. Those of us in the opposing camp were vindicated - too late - at necropsy. Obedience and fear of consequences kept our mouths shut. But such cases continue to haunt me (dvm360.com staff, 2017).
} 
things like [incivility] it's much more difficult because the situation is so multilayered, who's version of that encounter is the most real?" (faculty 2).

With a student, complexity was a space of opportunity. Exploring The Letter within groups was something desirable, but not possible. She claims to "really like talking about complex issues like this because I feel like it helps me grow" (student 4). She explores the complexity of experiences, of people, and learning about and reflecting on both. Considering how Young Veterinarian opens The Letter by stating they don't recommend folks to go into veterinary medicine, she disagrees, "[I] would tell someone to go to vet school if they wanted" (student 4), but with the caveat what is most important is knowing yourself as a complex person and knowing what you need (student 4). For instance, for her, she knows she needs to be careful to "pick her people" to study with, and elaborates that those folks might be different than her friends she socializes with. Other people are also complex and, for her, it's important to be generous with them, "giving people the benefit of the doubt, giving people a chance to make mistakes, to be overwhelmed and not coming down on them for it, but supporting and listening to them" (student 4). In regard to The Letter and the comments, the way she sees it, "I just think a lot of people [are] not giving her the chance to have a different experience" (student 4). She takes pride in curating opportunities to have different experiences. She discussed instances of students appealing to authority in issues of suspected misconduct or honor code violations rather than being capable of self- or social-policing. "I'm very much not that person... I no longer smile and suck it up just because someone is my boss. If I don't agree with something you're doing, I'm not going to put my integrity on the line to do that" (student 4). 
Spaces of expectation. As sources of (dis)connection, these affectual values of perspective, complexity, and curiosity work in many ways to produce connections among situations which otherwise are forcefully (dis)connecting. Perspective brings about a relational force of being and feeling with. Seeing with. Often without judgement, yet at times caveats come in to play and are potential (dis)connections of place-making. Placemaking is a merging of past, present, and future where faculty look back and see the shortcomings of a place in time. Young Veterinarian's claim of anger in relationship to hard work and little reward, for some seems hasty because of their place. "You don't see the reward when you're in vet school, you're not there yet, you have to work a little to realize the reward-it's like everything in life is not instant gratification" (faculty 10). Students hope the passage of time will augment this space and place Young Veterinarian is in, "I hope that this person needs just like a few more years because like they're freshly out of vet school... maybe not in a position to make a statement about the entire profession" (student 3). Yet perspective and complexity move as affectual urges which need and desire connection. Paradoxically, complexity can work to produce (dis)connection by jamming the space with all possible connections and arresting at sense-making, rather than staying with the openness of complexity. This is a pause and/or a movement away. Curiosity invites others into the relational space through inquiries which troubles and problematizes potential (dis)connections. The space of inquiry was a connecting force among queried difference.

As sociopolitical forces, these affectual values often operated in many affirming and legitimizing ways. However, these connections of legitimacy are actual moves to delegitimize or minimize those affects of hidden curricula. They offer perspectives and 
vantages by which community members live with in order to live with the (dis)connecting and at times painful forces among them. As an account of the hidden curricula, these moves represent a departure from how The Letter stayed with the trouble at hand and offered no statements of relief. With the singular focus of The Letter, discussions at times mirrored this focus and made apparent the departure and surprise which constitutes hidden curricula—confrontation with an alternative perspective. The prevailing assumption is that repeatability equals validity. A single claim of experiences is in question, and to question the question through alternative perspectives is the surprise. The sticky affect is to question validity based on singularity. This sticky-ness is apparent in a story one faculty gave,

I get to read the comments and I get to read the comments and follow the instructors and follow the interns and follow the residents and you can have the very same person with the very same group and you can have four students that talk about how they loved this instructor how they were always there they were always caring and wonderful and then other person that says they were the most horrible terrible thing that didn't care how they felt and didn't care how they did and this is the same person in the same group and you're just like how could this be? (emphasis theirs, faculty 7)

In another way, more specific to The Letter, a faculty urged for proof of concept, What I would like to see is follow up I would like to get a larger sample size of our graduates-recent graduates and see ok ( 2 seconds) if these are real issues then we have work to do as a college we have things that need to be fixed (faculty 1). 
Another faculty also suggested The Letter is not enough proof, but in a different way, "without context [or specifics of how they define heinous], ${ }^{22}$ I have a hard time understanding it so I'm going to remain skeptical until I have more information" (faculty 6). This last maneuver suggests the perceived or planned intent supersedes the experienced impact of behaviors, statements — of affects. Overall, the departure from this, or hidden curricula, is to suggest validity of a perspective held by one person. The departure is to suggest validity of an impact which departs from intent. The hidden curriculum is rejection of affectual difference or singularity.

\section{Resilience, Balance, and Emotional Neutrality}

Affectual values of balance, resilience, and emotional neutrality interdigitate. Balance emerged for faculty as an emphatic desire to maintain a near homeostasis-like quality of life. An unflappable stance of being, or perhaps appearing, "balanced." For another faculty, it was keeping work and home life separate. Always ensuring quality and reasonable quantities of time were spent away from work and investing in personal life. Balance brought together sentiments of resilience, positivity, and emotional neutrality in their affects. Emotional neutrality was the acceptance of an emotional response with purposeful withholding or suppression of that response; an affectual value of being and appearing unaffected. It was moving on, looking past, or ignoring a situation and associated affects. Resilience, on the other hand, was persistence in the face of challenge or embracing challenge or adversity. In ways which draw a distinction between resilience

\footnotetext{
${ }^{22}$ I've witnessed some utterly heinous behavior from respected "professionals," directed both at students and at fellow doctors.
} 
and emotional neutrality, emotional neutrality was positioned in such a way that it represented a necessary, and at times most important, strategy of resilience.

Stories tracing the genealogy of balance emerged primarily with faculty. For one, the quest for balance traces back to beginning veterinary school. At an orientation prior to matriculating, a faculty suggested students might need to give up some of their personal life to succeed - this faculty participant recalls hearing and then looking past this. Instead, they turned to their mother and said, "I'm going to do this... but I refuse to make that my life and I'll do what it takes to make that not happen" (faculty 9). However, this faculty feels constrained by the lack of rules and set expectations or accountabilityproducing feelings of powerlessness. Powerless to enact meaningful change in their department or service or in the profession. The pressures to conform to a different set of values are strong — there's a "top down issue of it —if the person who affects your daily work-life doesn't value their personal life, yours won't be valued" (faculty 9). It's not just personal life, but value as colleague and contributor to the service. I asked how often do they feel like their side of the story, their constraints or values, are seen and heard. They replied, "How often? ${ }^{\circ}$ Never $^{\circ}$. Never. Never. I cry about it a lot. But, I believe in what I'm doing and I'm personally committed to education so I continue to do it" (de/emphasis theirs, faculty 9). Relating to these multifarious sources of pressure, a different faculty described a relationship among institutional pressures and those of a practitioner-owner, "you have to make money, that's required, you have bills to pay you have loans to pay and on and on and on so there's going to be that pressure... it's an institutional component not just an individual one" (faculty 6). But, they are adamant about taking breaks and time for yourself. Although they emphasize how they make leaving around 
five a priority, there are hints at a level of personal responsibility and perhaps institutional culture in affecting balance. "If they are awarded that time to reset and think about their day catch up, what they do in that free time is up to them ... I encourage them to not spend a lot of time here if you can find down time use it find that time for yourself because without it you're-this, this is what happens," referring to The Letter (emphasis theirs, faculty 6).

This insistence on balance was affectually braided with resilience. The acknowledgement of multiple layers of stress as "inevitable" (faculty 6) and the stressors lodged by Young Veterinarian in The Letter are viewed by a faculty member as a lack of resilience. Balancing work and life and the multiple sources of stress are "just life" (faculty 10) and “it's never going to be stress free, I'm sorry, it's just not going to be stress free," (faculty 6) so you must simply move on. Other faculty echo these sentiments, "veterinary school is very difficult and challenging, and it's hard work, but it also prepares you for a career that is very difficult, challenging, and very hard work" (faculty 7).

Students' genealogy of resilience was through personal encounters of depression or anxiety that connected back with The Letter. ${ }^{23}$ One student was diagnosed with obsessive compulsive disorder (OCD) while in her early years of study at veterinary school. She articulates how she is unsure if it emerged because of veterinary school or it just happened to be while she was in veterinary school, but this causes her to question if she can be like other veterinarians and colleagues.

\footnotetext{
${ }^{23}$ And why are veterinary students so unhappy? Why do they suffer from anxiety and depression at alarming rates? (dvm360.com staff, 2017).
} 
I see these vets and technicians and even other students just being super-efficient and super confident in their abilities and that's really what I want to be and I see my OCD as a hurdle... I'd like to think I've accepted it but I also don't want it to hold me back and I want to just be on a level of these people I see and hope that it's not something to impair me from getting to that (student 1).

A different student threaded together her experiences of depression and competitive cutthroat-ness described by Young Veterinarian. ${ }^{24}$ "I actually experienced depression in undergrad with my pre-vet program and [it] was super competitive and we had our friends, but everybody was like if they could undercut each other, they would" (student 4). When her grades dropped, faculty started to notice, but many didn't do anything, which was disappointing. It was her advisor's reaction that stuck with her, they suggested "why don't you just drop out" (student 4). To this student, the message was "maybe you don't belong in this program... even just facing adversity is looked down upon" (student 4). This was bewildering, she recalled how her family has taught her "when you get knocked down you try your hardest to get back up. You don’t give up. You don't drop out of school" (student 4). This student didn't give up, and overcoming adversity is something she holds dear. In fact, it is one of her "favorite things to talk about, challenge and thriving in challenge" (student 4).

\footnotetext{
${ }^{24}$ This field needs collaboration, camaraderie and healthy competition. Instead, it has backstabbing, gossip and cutthroat antagonism. And at the university, I saw efforts to sabotage careers out of personal vendettas. I saw great attempts to discredit and embarrass clinicians in front of their students and peers. I saw patient care go by the wayside, a casualty of intra- and interdepartmental quarrels. And I saw-and even received - unjustified, over-the-top criticisms and punishments in order for someone to maintain a façade of undeserved authority (dvm360.com staff, 2017).
} 
Genealogic tracings of emotional neutrality were variably focused. On the one hand, it was highly personal, relational, and a sociopolitical stance. On the other, it was personal, relational, and very much in response to The Letter. One faculty relates back to experiences in veterinary school as a part of a first big wave of women and dealing with attitudes of some professors who believed "women shouldn't be here and were just here because we were looking for a husband and we were going to get married and have children and drop out" (faculty 1). Looking back, she ${ }^{25}$ sees incidents "where we were flagrantly discriminated against, not allowed to do some things that the male students were allowed to do," but understands their perspectives now as "the times [being] what they were" and it was simply part of the culture (faculty 1). She didn't let it get to her and still doesn't "harbor any resentment or anger" (faculty 1). She has the attitude you work hard and show people you can do good work, but "you don't need to cry about how bad you got it" (faculty 1). She mentions despite a lifetime of gender, or other bias, it "never bothered me to the point where I would have written something like this, you just have to let it go" (faculty 1). Another faculty, echoes these sentiments of letting things go. They share what would be the best for Young Veterinarian, "I'm not going to give [Young Veterinarian] a hug and say it gets better" (faculty 6). The extend empathy, connecting themselves with Young veterinarian, "I'm going to say yeah it sucks that you have to go through this," and then share their expectations for affective neutrality.

We could certainly examine the whole culture and try to change some things, but some of these things will continue to exist because we have a diverse population

\footnotetext{
${ }^{25}$ Here I deliberately use this participant's gendered pronouns as they are discussing gender discrimination, bias, and sexism.
} 
of people who are here and how they are going to approach students — but going forward you're going to have to build a tough skin (faculty 6).

People will treat you poorly, but it is what it is - 'I'm sorry, life's tough" (faculty 6).

Spaces of expectation. Faculty were quick to discuss the necessity of resilience, but in a way which produces distance and a (dis)connect with others. It works as a catchall label for failure to balance and cope with mounting stress of life constrained by a demanding curriculum. In a different way, students feel a (dis)connection with their affectual resilience because it produces a space where they don't see themselves in their mentors when they (want to) ask for help. These instances of rejection and a lack of resonance (dis)connects the hard work leading to a moment. In that moment, the past is erased, in favor of a materialized moment of 'failure' to endlessly endure.

For faculty who have attempted to counter this (dis)connect, citing concerns that “[students] feel like they can't even succeed without contributing a lot of heartache and sweat and tears and things that would cause them to be mentally unhealthy," but found attempts to inject positivity produced quite the opposite, "everyone goes silent" (faculty 9). As a result, this faculty member stopped trying to be positive and instead is neutral as a survival tactic.

Neutrality is a force favoring sameness. For some, labels of being "dramatic" (faculty 1) or "butt-hurt" (student 3) produce a categorical mechanism for (dis)connection when emotion and/or affect is expressed in unexpectedly. Then as a sociopolitical force, like other affects, sticks and is legitimized through these labels and policy mandating 
'effective' function under stress. ${ }^{26}$ Feeling, emoting, or being affected is a force of difference and alienation. Feeling, emoting, or being affected is a departure from the legitimate norm and constitutes hidden curricula.

These hidden curricula expand in how other affectual values produce affectual difference as an individual matter, which produces (dis)connections and exclusion. A student who described the affects of Young Veterinarian as coming across as "butt-hurt" expands on how their stance is not unsympathetic, but rather a matter of ethics.

The way its presented here in a lot of ways makes it seems like, oh woe is me, and that's not how I feel. [Young Veterinarian's] talking about we're blamed for killing animals and practicing pseudoscience and crucified on social media, well, like, who gives a shit if you think what you're doing is right? ... I guess it's sad that it happens, but I also don't think that, (1 second) that should stop people from trying to do it. Because, you know, that's dangerous. What if what people say on Facebook can control everything that we do? (student 3).

The highly individuated person as fully agentic, unconstrained by social pressures or norms perspective is shared by faculty. Regarding the use of free time, a faculty sees individuals as fully accountable "if they are awarded that time to reset and think about their day catch up what they do in that free time is up to them" (faculty 6). These relational (dis)connections dismantle and deny the relationship among people and their environments as mutually reinforcing. In these ways, suggesting otherwise, to suggest

\footnotetext{
26 The candidate/student must possess the emotional health required for full utilization of his/her intellectual abilities, the exercise of good judgment, the prompt completion of all responsibilities related to diagnosis and care of animal patients, and the development of mature, sensitive and effective relationships with clients. Candidates/students must be able to tolerate physically taxing workloads and to function effectively under stress (Partner College of Veterinary Medicine, 1998).
} 
social, political, or relational constrains would be illegitimate. The Letter, then, as surprising, offers a glimpse of hidden curricula. Where feeling, being affected, and feeling constrained or even by others is non-normative and unexpected, as epitomized in "The way you push on through and you do a good job - and you get noticed for the quality of your work, not for how loud you're willing to complain for [sic] what you're not getting" (faculty 1).

\section{Positivity and Helpfulness}

Affectual values of positivity were felt dear for several faculty and a student. Positivity is holding onto positive aspects of everything and looking on the bright side of all things. A firm belief that what you look for is what you will find, and looking for positive things means your life will be positive. At times, a coping mechanism to overlook or bear the bad which happened with the good. Helpfulness was a plight of a faculty member which often worked with positivity. It was a preponderance or emphasis on providing assistance, solicited or otherwise, to others.

For the student, the genealogy of her positivity was about maintaining a space outside what she called the "culture of negativity" (student 1). This possible space is rooted in her beliefs that your outlook depends on how "you decide where you look" (student 1). However, this decision to look on the positive is also dependent on her free time, or in essence, her ability to take care of herself. Times where she was stressed and feeling overwhelmed a technician was so grumpy with her "it didn't matter that I then got to go run anesthesia on some crazy cool surgery the fact that [the interaction] happened just soured my day" (student 1) stand as reminders to the importance of time away and time for yourself in cultivating this capacity. But recognizing this is not always a two- 
way street and she feels a social pressure to set-aside her need to have free time for selfcare. "Free time does play a role, just getting acknowledged that you are a human that has needs, but then it's hard to ask for that acknowledgment when you see the people above you are in the same situation" (student 1). She also feels a social pressure, in being stressed and overwhelmed, to overlook how "everyone is trying to do their job well" (student 1), and rather find someone or someplace else to point the finger to when things go wrong. How this attitude and behavior is sometimes reinforced, that "always something to be complaining about there's always something that could go wrong there's always something that could go faster and if you choose to focus on those things" those things become the norm, the reality, and all there is to see (student 1).

For a particular faculty, they found The Letter "heartbreaking" and admits having a hard time relating to its affects (emphasis theirs, faculty 7). For them, veterinary school is hard work, difficult, and challenging, but this is important to prepare students for a "career that is also very difficult, challenging, and very hard work" (faculty 7). Moreover, they emphasize,

The attitude you bring to the table, to your life, and to your career is going to be reflected back in what you encounter, and if you come at things in a negative way - that everything is out to get me and everything is bad and everything is negative - then that is what you're going to see and perceive. But, if you come at it with 'that was really hard, let's see what can I do to try to make it better next time', that's what you're going to encounter. Really, a lot of what surrounds you is the attitude you bring to it (faculty 7). 
This was powerful for them, although many parts in The Letter felt true, it "sounded like such a negative, evil, bad, and unhappy place-I just don't see it" (faculty 7). A house officer articulates this affect from their vantage,

I think when I read it, it's-these recommendations come with this assumption that the people that you go to school with at the top actually recognize what they're doing, and I don't know that I believe that [this ignorance is] personal or purposeful from those individuals. So, I think in order to implement these recommendations you would have to enlighten senior faculty to these issues, and I don't-I don't know if even after you told them they'd realize it, because I don't think it's on purpose (house officer 2).

Another faculty traced positivity back to The Letter, seen primarily as "grinding the axe" (faculty 6). For them, The Letter or a letter they would write should focus on positive facets, because articulating a problem is, to them, problematic. Rather, if problems are posed they should be helpful. They should provide "suggestions if you are struggling" and ways to help move forward, past, or to regain balance to your life (faculty 6). Helpfulness was an important affectual value for this faculty. They want to help Young Veterinarian, "I would like to sit down and help this person. I don't want to dismiss them, I want to help them... work through these issues" (faculty 6). They want to help other participants reason through their ideas, "what does struggling look like to you?" (faculty 6). They sought to help me produce 'good' data for this project, "I think it would be- - just to help you — an administrative response [would be good]" (faculty 6). Helpfulness was a central affectual response and value in how this faculty related to The Letter, to others 
Spaces of expectation. Positivity worked in many relational and sociopolitical ways in the space of expectation. Among forces of connection, it produces opportunities to see what is positive and good in the world around, and in particular other's actions. It is a means to stay with the hard work of the veterinary medical profession. It produces a space of acceptance of cumulative tribulations.

In producing concepts of what is or could be positive, in itself is a space of expectation which can be freeing or constraining in how it affects relational and sociopolitical affects of expectation and evaluation — of what should be. In constraining the ways in which 'good' and 'positive' are seen and felt, (dis)connections are produced through distance among difference. Helpfulness attempts to bridge this (dis)connect, but rather than assisting, serves instead to reify and expand the distance among. The words of faculty here demonstrate this blinder to other-ness, "I just don't see it" (faculty 7). The house officer articulates the blind spot well, people don't see it and this and it is not intentional. Yet, if you don't see something someone else does, positivity and helpfulness can produce a delegitimizing force for individuals who articulate such difference among hidden curricula, and therefore legitimizing for The Letter. With positivity, the surprise is The Letter and constitutes an affectual account of hidden curricula. With helpfulness, the surprise is responding with certain affects determined to be unhelpful. Like positivity, the surprise is not 'going with the flow'

With helpfulness, the surprise is The Letter and how Young Veterinarian is responding - they are not helping themselves in the 'right ways'. To articulate issues of hidden curricula rather than brushing them off is a departure from what is expected. To name and explain a problem is an affectual move outside of what is typical. 


\section{Freedom and Agency}

Freedom was a very forceful affect for house officers. It constituted feelings of autonomy regarding external forces such as culture or financial burdens. In particular, the lack of constant concern about finances, especially in relationship to the debt burden accrued while in veterinary school. The cost of veterinary school, in addition to any costs accrued while attempting to get in, do not provide for a viable living situation and are a source of significant stress after graduation. Agency was closely related and was one faculty's real or perceived ability to enact change or make moves in their worlds. For them, it was beyond the feeling of freedom, it was enacting change and producing difference, which many times felt impossible.

Freedom emerged and occupied a large proportion of space in house officer discussions. Freedom was ever-present in relationship to feeling trapped by the profession and associated debt. In some ways, The Letter resonated and rippled through many experiences one house officer had in private practice and in academia. Despite having an "incredibly good, supportive practice" they offer a consideration, no one is "immune from that, that feeling" which pulls you into a culture of overworking (house officer 2). This overworking is professionally necessary in order to "put in your dues" of "some blood, sweat, and tears" to simply be given or "get a vacation day" (house officer 2). This stitches back through what Young Veterinarian described students being subject to, suffering and slaving away. ${ }^{27}$ The lack of financial or business/non-compete

\footnotetext{
27 It's true that veterinary medicine attracts Type A people - the overachievers and the perfectionists. But I'm not referring to stress from internally driven motivators. There's a prevailing attitude in veterinary medicine that people need to "put in their time" — work like a dog for years, suffer, slave away, and slowly crawl to the top of the pile through copious blood, sweat and tears. I disagree (dvm360.com staff, 2017).
} 
discussion in The Letter was surprising and intriguing because these are huge issues affecting freedom. One of this house officer's non-competes was for a 100-mile radius from the practice. Something described as effectively trapping people. They offer advice to students heading into general practice because they want them to think about some pitfalls

Your first job you take, don't buy a house, because that's going to anchor you, if you've got like a mortgage and a house and you decide that you want to change jobs but you have a non-compete that does not allow you to live within an hour, you know, or work within an hour of where you just bought your fancy new house, you're going to be in a tough situation (house officer 2).

Considering these pitfalls to freedom, they disagree with some aspects of The Letter-not the 'truth' of Young Veterinarian's affects, but more what we should do with it. One source of anger articulated by Young Veterinarian is that of bombardment by statistics regarding salaries. This was impactful for a house officer, that made me go ah, has he or she been in practice, because that's true, and I think that if anything, students should be more prepared for that, about those statistics and about the debt. And I think we're not doing a good enough job informing people that this is a very serious commitment that you're making. Because that's life, that's the real world, and it's not happy but I think that it is much more devastating to your mental health if you're not prepared for that... I don't think it should be ignored, I don't think we shouldn't talk about it because it's upsetting to hear as a student. Because it's upsetting to experience (house officer 2). 
Some faculty discussed supporting the freedom of students to consider leaving once they are in veterinary school if they believe the profession (or process) is not right for them. They said, "maybe one thing we need to emphasize more to the students early on... if you decide this is not for you there is no shame in stopping and cut your losses" (faculty 7). On the other hand, this does not feel possible for all students, "I have some friends by like second year of vet school they were like, 'I don't know about this anymore,' but by then you're already in pretty deep with debt, and are you going to start over in a different program and just eat that money?" (house officer 2). Even once newer graduates are out in practice, they do not feel like they can leave. "I definitely know a lot of people in private practice and in general practice that are like, 'I don't think I like veterinary medicine, but am I going to change now? What would I do where I would ever earn this back, like make up for this debt?'” (house officer 2). This trap was affectively described by another house officer, "You're afraid of quitting, you hate your life" (house officer 3).

Although house officers were brought together by an affectual urge for freedom, a faculty explored freedom through a different lens. They found the passages in The Letter regarding backstabbing and undue competition expressly frustrating. ${ }^{28}$ Like Young Veterinarian, they feel this and make clear, "it definitely hinders my ability to do my job and always has, when there's someone working against me" (faculty 9). This makes them feel hopeless to enact change in the current environment, and instead operates from a place of patience —of inaction. Watching other faculty be consumed by the culture after

\footnotetext{
28 This field needs collaboration, camaraderie and healthy competition. Instead, it has backstabbing, gossip and cutthroat antagonism. And at the university, I saw efforts to sabotage careers out of personal vendettas. I saw great attempts to discredit and embarrass clinicians in front of their students and peers (dvm360.com staff, 2017).
} 
running headlong into it and being "stopped [by it like] a brick wall," and in turn adopting the beliefs that "students are a dime a dozen" because "you give up and you join the crowd" (faculty 9). They refuse to adopt this belief and instead wait. "I just think it's a tincture of time ... it doesn't make it any easier for anyone who is currently in school or will be in school for the next few years but it will change... I don't know, I feel like it's just the tincture of time at this point" (faculty 9). This faculty faces issues of freedom, like house officers, they feel trapped by the culture and helpless to enact change in their environment even though they feel "something has got to change" (faculty 9). This faculty feels a profound lack of agency, which is an affectual value articulated with The Letter.

Spaces of expectation. Freedom is a (dis)connecting force-people want autonomy and agency and current environments are unsupportive. Debt-strapped graduates feel trapped within a void of freedom and subject to the whims of their supervisors because they need the job. They do not feel free and do not feel freedom to make a difference so feel (dis)connected from other veterinary professionals. Others are under different financial constraints and are (dis)connected among the forces of relation among debt and social, professional sacrifices. Students feel they are too far into debt once they start and cannot leave. Once they leave they are even further in debt and are trapped by a non-compete and potentially a mortgage. Faculty are in different situations and feel trapped by cultural norms. In feeling trapped, many feel alone, many are unable to relationally connect.

The trappings of overwork are codified in the CVM's Guidelines for Promotion and Tenure, "Merely demonstrating competency or satisfying minimum criteria in 
assigned duties is insufficient to assure promotion and/or tenure" (2017, Section 2.5). Meeting the requirements of your appointment and being competent is not enough, you must go above and beyond. In relationship to many other values, this produces or bolsters (dis)connection when balance is sought, or when freedom and/or agency are lacking. Desiring freedom and agency produce legitimizing forces for The Letter as an account of hidden curricula. These affectual desires emerge among their absence. The Letter, in painting a culture of over-working and paying one's dues, is legitimized. The departure, or surprise, would be to feel free or capable of producing change. In the way the house officers all expressed surprise for the lack of attention to debt-burdens, this is clarified. As Young Veterinarian did not produce affects related to indebtedness, they saw an absent present, freedom. They desired that freedom from financial worry.

Overall, analyses produced an articulation of possible paths with and among the affects which surrounded The Letter. As sticky, these affects produced spaces of expectation enmeshed with relational and sociopolitical forces of (dis)connection and illegitimacy, respectively.

These movements among affectual values as forces offer genealogic tracings of the many ways that which is taken for granted is simultaneously profound. In considerations for belonging, spaces of belonging are important for the professional socialization process and the maintenance of well-being. Although some affectual values produced this necessary space, some worked in opposition—producing (dis)connections. These insights are deliberated and discussed with relevant scholarship in the next chapter. 


\section{CHAPTER 6: DISCUSSIONS AND DELIBERATIONS}

This exploratory work illuminated hidden curricula through nested norms and values in practice. These affects were in response to a public narrative, The Letter, which articulated many encounters with, and associated facets of, hidden curricula in a CVM. This is one of few studies in veterinary medicine which explicitly focuses on hidden curricula (see Mossop et al., 2013; Roder \& May, 2017), and the only research which opens up and questions the process of becoming and belonging in relationship to hidden curricula. This embraces McNaughton \& LeBlanc's (2014) insistence to move scholarship on emotion and affect to social forces. This move encompasses social, cultural, and political mechanisms for control and explanation of affect and by doing so, provides a mechanism to respond to Whitcomb's (2014) call for scholarship on the hidden curricula in veterinary medicine.

\section{Hidden Curricula as Affectual Ether}

As long as the world shall last there will be wrongs, and if no [person] objected and no [person] rebelled, those wrongs would last forever. - Clarence Darrow

Many movements among the affects legitimized The Letter as an account of hidden curricula. Faculty, students, and house officers, alike, affirmed many of the sentiments and affects of Young Veterinarian. Although scant scholarship stands to bear witness to hidden curricula in veterinary medicine, from the insights of this study, it appears what is 'hidden' is actually quite visible. Likewise, MacLeod (2014) urges

medical education scholars to recognize the hidden curricula are not so hidden - they are well known. As well-known phenomena, hidden curricula can easily become a sweeping category of "systematic side effects" (Vallance, 1974, cited on p. 540) which obscures nuanced interrogation of problematic aspects of non-academic functions in professional 
education. Yet, like the house officer articulated, people do not see The Letter or other dimensions of hidden curricula and it remains hidden for them—like several faculty participants who declared, "I just don’t see it” (faculty 7). This harkens Martin (1976) positioning of hidden curricula as "of some setting, at some time, for some learner" (emphasis original, p. 138). This suggests a simplicity of the relationship between the descriptive name of hidden curricula and its variable visibility: Just because you do not see it, does not mean it is not there. It may not materialize for you in those ways.

There were several groups of affects which swirled together and marked surprises and departures from this known, yet in many ways unknown and hidden curricula. In the discussion that follows, the affectual ether is put into conversation with several important facets of scholarship to date with particular attention to how these foci relate to belonging. Apple (1971) insists socialization, which produces feelings of belonging and exclusion, often occurs in terms of pitting "happy cooperation" with conflict. In many ways, lines of distinction, much like the online article comments, were drawn in conversation based on affects, valuations, or emotional expression therein. These distinctions swirled around three important areas representing departures from expectations - the hidden dimensions of the hidden curricula: Onto-epistemic tensions, emotional neutrality, and freedom. I explicate these caches of swirling affects in dialogue with other scholarship attending to mental health, well-being, and those to promote belonging and inclusion. I conclude with possible futures in areas related to research and to (professional) practice. I provide a post-script of preliminary deliberations for the partner CVM where this work was situated.

\section{Onto-epistemic Tensions}


In this study, insights showed how affectual values played an important role for participants in determining and positioning their responses to The Letter and/or Young Veterinarian. Affirming neuroscientific assertions which place emphasis on importance of affects as forces affecting processes such as attention, perception, and memory (McNaughton \& LeBlanc, 2012). Using affect, the subjective and textured genealogies, lives, and experiences of participants in relation with The Letter were encountered, traced, and told. In these responses, emotions and affects were important facets. In relationship to philosophical traditions of affect and emotion, this affirms Hume's position with emotions as key to moral reasoning — considering the right/wrong qualities of certain behaviors - which, subverts and counters the Cartesian split of mind/body (Ellis \& Tucker, 2015).

Conversely, insights also showed affects as relational forces insisted others maintain a split between mind and body. In these ways, knowledge originating through the body, as affect or emotion expressed, was evaluated as unreliable because of this affective, "irrational" quality to it. Kant positions emotion as unstable oppositions to reason and thought (Ellis \& Tucker, 2015), and many responses to Young Veterinarian were of this seemingly Kantian perspective. In particular, those responses with loyalty, with emotional neutrality, with resilience, and with positivity, which sought to delegitimize Young Veterinarian's embodied knowledge, or reject the face-validity of their claims as if Young Veterinarian was incapable of knowing of and with their body for themselves. These onto-epistemic tensions in the affective responses produced through moral judgements of affect and emotion, with affect and emotion, were commonly encountered. 
Subjective face-value. Across many affectual values and within the spaces of expectation, insights were gleaned regarding rejection of other's embodied knowing. This face value assessment of affectual validity was imbricated with demands for repeatability, more contextual information, or a larger sample size. The demands seemingly necessary to "see if these are real issues" (faculty 1). This tension is rooted among philosophical assumptions of bioscientific methods and post-positivist objectivity of knowledge, and the subjective experience and associated affects of individuals in a complex and social world. These tensions are rooted in how (veterinary) medical doctors are trained "that the only true medical knowledge comes from empirical, objective, quantitative inquiry" (Wear \& Castellani, 2000, p. 605). In this regard, Royal (2017) pleads with readers and scholars of the Journal of Veterinary Medical Education, to stop using the term 'face validity,' calling it sloppy. The sweeping claim is levied, all educational scholarship operates under the same guiding assumptions and accordingly it is "critical that veterinary education researchers recognize modern conceptualizations of validity given the very notion of validity is considered by many to be the cornerstone of all scientific inquiry" (p. 206). Conflating natural sciences with all, including how we might socially relate and connect to one another, which leads to the rejection of Young Veterinarian and The Letter, then, is unsurprising.

The bulk of literature regarding mental health and well-being in veterinary students is quantitative, which typically operates under the same guiding assumptions about knowledge as objective and experiences, processes, and affects effectively captured numerically. These assumptions and associated scholarship, which guides practitioners, continues to affirm these perspectives of knowledge and T/truth. Where Truth is a global 
Truth, and truth is a personal truth, and in these ways, insights from this study suggest a merging of Truth and truth, where truth is rejected. Likewise, Mossop and colleagues (2013) sought to validate the existence of a hidden curricula through the validation of a tool. Considering conceptualizations of hidden curricula as "of some setting, at some time, for some learner" (emphasis original, Martin, 1976, p. 138). The necessity of validity through repetition in exploring a highly idiosyncratic and shifting 'entity' is quizzical. At the same time, it demonstrates the profession's robust emphasis on certain assumptions, which also are operating to deny legitimacy of highly personal affects which affects mental health, well-being, and feelings of belonging. More work which qualitatively explores difference using different paradigmatic assumptions to infuse new ways of seeing, being, and researching into the field are needed.

Alternative perspectives. Confrontation with an alternative perspective, like The Letter, was a surprise for many. In many ways, it was similar to the subjective face value rejection, however this was grounded in the fact that the individual, themselves, did not have the same experience in the same environment. An inconceivable truth of another. Alternative truths of a shared experience as unthinkable. This manifested in several different ways. One with illumination of Young Veterinarian's CVM affiliation being the same community the study was situated in. Another with comparing experiences as a student—“I don't feel this way that much... maybe it's just because I haven't been unlucky enough and my day will come" (student 3). Another with considering how all students on the same rotation could possibly have different perspectives on the "shared" experience. 
You can have the very same person with the very same group and you can have four students that talk about how they loved this instructor... and then other person that says they were the most horrible terrible thing... this is the same [instructor] in the same group and you're just like how could this be? (emphasis theirs, faculty 7).

Like rejecting the face value of a subjective experience, this response is unsurprising given the nature of knowledge, the epistemology, that infuses medical curricula plans and enactments.

Fully autonomous subject. Several insights from this study indicated affects which position others as fully autonomous, capable of making unconstrained moves. The Letter, as a departure from this perspective was a surprise, and constituted an affect of hidden curricula. Like the comments rooted in balance about the use of free time, and an expectation that all free time can be used to engage in relaxing and rejuvenating self-care or discussions which suggested people acting immorally or unethically because of social pressures. Putting the scholarship of mental health and positive psychology of veterinary medical students and professionals in conversation brings about several insights. The work which suggests optimism and curating self-esteem (Gardener \& Parkinson, 2011) or mindset (Root Kustriz, 2017) are autonomous choices indicates the affectual values in this study which point to a fully autonomous subject are not uncommon. That is, each person has free-will and is full autonomous.

Yet, much work suggests otherwise. For example, a recent study identified several social pressures and reinforcing mechanisms which contributed to medical students' reluctance to seek help for mental illness or distress (Winter et al., 2017). In particular, 
pressures to be tough and hide emotions, or expressing unanimous belief that attending lectures or clinical placements "when ill was normal and expected" were key pressures in how they conducted themselves and made decisions for their well-being (p. 151). Individuals who are living with anxiety or depression are particularly disadvantaged by these messages about resilience or positivity since the very nature of their illness precludes such choices about how to feel. Specifically, approximately one- to two-thirds of veterinary students are at a point where they are likely to be unable to choose to be happy, positive, or to not worry about things. The fact that they are often asked to do so, sends the message they are doing it wrong or are not enough. The paradox of belonging as they relate to mental health, here, are evident. Inability to cope as an agent of free-will, even with mental illness, is unwelcome.

In response to insights such as these regarding the nature of being and knowing, of professionalism and hidden curricula, Wear \& Castellani (2000) and Waddell (1982), alike, recommend incorporating humanities, philosophy, and sociology into the (veterinary) medical curricula and/or requiring greater emphasis prior to matriculation. In particular, Wear \& Castellani (2000) recommend the development of "a sociologic consciousness," which could widen the skills of students, allowing them to use different kinds of knowledge which are necessary to the practice of medicine. In particular, they recommend targeting four skills in addition to weaving in interdisciplinary inquiry throughout the curriculum.

The first skill of four is a familiarity with, and portability of epistemology through taking 
a philosophy of science or sociology of knowledge course that promotes (1) a critical approach to knowledge, (2) an enlarged conception of what it means to "know," and (3) an appreciation of the conceptual elegance and truths of science tempered by skepticism for any claims to pure objectivity or rationality (p. 608). The second skill involves interrogating and learning how students of medicine position themselves in reference to other sectors of society. This is an unpacking of how they are taught to "know best" and how this knowing looks different and is perceived differently for other sectors. In particular, the poor and disadvantaged who normally do not have the same level of control over their lives as medical professionals. The third skill involves developing a "mobile mind toward multiple human values and orientations" (p. 609). This skill works to contrast rigid scientific ways of thinking imbued with dichotomies and absolutes and would help students grapple with questions such as "How could someone really believe in alternative healing" (p. 609)? Or in veterinary medicine, "Why would someone who has the financial means elect for conservative care for their pet?" The fourth skill of sociologic consciousness is "openness to the environment, to diverse ways of thinking and acting" (p. 609). This emancipated belief about human life is genuine compassion and "an authentic acceptance of people in all their varieties, values, and lifestyles" (p. 609).

The four skills are positioned alongside interdisciplinary inquiry as a mainstay of the curricular and pedagogical practices in a professional program. They suggest disciplines such as "bioethics, literature, philosophy, sociology, and history of medicine" (p. 609), and ensuring this is not a parallel curriculum. The parallel curriculum would serve to reinforce the dichotomy, so an intentional meshing of different ways of knowing, 
being, and thinking into the more traditional classroom spaces is necessary. This deemphasizes the tendency to characterize bioscience, or natural sciences, and medicine as a "magic bullet."

\section{Affective Neutrality}

Altogether, this study and prior scholarship indicate emotional socialization into (veterinary) medical professions demands newcomers develop emotional/affective neutrality as a marker of belonging. Women may feel particularly excluded and historic, gendered conceptions of epistemology and affect are understood to be central to these insights.

Emotional neutrality was a powerful affectual value and many insights circled back to emotional or affective neutrality as a sticky affective norm - the known hidden curricula. For instance, movements away from Young Veterinarian's emotional and affectual response to mistreatment, yelling, or even abuse were common-place. "That's life" (faculty 6). "It is what it is" (student 3). "Just grin and bear it" (student 1). "You don't need to cry about how bad you got it" (faculty 1). The demand for and socialization into affective neutrality are echoed across decades of scholarship in (veterinary) medical education. Smith \& Kleinman (1989) indicated emotional talk is taboo and hidden curricula demands detachment, affective neutrality, and marginalization of emotions. Cribb \& Bignold (1999) elaborated on these findings in relationship to what they described as "worryingly high level so stress and mental health problems, such as depression" (p. 200). Phillips \& Clarke (2012) revealed four characteristic responses of medical students to hidden curricula, one being dissociation or keeping quiet. 
Yet, women, representing a majority of students and practitioners, face a particular challenge in enacting and embodying these professional ideals. This is because women are socialized to more openly express (Jaggar, 2009) and communicate emotions (Underman \& Hirshfield, 2016), which could produce dilemma—being a good doctor is being a bad woman. Irvine and Vermilya (2010) noted how mandated affective neutrality was leveraged against women as a mechanism for exclusion. In particular, "male veterinarians argued that [veterinary practice] required an unsentimental attitude that women did not possess" (p. 59). Women may face harsher critiques and experience bias as a result of these oppositional affective expectations, which has implications for how they are evaluated as doctors-in-training (Underman \& Hirshfield, 2016).

Considering the categorical stressors articulated by Reisbig et al. (2012), emotional socialization, in the ways described here, likely represents a transitional stress. Transitional stressors are associated with fitting in or homesickness, and are correlated with increased depression, anxiety, and decreased life satisfaction. As transitional stressors are innately distressing and produce affects and emotions, the transitional stressor of meeting the dominant norms of emotional neutrality, as an emotional event, increases the affects and the stress associated with suppression. It is possible this is related to what Austen (2016) suggested, "as the weeks of grueling work blur into months and years, clinical detachment may lead to numbing not only the emotions of our patients, but also the emotional resonance of colleagues, friends, and those we love most" (p. 377). Affective neutrality may topple attempts to relate to people around us and 'see' resilience, because the neutral status obscures and minimizes those cumulative efforts related to resilience. That is, affective neutrality is necessarily a state of resilience. A 
greater awareness and understanding of this double-bind has huge implications for conceptions of resilience in practice and in research. Further inquiry into the relationship among resilience and affective neutrality is needed to explore this complicated relationship.

The norms of affective neutrality likely have a large impact on mental health service use and other help-seeking behaviors. Many studies indicate the large proportion of veterinary medical professionals suffering with mental ill health, and remarkably low proportions seeking services (see Cardwell et al., 2013; Karaffa \& Hancock, 2018a). The normative affective neutrality could work to stigmatize affects other than neutral, thereby contributing to the lack of service use. Many report participation in counseling or being associated with mental ill health would affect future school or career opportunities, which further implicates a social and cultural barrier to help seeking and being seen as anything other than unaffected (Cardwell et al., 2013; Winter et al., 2017).

Taylor and Robinson (2009) suggest harnessing this potential for transformation through adopting a lens of women's ways of knowing as a mechanism for professional development within the veterinary profession. In particular, implementing strategies to support more constructivist pedagogies which center experiences on learners and are rooted in "establishing an environment of mutual trust, respect, honesty, caring, and empathy" (p. 140). In addition, they suggest expanding conceptions and perceptions on the nature of knowledge, or epistemology, and embracing different and gendered ways of knowing through a model of epistemological reflection.

Balance and resilience. The interdigitating concepts of balance and resilience with emotional/affective neutrality was an interesting insight. Affective neutrality was 
positioned as a strategy of balance which helps maintain resilience. Almost as if the challenge requiring resilience was to maintain neutrality above all. The reification of this the student handbook lends support for the ways in which resilience is conceptualized at this institution. Contemporary literature examining veterinary student resilience suggests they lack it. McArthur and colleagues (2017) indicated only six percent of students could be classified as 'highly resilient'. However, student participants shared many stories of remaining resilient in the face of mental illness, abuse or mistreatment, and professional rejection. Further, resilience as an affectual value emerged primarily with students. These discordant findings suggest, like Baker and Sen (2016), we might be harboring an unrealistic ideal of supernatural resilience which dismantles and shames the innate vulnerabilities of being human. Further considering Winter and colleagues (2017) findings, professional socialization into what seems to be supernatural resilience could be a significant source of stigmatizing beliefs about personal enactment of balance and wellness. Karaffa and Hancock (2018b) corroborate this, indicating veterinary medical students perceive others are less willing to seek mental health services than they were. This pluralistic ignorance, or false norm, has impacts on help-seeking attitudes or behaviors regarding balance, well-being, and mental health.

Power and hierarchy. Affects of power and hierarchy were rampant among the insights of this study. Many faculty affirm the presence of or participation in what Young Veterinarian described as students being "mistreated, yelled at and punished for things we didn't to" (dvm360.com staff, 2017). Students also corroborated this affect and suggested it was expected and elaborated on how they cope- though positivity, complexity, emotional neutrality, and resilience. 
The hidden curriculum with respect to power and hierarchy was Young Veterinarian's status as a whistle-blower. Insights suggest the problematic nature of making claims of abuses of power and hierarchy— to be normal you go with the flow and do not report it. The surprises, or departures from this norm entailed apologizing or implicating one's self in issues of harassment, mistreatment, or abuse further cement the norms of power abuse, which then affect those affects that produce the norms of nonreporting. Wear and Aultman (2005) also reported women who experienced, labeled, or reported sexual harassment are in violation of professional norms of what a trust-worthy colleague looks like. Likewise, Wilkinson and colleagues (2006) noted most students do not report abuse. Many do not report for fear of being ostracized (Wear \& Aultman, 2005; Wilkinson et al., 2006) Richman and colleagues (1992) demonstrated a link to abusive experiences and maladaptive coping behaviors such as drinking for escape purposes. Together, these results suggest whistle-blowing is socialized as an unprofessional behavior. For students, given the connection among experiencing harassment or abuse, distress, and feelings of belonging, additional research is warranted to explore these relationships in veterinary medical students.

In addition to the sticky affective norms of non-reporting, sociopolitical issues of faculty evaluation lacking emphasis on civility and collegiality further endear the perpetuation of incivility, harassment, and mistreatment to abuse. Wear and Aultmann (2005) corroborate the normality and routine nature of harassment in medical education. In their work with sexual harassment, they also described how non-reporting is a part of cultural norms. They indicated whistle blowing is seen as unprofessional, so socialization supports the routine nature of unchecked and unreported harassment. In this current 
study, faculty who described attempts to counter pervasive culture being met with silence offer a personalized account of how powerful norms can be in maintaining status quo. Further inquiries into social affects around power, teaching, and learning in veterinary medicine are needed.

Experiencing harassment and abuse contribute to increased stress and engagement in maladaptive coping strategies, such as drinking for escape purposes (Richman et al., 1992). Although harassment does not constitute the majority of student experiences in professional programs of veterinary medicine, Greenhill and Carmichael (2014) reported $14.8 \%$ of veterinary students experienced some form of harassment. This proportion was increased for participants identifying with under-represented minority groups in veterinary medicine, such as non-white race/ethnicities or LGBTQQ students. Wilkinson and colleagues (2006) indicated approximately one-sixth of medical students considered leaving the profession because of abusive experiences. In this study, one student described how they dreaded going in, yet never considered leaving. House officers described how although they felt like, or heard about colleagues wanting to leave, they all felt trapped by the financial burden of student-loan debt. Questions arise surrounding this relationship among student debt, feelings of being trapped, and persistent despite experiences of abuse in relation to what Kassebaum and Cutler (1998) describe as the “transgenerational legacy" of future mistreatment by those who have been recipients of mistreatment (p. 1157). This illuminates an area in need of research and interventionsupporting the growth of coaching, mentoring, and teaching practices for clinical veterinary faculty. 
Mental health and well-being. Two students disclosed living with or recovering from mental illness. One lives with OCD and the other is recovering from depression. Two faculty participants have previously disclosed they are living with or recovering from mental illness. Although this study is not quantitative in nature, the proportional approximations of mental illness in participants $(28.5 \%)$, and the reported prevalence of anxiety and depression in veterinary students, $36.2 \%$ and $33.9 \%$ respectively, is noted (Karaffa \& Hancock, 2018a).

Questions of Young Veterinarian's mental health surfaced in conversation, some prompted in relation to how singularly focused The Letter was in regard to "negative" affects and experiences. These were to open discussion, maybe Young Veterinarian is depressed? These conversations rarely stayed with notions of mental illness and instead circled to issues of contemporary positive psychology, such as positivity or helpfulness, or those of belonging; of relational (dis)connections. Scholarship with veterinary students emphasizes the interrelationship between positive psychology and well-being, and an inverse relationship with depression and anxiety (e.g., Bakker et al., 2017; Gardiner \& Parkinson, 2011). Students who moved with affectual values of positivity, described buffering distressing situations with their positive outlook. Often, these moves were with gratitude. These insights affirm Gardiner and Parkinson (2011) descriptions of students with greater optimism being less stressed and higher life satisfaction. Moreover, the moves to buffer distress that helped students remain resilient affirm Bakker and colleagues' (2017) work with PsyCap resources.

Faculty also moved with positivity, yet in doing so, worked to subvert a key assumption of positive psychology: That which is good is not simply the absence of bad 
and that both bad and good (and everything in between) are legitimate and genuine. This extreme positivity worked to obscure what might be or was considered not good and this worked to exclude others who saw or described what was 'not good'. These blinders can work to overshadow opportunities for peer accountability or moments where community members could act as an ally.

Branch (2005) described the use of critical incident reports in fostering and developing reflective practice to support addressing deeply held values and attitudes nested within particular contexts and experiences. These narratives are composed in response to prompts which ask the writer to describe an incident judged to be of great importance to their work as a doctor (or doctor-to-be). These could be learning experiences, especially challenging or meaningful moments, witnessed events which were highly influential or disturbing (p. 1063).

Insights of each affectual value demonstrated operation as relational forces that produced many conflicting (dis)connections and spaces of inclusion/exclusion. The connections and inclusions are important to develop a welcoming atmosphere to promote belonging in support of mental health and well-being (Cardwell \& Lewis, 2017). Yet, emotional neutrality as associated with affectual exclusion were common forces which circulated with many affectual values (e.g., accountability, positivity, or loyalty). Perspective operated as an empathic wondering, which opened space for being and feeling with Young Veterinarian or others_-often without judgement. With perspective, students appear to construct spaces of belonging for themselves and others where connections among myriad (dis)connections are produced. Curiosity also invited others into a space of wonderment and perspective_-problematizing (dis)connections. 
Complexity produced connections but at times went above and beyond, producing a space of (dis)connection through inaction and arrest. Together these insights suggest the production of a welcoming environment of inclusion to support belonging and well-being is complex and contradictory. Enhanced scholarly, professional, and institutional attention to the ways in which welcoming environments are produced and experienced are needed.

Perspective taking is sometimes described as one of the cognitive components of clinical empathy, yet clinical empathy is highly complex and more than mere cognition or communication (Schoenfeld-Tacher et al., 2015). Clinical empathy is an embodied expression which is felt and plays a key role in clinical and patient outcomes, as well as establishing relationships. Although perspective taking was common place for students, it was less so for faculty. This insight is surprising given the recent scholarship which showed declining empathy in veterinary medical students (Calderon-Amor et al., 2017; Schoenfeld-Tacher et al., 2015). Questions persist among empathy as affect in relation to spaces of professional connection and belonging. How do we recognize and support those mechanisms to live-with (dis)connections that evade our attempts to capture and know of them via metrics, assessments, and validated instruments? Nested in these questions is a dire need for increased qualitative scholarship to explore the intricacies and idiosyncrasies of empathy as an affect.

\section{Freedom, Debt, and Hope/lessness}

A novel insight of this study is the connections among student debt in relationship to well-being, belonging, and feeling hopelessly trapped. Freedom emerged as an affectual value of absence - a frustration which questioned practices, policy, or even 
Young Veterinarian's experiences in practice. Other work suggests that freedom is also constrained in veterinary school as well. Meyer-Parsons and colleagues (2017) recognized spontaneity/freedom as unwelcome feelings in a veterinary curriculum. Freedom from external control is autonomy, and autonomy is inversely related to burn out.

McArthur and colleagues (2017) suggested "significant time commitments and rigid structures that may largely dictate the personal life of the student" add to this lack of feelings of autonomy and in turn contribute to burnout (p. 15). The unforgiving intensity of many veterinary curricula are elsewhere demonstrated to contribute to hopelessness (Sutton, 2007). Even when compared with medical school peers, veterinary students reported lower quality of life (Labbafinejad et al., 2016). Individuals who are living with depression often report feeling sad and hopeless (Hafen et al., 2006). This raises curious questions about how affects of hopelessness are interpreted or measured, and how they ultimately work to augment perceptions of mental health or well-being. Is feeling hopeless a coping strategy of setting realistic expectations? Is feeling hopeless the norm? Is being depressed the norm? Are they all normal and so entangled the distinctions are less of a concern than the starkness of this shared affect—hopelessness?

The time commitments of practice in relationship to the suffocating debt and other financial entrapments (e.g., mortgage or non-competes), operate in similar ways, contributing to a lack of autonomy and hopelessness. Recent work suggests the longitudinal relationship between subjective financial strain and mental health is inconsistent and mastery, in part, mediates this inconsistency (Koltai, Bierman, \& Schieman, 2018). Mastery as a psychosocial concept refers to the "individual placement 
in structural conditions of power and privilege throughout the life course" and can "buffer the effects of stressors on distress" (p. 108). The lack of control regarding physical time in veterinary school or financial entrapments of practice likely contribute to the low levels of mastery for these individuals, which impacts feeling distressed. Indeed, Mastenbroek (2017) identified how supporting the development of personal resources to foster self-acceptance, awareness of own influence, and responsibility had positive impacts on veterinarians' perception of their job demands and work-related exhaustion.

Questions of financial freedom conjured questions of social justice in relationship to the meritocracy of financial awards. The critiques and paradoxes of meritocracy are many — mainly centering on beliefs which locate causes of difference in status solely in individual talents and efforts. Scholarship has demonstrated organizations which attempt to work against bias, and use merit for promotion, actually affirm discriminatory practices (Castilla, 2008; Castilla \& Benard, 2010). Other scholars indicate another paradox of meritocracy, it produces an increase in self-stereotyping (McCoy \& Major, 2007). In terms of belonging, endorsing meritocratic worldviews work to produce and justify (dis)connections and exclusion based on merit—with those in higher, more deserving statuses being considered more talented, valuable, or hardworking than those in the lower statuses (McCoy \& Major, 2007). Transparency of (thought) process and equity in award distribution are recommended to be rethought as both policy and personal commitment towards social justice (Rodriguez, 1998) and inclusion.

\section{Inclusion and Belonging}

Affects worked to produce connection and spaces of legitimacy in many ways. In the paragraphs that follow, movements towards inclusion and belonging with affects 
explored in this study are deliberated and discussed. Belonging constitutes the "feeling of being taken under the wing of the profession" (Cardwell \& Lewis, 2017, p. 33). Cardwell and Lewis (2017) urge the profession to consider professional belongingness in terms of its capacity to affect "collective interest in, or responsibility for, individual well-being" (p. 35). Although they emphasized the importance of a welcoming atmosphere to promote belonging, other factors affect perceptions of what is or can be considered welcome.

Bartram, Yadegarfar, and Baldwin (2009) illuminated an association between workplace characteristics and mental health, noting prior psychological distress affects current perceptions - confounding the relationship. Given these reciprocal and convoluted affectual relationships, it is important to note the movements highlighted next are not categorical imperatives, but rather demonstrations of those insights in this study which constituted a movement to a space of yes-and. Of making space for, and seeing the legitimacy of, other ways of knowing and being and considering how our vision of and for, and our responses to, are shaped by the many affects which accompany us to the moments, spaces, and histories we are among.

\section{Spaces for difference}

Many affects produced spaces for difference among them. Connections with corroboration or without justification. Insights from this study illuminated spaces for difference which produced spaces of expectation for, like Wear \& Castellani (2000) state, "an authentic acceptance of people in all their varieties, values, and lifestyles" (p. 609). As cumulative, these affects have the capacity to produce new sticky spaces, new norms. 
Affect/emotion. The interesting work of silence in this study worked to support spaces of different affectual expressions and experiences. The work of silence also worked to produce (dis)connections through legitimizing potentially discriminatory statements, harassment, or other mistreatments. Yet, in these (dis)connections the shared silence can produce connections among palpable and perhaps knowing discomfort. Similarly, wait-time, or "full stops," in communications can support relationship building (Adams \& Kurtz, 2017). In particular, creating pauses for affect and to affect in enacting empathy and acceptance are particular skills highlighted by several scholars of veterinary communication (Adams \& Kurtz, 2017; Kurtz, Silverman, \& Draper, 2005).

Perspective, curiosity, self-reflection, and at times complexity all worked to produce spaces for differences in affect. Perspective was empathy-like, the holding dear of many possible situations of others and withholding judgement and offering grace. Also, maintaining a perspective of the bigger picture and the various relationships nested within. Humility nested within a recognition of privilege. Holding space for others, "giving people a chance to make mistakes, to be overwhelmed, and not coming down on them for it" (student 4). Allowing complexity to be complex in earnest attempts to remain open, curious, and resist closure and judgement by giving people "the chance to have a different experience" (student 4). Social supports for spaces to enact this differential affect are important to protect veterinary students and professionals from persistent stressors which can lead to distress (Weston et al., 2017).

Empathy, or empathic-like practices, such as these, support social relationships through our ability to put ourselves in another's shoes (Schoenfeld-Tacher et al., 2015; Shoenfeld-Tacher, Shaw, Meyer-Parsons, \& Kogan, 2017). Yet, Roder and May (2017) 
identified how students curate cadres of peer support and professional role-models to buffer cumulative dis/stress and look for those who have qualities they already deem to be important. In searching for someone to help you feel like you belong for feeling different, you are likely to search for someone to make you feel like you belong for feeling the same way. The search for affectual symmetry as affirming could work against the apparent need for inclusion. The intricate relationship between inclusion, diversity, affirmation, and belonging warrants further inquiry. Especially considering the rapid gender shift, the relationship among gender and affect and/or emotion, and the profound lack of diversity in the veterinary medical profession.

Social justice. As an affectual value, social justice worked to balance the weighty cloak of objectivity through an embrace and validation of counter-stories. Greenhill and Carmichael (2014) suggest "curricular programs must embrace intersectional frameworks that promote the fact that minority groups are diverse in their own right" as necessary for meaningful change (p. 118). Likewise, Wear and colleagues (2017) advises on mechanisms to build curricula for social justice in medical education, demonstrating the possibility of doing differently. In addition, they urge practitioners and teachers to resisting temptations to avoid discussions of topics not directly related to medicine or their discipline (Wear et al., 2017). Although veterinary medicine appears to be focused on animal health, the emphasis on One Health, and the fact that animals and people are inextricably linked, the pursuit of similar change should be considered.

\section{Possible Futures}

This exploratory study produced many possible futures by way of various insights. In the paragraphs that follow, I will revisit many of areas of scholarly inquiry 
briefly touched upon in the preceding sections. Additionally, I will make suggestions for deliberation regarding professional practice. I conclude with a post script where I offer matters to consider for the CVM this research was situated in.

\section{For Research}

Many new questions for further inquiry were produced in this work. Power dynamics in various contexts and the relationship among conduct norms and reporting practices were multifarious. These issues appear to be common in medical education, and (veterinary) medical sociologists ought to consider this an important area of worthy of further, more nuanced, investigations. In particular, as many women insist incidents of harassment are not only commonplace but most be endured (Babaria, Abedin, Berg, \& Nunez-Smith, 2012), issues of power abuses in relationship to institutional hierarchy, policy, and gender are areas for continued scholarly inquiry.

The role of debt in well-being and belonging was a surprising finding. Particularly as The Letter does not give financial hardship any consideration as a stressor or having an impact on the mental health or well-being of practitioners. For young practitioners in this study, namely the house officers, this was at the forefront of their affects. Results from a current, non-peer reviewed study conducted by the AVMA and Merck Animal Health is being widely distributed, and sheds light on issues of finances and well-being. One press report on the unpublished findings indicated, "poor mental health and low well-being were closely associated with the stresses of professional life, including inexperience, excessive work hours, and educational debt" (Nolen, 2018). This suggests the relationship among stressors of veterinary professional life which encompass loan indebtedness are beginning to gain attention. Yet, this warrants a greater emphasis and 
scholarly attention in peer-reviewed journals, so that methods and methodologies can be appraised and critiqued.

The concept of emotional and/or affective neutrality as normative was not surprising given the dearth of scholarship in medical education which demonstrates the long-standing tradition of emotional socialization in this regard. Greater quantities of scholarship and more nuanced explorations of this emotional socialization into affective neutrality, or what Gordon (1996) calls the "culture of objectivity," are needed. The rapid and sustained gender subversion in the veterinary profession is unique in comparison with human medicine. Inquiries which more deeply probe the relationship among gender, emotional socialization into the veterinary profession are dire. Especially in consideration for the role feminization plays in driving down salaries and 'respectability' of positions or professions (Irvine \& Vermilya, 2010) and the relationship among revenue, ability to pay off debt, and mental health are beginning to be established.

Overall, more research on the relationship among affect/emotion, affirmation, and inclusion in the veterinary profession, from a critical stance, are needed to explore these relationships. In particular with regard to gender, race, and professional norms. In particular, in relationship to the tensions produced with over-reliance on post-positivist and positivist (e.g., natural sciences) assumptions and quantitative methods, it is urgent the field move to incorporate more qualitative work. Care is needed, as critiques on qualitative work are rooted in assumptions which do not guide the scholarship. Newness is needed to break the cycle of an unwavering focus on objective, quantifiable "humans." To do differently, given the affects articulated above as associated with the overemphasis on certain epistemologies, is a moral and ethical imperative. 


\section{For Professional Practice/Curricula}

The insights gleaned from this study showed how those ways in which we value certain things affect how we respond, connect, include, and act as sociopolitical forces. Implications for practice largely surround interrogation of histories and assumptions. What does respect mean? How do I feel respected? Are there other ways to demonstrate respect? What is unacceptable? Why? What does this really mean-what values do I have which might affect these moral conceptions? This interrogation requires vulnerability to unpack what is taken for granted. Vulnerability to consider how responses speak volumes about us and our values. Those values and valuations, those affects, are social forces which circulate and produce (dis)connections which impact feelings of belonging. Boler (1999) suggests a pedagogy of discomfort in exploring emotions and affects as necessary and embedded in teaching and learning.

Many questions of different ways of knowing and being in the profession were ever-present. Although, as a profession, we are heavily trained in the ways of thinking rooted in natural sciences, these insights suggest we have a need for additional growth in learning, understanding, and living with other ways of knowing and being. Programs or curricula designed to support the exploration of various subjectivities, epistemologies, and ways of being are suggested. Faculty/community book clubs; incorporation of other disciplines, such as the humanities, into core curricula; or other ways to develop cultural competence could be helpful. If nothing else, consider adopting a policy which incorporates means to reserve judgement so you can stay with and seek the whole story when matters matter (and all matters matter to someone, but not everyone, and perhaps not to you, and that is ok). 
Awareness of the social norms regarding affect and emotional expression are paramount. In particular, the ways in which these norms privilege certain ways of being and expressing ideas suggests considerations for bias need to be addressed. Recent work by Gomez-Garibello and Young (2018) addressed the ways emotions bias and assist evaluation. Attention and introspection is needed to cultivate awareness and harness emotions and affect in relationship to student or peer evaluation, for grades or other 'fitness' of practice. To the point, Apple (1971) charges, there must be "continual attempt to bring to a conscious level those epistemological and ideological assumptions that help structure the decisions made" (p. 38).

Adopt personal accountability for impact versus intent. Although we are not responsible for how our affects affect another, we can and perhaps should be able to respond when the affective impact is a departure from intent. We are shooting for a target but with so many forces at play, we might miss. We might make a mistake. This is not an ethical judgement, but rather a question of moral care and vulnerability.

\section{CVM Post Script}

And we're slow to acknowledge the knots in our laces, heart it races - Bird (2007).

Many issues rooted among power were enlightened with the insights from this study. Mistreatment and incivility are known pervasive issues in this institution and nonreporting is commonplace practice. These findings are not unique to this institution and should be considered something inherited, which we can assume responsibility for recognizing, countering, and correcting if we choose. Research suggests multiple mechanisms to address, confront, and counter abuses of power are necessary because the issue is so complex and culturally entrenched. Simply instituting one-time training 
sessions cannot counter a long-standing culture which permits these actions. The reporting structure for students must be clear and ensure confidentiality (Fnais et al., 2014) because perpetrators are often supervisors (e.g., faculty) and the hierarchy (and power) wielded by status intensifies fear of negative consequences or retribution for reporting (Fnais et al., 2014; Wear \& Aultman, 2005; Wear, Aultman, \& Borges, 2007). Further, in health professions, there may be a reluctance to be viewed as a victim or fear they are simply being "too sensitive" (Wear et al., 2007). Care must be taken to not ostracize whistle-blowers or accusers, and instead offer support for the difficult decisions nested in the act of experiencing and reporting such treatment in a culture which asserts emotional neutrality as best. Final cautions include care to not weaponized the discourse of civility in response to allegations. Victims want and need to be heard, rather than policing their language, listening to what they are saying is the most important task at hand.

There was a profound interest in avoiding conflict in these insights. Whether it be a comment positioning a supervisor looking past uncivil behavior toward colleagues, thinking and feeling some yelling would be appropriate and 'par for the course'something to grin and bear, or even my own reluctance to confront potential violations of established ethical guidelines in discussion sessions. Conflict is ever present and the surfacing of conflicts are inevitable. We will never all get along or agree, nor should we endeavor to be so homogenous. Apple's (1971) 'happy cooperation' is positioned as the polar opposite of conflict. As happy cooperation and conflict are both sides of the same coin, one side is centered by hiding the presence of the other. Positioning this dichotomy is not to reinforce an either/or, but rather to emphasize a tension among these ideals. For 
example, insistence on happy cooperation on the whole, works to perpetuate certain conflict and maintain the underlying discomfort or affect. Conflict is rooted in power dynamics, as are conceptions of what happy cooperation can look like. Programmatic interventions to explore power, develop comfort in the discomfort of conflict, and improve communications are recommended. Many resources are available, Janss, Rispens, Segers, and Jehn (2012) is one. Janss and colleagues (2012) discuss power and conflict as mediators of teamwork in the health professions, offering a framework for work with these concepts. Angoff et al. (2016) discusses how their institution grappled with issues of power abuse and confronted them by instituting two "Power Days". Investing in training in conflict mediation, with particular emphasis on social justice and story-telling, could be beneficial.

Considering the layers of power among these insights, the maintenance of power and authority are insightful. Other implications for practice, in particular an ethic of vulnerability and pedagogy of discomfort (Boler, 1999) could be considered helpful in opening conversations about those stories that keep us closed. Across many discussions, I was struck by how often folks were talking about similar struggles differently. And how nested in affects there was a lonely discomfort, a worry, ever present.

I want to conclude with an expansion on that affectual realization brought about while working with the participants and data. There is so much that connects us all. We all share worries about similar things. We all love. We all find places of joy and sorry and hope and despair. We all want for good things for ourselves and those we love. We all want to belong. Yet, there is profound beauty in the asymmetric similarity. The difference among as what (dis)connects us. The disconnection reliant on the connection needed to 
establish (dis)connection. The feeling I got was everyone felt alone- especially participants who requested an individual session—namely, unranked clinical/teaching faculty. The (dis)connections made stark by petrified isolation and endless silence.

My sincere hope is we seek out stories yet untold and plunge headlong into unexplored affects, making space for the legitimacy of the highly textured, mosaic of everything. We acknowledge the knots in our laces, and look up to affect...

This will be hard work. I know we can do it. 


\section{APPENDIX A}

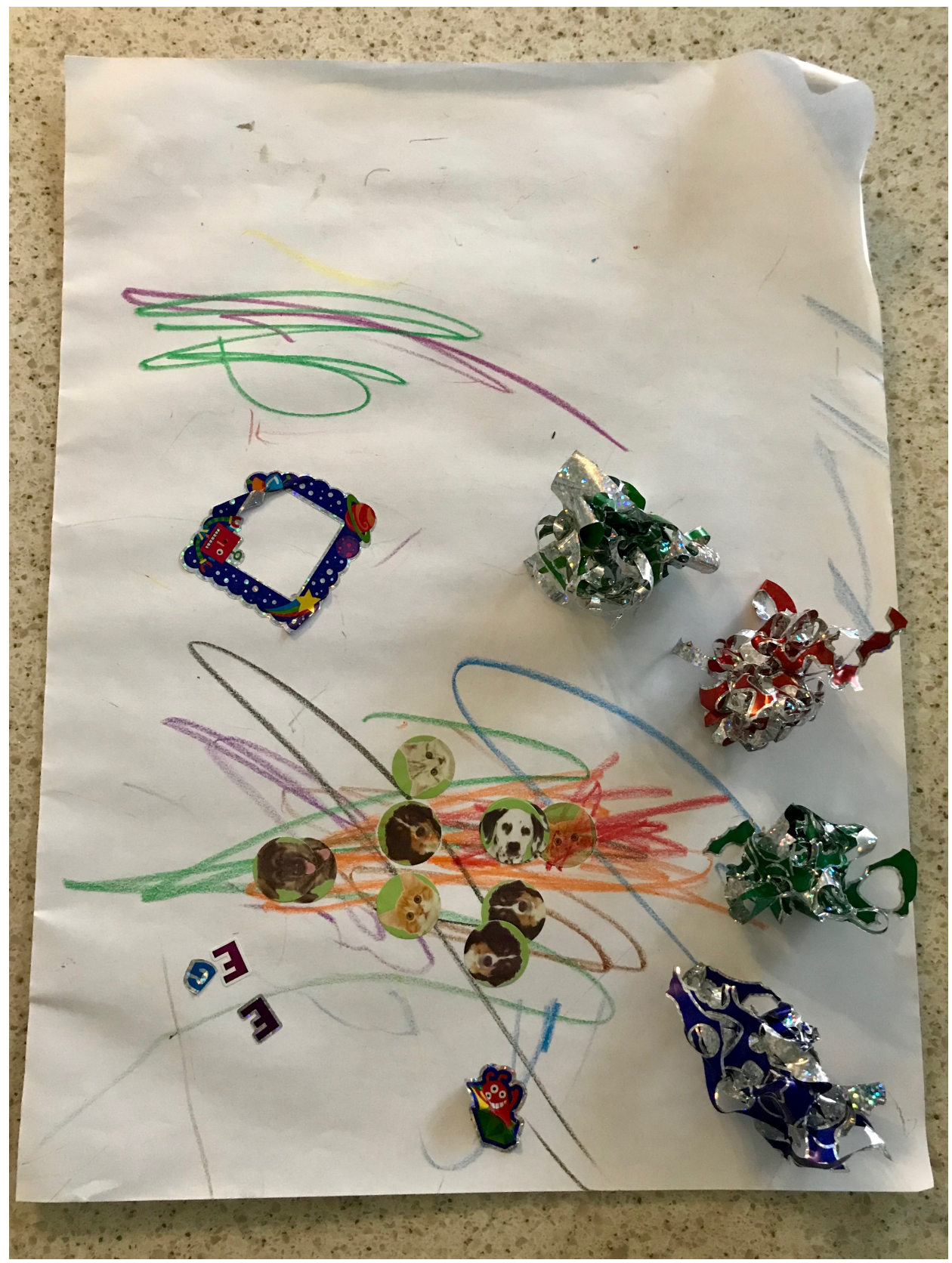

Figure 1. Mixed media artwork by Edward G. Hancock, dated February 17, 2018, titled Dissertation. 


\section{APPENDIX B}

Copy of participant recruitment email.

I am looking for several people to help me with an important research project I'm undertaking. I am conducting a study, titled Genealogies of Affect Among a Young Veterinarian's Public Letter, to explore the connections our profession is making with a public letter published on dvm360.com. The public letter can be accessed here: An open letter from a disillusioned veterinary school graduate. I am looking for people who are interested in having conversations and sharing their response(s).

This research involves joining in thoughtful discussion of the public letter, your response(s), and the culture and climate of veterinary medicine. There are several ways to be involved including peer group discussions, one-on-one conversations, or alternative/creative responses.

The informed consent is attached to this message if you are interested in reading more about the project. You can also email me at hancockts@mail.missouri.edu with your questions or we can meet in person to discuss the project and ways to be involved.

Please email me at hancockts@mail.missouri.edu if you are interested in helping with this research project.

Thank you,

Tamara

Tamara Hancock, DVM, MS, Dipl. ACVP (clinical)

Graduate Fellow, College of Veterinary Medicine

Doctoral candidate, College of Education

University of Missouri 


\section{APPENDIX C}

Semi-structured interview protocol and script.

\section{Pre-Interview Script}

Thank you for participating in my research intended to explore the connections the profession is making with a public letter published on dvm360.com.

When I read The Letter for the first time, I was struck by the honesty and vulnerability required of the author. The author, Young Veterinarian, makes intriguing contributions to the bigger discussions around mental health and well-being, academic medicine, culture and climate, and professionalism. Many folks took the time to make public comments or shares. I'm curious how people respond and connect in person and in conversation.

The purpose of this space is to explore and discuss your responses, connections, reactions, and experiences rather than question, attack, or disrespect the Young Veterinarian and their truth. The author expressed strong emotion and acknowledging that you may feel strongly and to help guide us in conversation, I have some guidelines for our discussion:

- All experiences are valid

$\circ$ We assume positive intent and offer others grace

- We stay present in mind and body

- We may disagree about ideas but we do not attack people These guidelines are for people who are physically present as well as those who are notparticularly the Young Veterinarian (the author of The Letter). 
I have been asked by many people if I know who wrote The Letter. I do not. The Young Veterinarian went to great lengths to remain anonymous and I respect their wishes.

In the interview that follows, I have several open-ended questions intended to explore your connection(s), response(s), and reaction(s) to The Letter. You may choose to answer any or all of them.

With your consent, I will audio-record this discussion and the recording will be transcribed verbatim. Your information will be kept confidential and you will not be identified individually.

Interview Questions and Follow-up Prompts

1. With the different discussion options - the group interview and individual interview, I'm curious, could you tell me more about what went into your decisions?

a. What are your thoughts and feelings about a group discussion?

2. What are your initial reactions?

a. [Foregrounding some thing I noticed] tell me more about that...

3. How are you connecting, or not, with this letter?

a. Particular experiences - any stories you would like to share?

b. Recommendations for respectful, relevant, realistic, and reasonable dialogue?

c. The Young Veterinarian?

4. What would your letter to the veterinary profession look like?

a. What would you use/edit from The Letter? 


\section{APPENDIX D}

Discussion guidelines used for all planned interviews.

The purpose of this discussion is to explore and discuss your responses, connections, reactions, and experiences—your truth—rather than question, attack, or disrespect the Young Veterinarian and their truth. The author expressed strong emotion and acknowledging that you may feel strongly, I have some guidelines:

○ All experiences are valid

$\circ$ We assume positive intent and offer others grace

- We stay present in mind and body

○ We may disagree about ideas but we do not attack people

These guidelines are for everyone. People who are physically present as well as those who are not-particularly the Young Veterinarian (the author of The Letter). 


\section{APPENDIX E}

Table 1. Jeffersonian transcription markings derived from Jefferson (2004)

\begin{tabular}{|c|c|c|}
\hline Symbol & Name & Use \\
\hline [text] & Brackets & $\begin{array}{l}\text { Indicates the start and end points of } \\
\text { overlapping speech. }\end{array}$ \\
\hline$=$ & Equal sign & $\begin{array}{l}\text { Indicates the break and subsequent } \\
\text { continuation of a single utterance. }\end{array}$ \\
\hline (\# of seconds) & Timed pause & $\begin{array}{l}\text { A number in parentheses indicates the } \\
\text { time, in seconds, of a pause in speech. }\end{array}$ \\
\hline (.) & Micropause & A brief pause, less than 0.2 seconds. \\
\hline . or $\downarrow$ & Period or down arrow & Indicates falling pitch or intonation. \\
\hline$?$ or $\uparrow$ & $\begin{array}{l}\text { Question mark or up } \\
\text { arrow }\end{array}$ & Indicates rising pitch or intonation. \\
\hline- & Hyphen & $\begin{array}{l}\text { Indicates an abrupt halt or interruption in } \\
\text { utterance. }\end{array}$ \\
\hline$>$ text $<$ & $\begin{array}{l}\text { Greater than/less than } \\
\text { symbols }\end{array}$ & $\begin{array}{l}\text { Indicates the enclosed speech was delivers } \\
\text { more rapidly than usual for the speaker. }\end{array}$ \\
\hline$<$ text $>$ & $\begin{array}{l}\text { Less than/greater than } \\
\text { symbols }\end{array}$ & $\begin{array}{l}\text { Indicates that the enclosed speech was } \\
\text { delivered more slowly than usual for the } \\
\text { speaker. }\end{array}$ \\
\hline$\circ$ & $\begin{array}{l}\text { Degree symbol } \\
(\text { option }+K)\end{array}$ & $\begin{array}{l}\text { Indicates whisper, reduced volume, or } \\
\text { quiet speech. }\end{array}$ \\
\hline TEXT & All capitalized text & Indicates shouted or increased volume. \\
\hline$\underline{\text { Text }}$ & Underlined text & $\begin{array}{l}\text { Indicates the speaker is emphasizing or } \\
\text { stressing the speech. }\end{array}$ \\
\hline$:::$ & Colon(s) & Indicates prolongation of a sound. \\
\hline (hhh) & & Audible exhalation. \\
\hline
\end{tabular}




\begin{tabular}{|c|c|c|}
\hline • & High dot (option+8) & Audible inhalation. \\
\hline$($ text $)$ & parentheses & $\begin{array}{l}\text { Speech which is unclear or in doubt in the } \\
\text { transcript. }\end{array}$ \\
\hline$((t e x t))$ & $\begin{array}{c}\text { Double parentheses and } \\
\text { italicized }\end{array}$ & Annotation of non-verbal activity. \\
\hline$\{$ text $\}$ & Fancy brackets & Jested speech. \\
\hline$(* 0: 00: 00.0)$ & & Time stamp of audio file. \\
\hline
\end{tabular}




\section{APPENDIX F}

Table 2. In-process example of side-by-side merging of data and writing and thinking in parallel columns.

\section{(Social) Justice and (Self) reflection}

(Social) Justice. "the maintenance or administration of what is just especially by the impartial adjustment of conflicting claims or the assignment of merited rewards or punishments" or "the quality of being just, impartial, or fair" (Merriam-Webster).

(Self) Reflection. looking inward and considering one's roles and contributions to issues at hand. A critique of one's actions or inaction as contributing factors. Related to power and accountability but at a depth and intensity that centers on the self as culpable.

\begin{tabular}{|c|c|c|}
\hline \multicolumn{3}{|c|}{$\begin{array}{l}\text { Social justice } \\
\end{array}$} \\
\hline $\begin{array}{l}\text { Individual } \\
\text { How did these affects } \\
\text { come to be for this person? }\end{array}$ & $\begin{array}{l}\text { Relational } \\
\text { How do these affects } \\
\text { produce (dis)connection? }\end{array}$ & $\begin{array}{l}\text { Sociopolitical } \\
\text { How do these affects } \\
\text { (de)legitimize The Letter } \\
\text { as an account of hidden } \\
\text { curricula? }\end{array}$ \\
\hline $\begin{array}{l}\text { F10: Almost didn't want to } \\
\text { come to MU as a faculty } \\
\text { member-so incredibly } \\
\text { white. } \\
\text { Grappling with role in } \\
\text { producing indebted future } \\
\text { professionals and what it } \\
\text { means in relationship to } \\
\text { producing a diverse } \\
\text { profession. } \\
\text { F3: rigid system of } \\
\text { advancement and } \\
\text { meritocracy fraught with } \\
\text { injustice-personal } \\
\text { accounts of this in } \\
\text { scientist/family dichotomy. } \\
\text { Curiously pushes back on } \\
\text { others attempts to define } \\
\text { and label. } \\
\text { HO1: Personal attempt at } \\
\text { financial security in Vet } \\
\text { School left him without } \\
\text { necessary merit to be } \\
\text { 'worthy enough' of a } \\
\text { scholarship -feels left } \\
\text { behind and this is shared } \\
\text { by other friends he has }\end{array}$ & $\begin{array}{l}\text { Opens space for (enacting) } \\
\text { difference through } \\
\text { connection. } \\
\text { Questions claims of others } \\
\text { (curiosity/f3), processes as } \\
\text { fair/just (ho1), or belonging } \\
\text { in an otherwise } \\
\text { homogeneous group (f10). } \\
\text { Reserves judgement on The } \\
\text { Letter or Young } \\
\text { Veterinarian. An intense } \\
\text { connection without } \\
\text { qualification or } \\
\text { clarification that demands } \\
\text { understanding. An } \\
\text { acceptance and perhaps an } \\
\text { (dis)connect from others } \\
\text { who seek to reject. }>>>\text { is } \\
\text { there an example of this? } \\
<<<\end{array}$ & $\begin{array}{l}\text { Work to legitimize through } \\
\text { connection and reservation } \\
\text { of judgement or frank } \\
\text { affirmation yet also seems } \\
\text { to legitimize in a } \\
\text { paralleling move-a stance } \\
\text { next to. A belief of and for } \\
\text { the purposes of progress } \\
\text { and justice. } \\
\text { In some ways, this affect } \\
\text { serves to (dis)connect } \\
\text { through questioning-- } \\
\text { Letter doesn't include } \\
\text { passages about finances- } \\
\text { this is tenuous though, } \\
\text { perhaps it is not an issue } \\
\text { for this veterinarian } \\
\text { ((could thread back } \\
\text { through how increasing } \\
\text { proportions of graduates } \\
\text { do not have debt))-it's an } \\
\text { incomplete account, but } \\
\text { this isn't a threat to its } \\
\text { "validity" as an affect. }\end{array}$ \\
\hline
\end{tabular}




\begin{tabular}{|c|c|c|}
\hline $\begin{array}{l}\text { discussed it with. Watching } \\
\text { the system perpetuate } \\
\text { similar failures for } \\
\text { apparent profits (student } \\
\text { failing 3x). }\end{array}$ & & \\
\hline \multicolumn{3}{|c|}{ (self) reflection } \\
\hline $\begin{array}{l}\text { Individual } \\
\text { How did these affects } \\
\text { come to be for this person? }\end{array}$ & $\begin{array}{l}\text { Relational } \\
\text { How do these affects } \\
\text { produce (dis)connection? }\end{array}$ & $\begin{array}{l}\text { Sociopolitical } \\
\text { How do these affects } \\
\text { (de)legitimize The Letter } \\
\text { as an account of hidden } \\
\text { curricula? }\end{array}$ \\
\hline $\begin{array}{l}\text { Described as innate facet } \\
\text { of 'who they are' - self- } \\
\text { critical was the terms they } \\
\text { used rather than self- } \\
\text { reflection. This reflection } \\
\text { at times is a critique, which } \\
\text { can be harsh. The self- } \\
\text { imposed perfectionism is a } \\
\text { challenge to not extend } \\
\text { into the environment. } \\
\text { Several interwoven stories } \\
\text { here... }\end{array}$ & $\begin{array}{l}\text { Can work to establish } \\
\text { connections where } \\
\text { (dis)connections were } \\
\text { fostered. } \\
\text { In some other ways, seems } \\
\text { to foster (dis)connection } \\
\text { when introspection } \\
\text { becomes more space } \\
\text { occupying-thinking of } \\
\text { email exchange with f5 } \\
\text { following MC. }\end{array}$ & $\begin{array}{l}\text { Self-reflection is a } \\
\text { legitimizing force that } \\
\text { internalizes the affects as } \\
\text { plausible and entertains } \\
\text { one's culpability in their } \\
\text { production. }\end{array}$ \\
\hline \multicolumn{3}{|c|}{$\begin{array}{l}\text { (social) Justice: } \\
\text { (faculty 10): } \\
\text { T: its hard too because as a profession we are the whitest profession }\end{array}$} \\
\hline \multicolumn{3}{|c|}{$\begin{array}{l}\text { F10: oh my god we are so white and it's really white here where I went to vet school it } \\
\text { was not this white ... like I went to ... there were } 80 \text { people in my class what has } \\
\text { struck me is the incredibly small number of Asian students I've seen here not to } \\
\text { mention African American students I'll be honest and you can record this as much as } \\
\text { you want when I came here to interview I almost didn't take this job I said to my } \\
\text { husband it's way too white there ... it made me really nervous and I think one of the } \\
\text { things that tipped me over the edge was talking to ... and she like if I'm good here } \\
\text { you'll be ok ((shared laughter)) I said ok but :I: yeah it's something about here that I do } \\
\text { not enjoy (3) }\end{array}$} \\
\hline \multicolumn{3}{|c|}{$\begin{array}{l}\text { F10 maintains a perspective about veterinarians' position in society, in the teaching } \\
\text { hospital. Being a vet and teaching are both privileges and with that privilege comes } \\
\text { some humility and a need for intentionality in interactions. F10 is concerned about her } \\
\text { personal involvement in producing indebted veterinarians with potentially limited } \\
\text { resources to generate income to pay it all back. "I feel complicit in setting them up for } \\
\text { these problems later in life by being a faculty member" (lines } 121-122 \text { ). Even more, } \\
\text { F10 ia concerned that this might "skew who becomes veterinarians, so that only people } \\
\text { who are wealthy and privileged [can]" (lines } 144-145 \text { ). For F10, this is problematic on } \\
\text { multiple levels, veterinary medicine is the whitest profession and she sees these }\end{array}$} \\
\hline
\end{tabular}


financial issues working against diversity in a major way, from limiting access to social capital to managing debt load afterwards - "I have colleagues whose parents pay their mortgages so they could get started" (line 180). A family with meager means cannot support the necessary financial burden of becoming a veterinarian. F10 is concerned about the future of the profession.

(house officer 1):

HO1 was frustrated that the system allowed a classmate who failed out three times, back in three times (1119-1127). "I just remember being so mad at whoever let it happen, whether it be family or administration, whatever. Because it wasn't going to work out and you could just see that and it just kept being allowed to happen" (lines 1121-1124). HO1 was frustrated by his own situation, and perhaps injustice, that contributes to HO1's debt burden to date. HO1 tells the group, "So a lot of my classmates and I worked a ton during vet school and just a drop in the bucket compared to, you know, interest and everything. But at the time it seemed like it was a good idea to do. But then you're devoting all that time and you're not potentially as involved in other extracurricular things, so then all of a sudden you're sitting there and you're like, 'How did this person get \$30,000 in scholarships?' and they've basically devoted no outside time, and it just gives them the perceived leg up to be able to devote that time that you're using to survive essentially, to devote to books and just keep that extra however much it was above you, and then just boom, financially rewarded again and again and again" (lines 1323-1334). Finances are a huge issue, and again, here The Letter didn't bring that up, which is both surprising and fascinating.

(faculty 3):

). In these ways and others, F3 calls upon courage to "stand up and try to break the cycle, to make a change for the better" (Music and Article, p. 6) towards progress for (social) justice. Inherent is an assumption that the system is rigid and you "feel you have to go along with [it]" only to reach a point "when you feel you are going against your principles and prostituting yourself just to succeed" (Music and Article, p. 1).

A final assumption he challenges is one which mirrors part of the Young Veterinarian's affectual experience, "there is a big sense of disillusionment ... I'm associate professor and there's still this 'I did it this way, it's been down this way, and therefore it is the only way and this almost intractability of the senior people that is should be any different because you know I went back to when we had [our child] and we were pretty much told 'you've decided to not be a good scientist. You want a balanced life? You will not be a successful scientist” (lines 168-176). F3 shares this curious connection with the Young Veterinarian that challenges the assumptions of what our metrics and vision of success mean, what they do, and how they are arrived at. "[Being told that] has forever ticked me off - maybe they're right but I have had a balanced life" (lines 178-179). This is echoed in lyrics, which bring the curiosity back to a push for justice,

No matter the plaudits I earn

The whoring and scoring for points

To strive to be superficial 
I'll live by your status

This is knowing your place beneath the ivory towers

Not a going concern

But a lowly beast of burden (Napalm Death, Persona Non Grata).

I'm pissed at these people, at the same people in my field, and the same people in DC that perpetuate this system (both men and women)... But maybe I can make a real difference in the real world (albeit a drop in the ocean). These bastards are leaving a broken world for my [kid] to fix in the future, just so they can be famous and/or rich in the present. I want to change this no matter how small my contribution may be.

(self)reflection

(faculty 10):

F10 is progress oriented and this entails a lot of introspection, reflection, and hard work. All of which F10 strongly values. "I work hard to empower students and teach them and do everything I can and give good service, and I felt lumped in with everyone else [in The Letter]. But maybe I'm not better than anybody else, we all want to think we're better than the people they're describing here and then as I read it a little bit... well, it made me stop and think. Do I behave that way? Do I behave that way consistently? Have I behaved that way in the past? Have I been self-aware that I've behaved those ways in the past and have I tried to change my behaviors at all?" (lines 198-204). F10 listens to a lot of self-help audio books (line 211).

(faculty 5):

Self-described as "self-critical" (line 745), Type A "perfectionist" (line 444) who at a different time in life held those same expectations for others. Being so self-critical and hard on themselves, F5 "internalizes a lot of it" (line 448) but commented that it sometimes does leak out in the form of "being critical of those around you" (line 449). Considering this, F5 saw themselves in the lines of The Letter which articulated a path of shit rolling downhill - "I take full blame for being one of those people" (lines 187188). F5 described a recent experience she regrets (line 201). "I self-reported myself and apologized to everyone in that room that had anything to do with it" (lines 201202). In this particular situation, F5 was called in to help with a procedure while they was off clinics - which is something that has happened multiple times before and seems to be a source of frustration for F5. "It happens so many time and so many months and so many years and you're trying to get on with your stuff--when you're off clinics, you expect to be" (lines 190-192). This day in particular, when F5 arrived to assist and perform the procedure preparations were not in place so F5 was required to invest a greater amount of time and energy in setting up and preparing.

"I regret it"

"You don't know what is going on at all-I'm guilty of this too — and we can be too quick to make judgements and you just need to talk to the person," 
when I read this article I was hurt but also I realized I was probably part of the blame $(* 20: 45.1)$

f5: I have to kind of look at it you know the wording of yelled at punished for things you know I think we all try to be very careful but when you're in the heat of the moment or you're $(\bullet)$ I think people need to realize when you're in a surgery I mean it's you and the patient and you're going you're trying to be as efficient as you can and you're not going to put up with crap ... because you have that patient there that's in a very vulnerable position

F5: there's no room for us I would say the majority of surgeons ((door slams)) $(* 21: 52.7)$ or even with an experiment there is no room for error because you could raise this transgenic rodent and it takes a year and you know have a very rare problem you did a lot of work to make that animal and then you have to do this experiment and you can't screw it up ... so everybody -it's important for people just like you know what faculty 6 was saying the context needs to be there because many of us are dealing with things that there is no room for error ... and we have to take some things very seriously -it's not on the clinics you know I don't chit chat that much or goof around or whatever I do my job and try to get things done and when there's nothing going on on the floor I go up to my office to do the rest of my job and the students don't they think I'm not around so it's a serious environment but in turn we also have to be very mindful of how we come across to others and we have to do it in professional manner

T: how do you walk that tension then

F5: huh

T: how do you walk that tension you are describing

F5: it takes a lot of energy it takes a tremendous amount of energy $(* 23: 23.4)$ and when I'm done when I go home I am one of those people who are sitting on the couch watching The Voice just to ((laughing)) you know veg and turn my brain off ((shared laughs)) I fully admit that

F5: it takes - all of us - faculty 6 you're probably a little more outgoing than

F5: but for me it takes a tremendous amount of energy to be wear a smile on my face walk down the hall and say hello be -create an environment of civility you know

T: well, be on it sounds like what you're describing

F5: be on but when in surgery I am totally on that patient trying to get it on and off the table $(* 24: 16.2)$ as efficiently as possible without making a mistake 


\section{REFERENCES}

Adams, C. L., \& Kurtz, S. (2017). Skills for communicating in veterinary medicine. Parsippany, NJ: Dewpoint Publishing.

AERA Council. (2011). AERA Code of Ethics. Educational Researcher, 40(3), 145-156. doi:10.3102/0013189x11410403

Ahmed, S. (2010). Happy objects. In M. Gregg \& G. J. Seigworth (Eds.), The Affect Theory Reader (pp. 29-51). Durham, NC: Duke University Press.

Alexandrova, A. (2014). Well-being. In N. Cartwright \& E. Montuschi (Eds.), Philosophy of social science: A new introduction. Oxford, UK: Oxford University Press.

Angoff, N. R., Duncan, L., Roxas, N., \& Hansen, H. (2016). Power Day: Addressing the Use and Abuse of Power in Medical Training. J Bioeth Inq, 13(2), 203-213. doi:10.1007/s11673-016-9714-4

Apple, M. W. (1971). The hidden curriculum and the nature of conflict. Interchange, 2(4), 27-40.

Apple, M. W. (1999). Power, meaning, and identity: Essays in critical educational studies (Vol. 109). New York, NY: Peter Lang.

Apple, M. W. (2013). Knowledge, power, and education: The selected works of Michael W. Apple (M. W. Apple Ed.). New York, NY: Routledge.

Association for Women Veterinarians. (1997). Our history of women in veterinary medicine: Gumption, grace, grit, and good humor. Madison, WI: omnipress. 
Association of American Veterinary Medical Colleges (AAVMC). (2017). Annual data report 2016-2017. Retrieved from Internet: http:/www.aavmc.org/About-

\section{$\underline{\text { AAVMC/Public-Data.aspx }}$}

Aultman, J. M. (2005). Uncovering the hidden medical curriculum through a pedagogy of discomfort. Advances in Health Sciences Education, 10(3), 263-273. doi:10.1007/s10459-004-4455-2

Austen, L. (2016). Increasing emotional support for healthcare workers can rebalance clinical detachment and empathy. British Journal of General Practice, 66(648), 376-377. doi:10.3399/bjgp16X685957

Babaria, P., Abedin, S., Berg, D., \& Nunez-Smith, M. (2012). "I'm too used to it": a longitudinal qualitative study of third year female medical students' experiences of gendered encounters in medical education. Social Science and Medicine, 74(7), 1013-1020. doi:10.1016/j.socscimed.2011.11.043

Baker, K., \& Sen, S. (2016). Healing medicine's future: Prioritizing physician trainee mental health. AMA Journal of Ethics, 18(6), 604-613.

Bakker, D. J., Lyons, S. T., \& Conlon, P. D. (2017). An exploration of the relationship between psychological capital and depression among first-year doctor of veterinary medicine students. Journal of Veterinary Medical Education, 44(1), 50-62. doi:10.3138/jvme.0116-006R

Barad, K. (2007). In Meeting the universe halfway: Quantum physics and the entanglement of matter and meaning. Durham, NC: Duke University Press. 
Bartram, D. J., Yadegarfar, G., \& Baldwin, D. S. (2009). Psychosocial working conditions and work-related stressors among UK veterinary surgeons. Occupational Medicine, 59(5), 334-341. doi:10.1093/occmed/kqp072

Becker, H. S., \& Geer, B. (1958). The fate of idealism in medical school. American Sociological Review, 23(1), 50-56.

Becker, H. S., Geer, B., Hughes, E. C., \& Strauss, A. L. (1961). Boys in white: Student culture in medical school. Chicago, IL: The University of Chicago Press.

Benbassat, J. (2014). Changes in wellbeing and professional values among medical undergraduate students: a narrative review of the literature. Advances in Health Sciences Education, 19(4), 597-610. doi:10.1007/s10459-014-9500-1

Binyamin, G. (2018). Growing from dilemmas: developing a professional identity through collaborative reflections on relational dilemmas. Advances in Health Sciences Education, 23(1), 43-60. doi:10.1007/s10459-017-9773-2

Bird, C. (2007). Heart it races. On Places Like This.

Bloom, B. S., Engelhart, M. D., Furst, E. J., Hill, W. H., \& Krathwohl, D. R. (1956). Taxonomy of educational objectives, handbook I: The cognitive domain New York, NY: David McKay Co Inc.

Boler, M. (1999). Feeling power: Emotions and education. New York, NY: Routledge. Branch, W. T. (2005). Use of critical incident reports in medical education: A perspective. Journal of General Internal Medicine, 20, 1063-1067. doi:10.1111/j.1525-1497.2005.0231.x 
Brazeau, C. M., Schroeder, R., Rovi, S., \& Boyd, L. (2010). Relationships between medical student burnout, empathy, and professionalism climate. Academic Medicine, 85(10 Suppl), S33-36. doi:10.1097/ACM.0b013e3181ed4c47

Cake, M. A., McArthur, M., Matthew, S. M., \& Mansfield, C. F. (2017). Finding the balance: Uncovering resilience in the veterinary literature. Journal of Veterinary Medical Education, 44(1), 95-105. doi:10.3138/jvme.0116.025R

Calderon-Amor, J., Luna-Fernandez, D., \& Tadich, T. (2017). Study of the levels of human-human and human-animal empathy in veterinary medical students from Chile. Journal of Veterinary Medical Education, 44(1), 179-186. doi:10.3138/jvme.0216-038R

Cardwell, J. M., \& Lewis, E. G. (2017). Vocation, belonginness, and balance: A qualitative study of veterinary student well-being. Journal of Veterinary Medical Education, 44(1), 29-37. doi:10.3138/jvme.0316-055R

Cardwell, J. M., Lewis, E. G., Smith, K. C., Holt, E. R., Baillie, S., Allister, R., \& Adams, V. J. (2013). A cross-sectional study of mental health in UK veterinary undergraduates. Veterinary Record, 173(11), 266. doi:10.1136/vr.101390

Castilla, E. J. (2008). Gender, race, and meritocracy in organizational careers. American Journal of Sociology, 113(6), 1479-1526.

Castilla, E. J., \& Benard, S. (2010). The paradox of meritocracy in organizations. Administrative Science Quarterly, 55, 543-576.

Chigerwe, M., Boudreaux, K. A., \& Ilkiw, J. E. (2014). Assessment of burnout in veterinary medical students using the Maslach Burnout Inventory-Educational 
Survey: A survey during two semesters. BMC Medical Education, 14, 255. doi:10.1186/s12909-014-0255-4

Clough, P. T. (2007). Introduction. In P. T. Clough \& J. Halley (Eds.), The affective turn (pp. 1-33). Durham, NC: Duke University Press.

Coe, R. M., Pepper, M., \& Mattis, M. (1977). The 'new' medical student: Another view. Journal of Medical Education, 52, 89-98.

Compton, W. C., \& Hoffman, E. (2013). Positive psychology: The science of happiness and flourishing (second ed.). Belmont, CA: Wadsworth.

Cook, A. F., Arora, V. M., Rasinski, K. A., Curlin, F. A., \& Yoon, J. D. (2014). The prevalence of medical student mistreatment and its association with burnout. Academic Medicine, 89(5), 749-754. doi:10.1097/ACM.0000000000000204

Cribb, A., \& Bignold, S. (1999). Towards the reflexive medical school: the hidden curriculum and medical education research. Studies in Higher Education, 24(2), 195-209.

Davies, B. (2014). Reading anger in early childhood intra-actions: A diffractive analysis. Qualitative Inquiry, 20(6), 734-741.

Daza, S., \& Gershon, W. S. (2015). Beyond ocular inquiry: Sound, silence, and sonification. Qualitative Inquiry, 21(7), 639-644.

Dornan, T., Pearson, E., Carson, P., Helmich, E., \& Bundy, C. (2015). Emotions and identity in the figured world of becoming a doctor. Medical Education, 49(2), 174-185. doi:10.1111/medu. 12587

Doyle, T., \& Zakrajsek, T. (2013). The new science of learning. Sterling, VA: Stylus Publishing, LLC. 
Dreeben, R. (1976). The unwritten curriculum and its relation to values. Journal of Curriculum Studies, 8(2), 111-124.

Drucker, E. (1974). Hidden values and health care. Medical Care, 12(3), 266-273.

Duffy, T. P. (2011). The Flexner Report - 100 years later. Yale Journal of Biology and Medicine, 84, 269-276.

dvm360. (2017). Twitter.com profile bio. Retrieved from https://twitter.com/dvm360 dvm360.com staff. (2017, May 26, 2017). An open letter from a disillusioned veterinary school graduate. $d v m 360$.

Ellis, D., \& Tucker, I. (2015). Enlightenment philosophies of emotion. In Social psychology of emotion. Thousand Oaks, CA: SAGE

Flexner, A. (1910). Medical education in the United States and Canada. Retrieved from Washington, D.C.:

Fnais, N., Soobiah, C., Chen, M. H., Lillie, E., Perrier, L., Tashkhandi, M., . . Tricco, A. C. (2014). Harassment and discrimination in medical training: A systematic review and meta-analysis. Academic Medicine, 89(5), 817-827. doi:10.1097/ACM.0000000000000200

Foucault, M. (1983). The subject and power. In H. Dreyfus \& P. Rabinow (Eds.), Michel Foucault: Beyond structuralism and hermeneutics. Chicago, IL: The University of Chicago Press.

Fox, R. (1988). Essays in medical sociology: Journeys into the field. New Brunswick: Transaction Books.

Gardner, D. H., \& Parkinson, T. J. (2011). Optimism, self-esteem, and social support as mediators of the relationships among workload, stress, and well-being in 
veterinary students. Journal of Veterinary Medical Education, 38(1), 60-66. doi:doi:10.3138/jvme.38.1.60

Gelberg, S., \& Gelberg, H. (2005). Stress management interventions for veterinary students. Journal of Veterinary Medical Education, 32(2), 173-181.

Georgakopoulou, A. (2017). 'Whose context collapse?': Ethical clases in the study of language and social media in context. Applied Linguistics Review, 8(2-3), 169189.

Giroux, H. A. (1990). Curriculum theory, textual authority, and the role of teachers as public intellectuals. Journal of Curriculum and Supervision, 5(4), 361-383.

Giroux, H. A., \& Penna, A. N. (1979). Social education in teh classroom: The dynamics of the hidden curriculum. Theory and Reseach in Social Education, 7(1), 21-42.

Goldberg, J. L. (2008). Humanism or professionalism? The white coat ceremony and medical education. Academic Medicine, 83(8), 715-722.

Gomez-Garibello, C., \& Young, M. (2018). Emotions and assessment: considerations for rater-based judgements of entrustment. Medical Education, 52(3), 254-262. doi:doi:10.1111/medu.13476

Good, M.-J. D., \& Good, B. J. (1989). Disabling practitioners: Hazards of learning to be a doctor in American medical education. American Journal of Orthopsychiatry, 59(2), 303-309.

Gordon, L. E. (1996). Mental health of medical students: The culture of objectivity in medicine. The Pharos, Spring, 2-10.

Grant, L., Genero, N., Nurius, P., Moore, W. E., \& Brown, D. R. (1986). Gender and time variations in medical students' value development. Sex Roles, 15(1/2). 
Greenhill, L. M., \& Carmichael, K. P. (2014). Survey of college climates at all 28 US colleges and schools of veterinary medicine: Preliminary findings. Journal of Veterinary Medical Education, 41(2), 111-121. doi:10.3138/jvme.0513-075R1

Gudmundsdottir, S. (1990). Values in pedagogical content knowledge. Journal of Teacher Education, 41(3), 44-52.

Hafen, M., Jr., Ratcliffe, G. C., \& Rush, B. R. (2013). Veterinary medical student wellbeing: depression, stress, and personal relationships. Journal of Veterinary Medical Education, 40(3), 296-302. doi:10.3138/jvme.1112-101R

Hafen, M., Jr., Reisbig, A. M., White, M. B., \& Rush, B. R. (2006). Predictors of depression and anxiety in first-year veterinary students: A preliminary report. Journal of Veterinary Medical Education, 33(3), 432-440.

Hafen, M., Jr., Reisbig, A. M., White, M. B., \& Rush, B. R. (2008). The first-year veterinary student and mental health: The role of common stressors. Journal of Veterinary Medical Education, 35(1), 102-109. doi:10.3138/jvme.35.1.102

Hafferty, F. W. (1998). Beyond curriculum reform: Confronting medicine's hidden curriculum. Academic Medicine, 73, 403-407.

Hafferty, F. W., \& Franks, R. (1994). The hidden curriculum, ethics teaching, and the structure of medical education. Academic Medicine, 69(11), 861-871.

Hannula, M., Evans, J., Philippou, G., \& Zan, R. (2004). Affect in mathematics education: Exploring theoretical frameworks. Paper presented at the Conference of the International Group for the Psychology of Mathematics Education.

Hardt, M. (2007). Foreword: What affects are good for. In P. T. Clough \& J. Halley (Eds.), The affective turn (pp. ix-xiii). Durham, NC: Duke University PRess. 
Hofmeister, E. H., Muilenburg, J. L., Kogan, L., \& Elrod, S. M. (2010). Over-the-counter stimulant, depressant, and nootropic use by veterinary students. Journal of Veterinary Medical Education, 37(4), 403-416. doi:10.3138/jvme.37.4.403

Irvine, L., \& Vermilya, J. R. (2010). Gender work in a feminized profession: The case of veterinary medicine. Gender \& Society, 24(1), 56-82.

doi:10.1177/0891243209355978

Jackson, A. Y., \& Mazzei, L. A. (2012). Thinking with theory in qualitative research:

Viewing data across multiple perspectives (1 ed.). New York, NY: Routledge.

Jackson, A. Y., \& Mazzei, L. A. (2017). Thinking with theory: A new analytic for qualitative inquiry. In N. K. Denzin \& Y. S. Lincoln (Eds.), The SAGE handbook of qualitative research (5 ed., pp. 717-737). Thousand Oaks, CA: SAGE Publications, Inc.

Jackson, P. W. (1968). Life in classrooms (1 ed.). New York, NY: Holt, Rinehard and Winston, Inc.

Jaggar, A. M. (2009). Love and knowledge: Emotion in feminist epistemology. In J. Harding \& E. D. Pribram (Eds.), Emotions: A cultural studies reader (pp. 50-68). New York, NY: Routledge.

Janss, R., Rispens, S., Segers, M., \& Jehn, K. A. (2012). What is happening under the surface? Power, conflict and the performance of medical teams. Medical Education, 46(9), 838-849. doi:10.1111/j.1365-2923.2012.04322.x

Jaye, C., Egan, T., \& Parker, S. (2005). Learning to be a doctor: Medical educators talk about the hidden curriculum in medical education. Focus on Health Professions Education: A Multi-disciplinary Journal, 7(2), 1-17. 
Jaye, C., Egan, T., \& Parker, S. (2006). 'Do as I say, not as I do': Medical Education and Foucault's Normalizing Technologies of Self. Anthropol Med, 13(2), 141-155. doi: $10.1080 / 13648470600738450$

Jefferson, G. (2004). Glossary of transcript symbols with an introduction. In G. Lerner (Ed.), Conversation analysis: Studies from the first generation (pp. 13-31). Amsterdam, Netherlands: John Benjamins Publishing.

Karaffa, K. M., \& Hancock, T. S. (2018a). Mental health experiences and service use among veterinary medical students. Journal of Veterinary Medical Education, In press.

Karaffa, K. M., \& Hancock, T. S. (2018b). Mental health stigma and veterinary medical students' attitudes toward seeking professional psychological help Journal of Veterinary Medical Education, In press.

Karnieli-Miller, O., Vu, R., Holtman, M. C., Clyman, S. G., \& Inui, T. S. (2010). Medical students' professionalism narratives: A window on the informal and hidden curriculum. Academic Medicine, 85, 124-133.

Kassebaum, D. G., \& Cutler, E. R. (1998). On the culture of student abuse in medical school Academic Medicine, 73, 1149-1158.

Killinger, S. L., Flanagan, S., Castine, E., \& Howard, K. A. S. (2017). Stress and depression among veteirnary medical students. Journal of Veterinary Medical Education, 44(1), 3-8. doi:10.3138/jvme.0116-018R1

Kim, J.-H. (2016). Understanding Narrative Inquiry. Thousand Oaks, CA: SAGE Publications, Inc. 
Kogan, L. R., McConnell, S. L., \& Schoenfeld-Tacher, R. (2005). Veterinary Students and Non-academic Stressors. Journal of Veterinary Medical Education, 32(2), 193-200. doi:doi:10.3138/jvme.32.2.193

Kogan, L. R., Schoenfeld-Tacher, R., \& Hathcock, J. (2012). Psychological services for US and international veterinary students. Journal of Veterinary Medical Education, 39(1), 83-92. doi:10.3138/jvme.0511.053

Koltai, J., Bierman, A., \& Schieman, S. (2018). Financial circumstances, mastery, and mental health: Taking unobserved time-stable influences into account. Social Science \& Medicine, 202, 108-116. doi:https://doi.org/10.1016/j.socscimed.2018.01.019

Koro-Ljungberg, M. (2016). Fluid methodological spaces. In Reconceptualizing Qualitative Research: Methodologies without Methodology (pp. 79-99). Thousand Oaks, CA: SAGE Publications, Inc. .

Koro-Ljungberg, M., MacLure, M., \& Ulmer, J. B. (2017). D...a...t...a..., Data++, Data, and some problematics. In N. K. Denzin \& Y. S. Lincoln (Eds.), The SAGE handbook of qualitative research (5 ed., pp. 462-483). Thousand Oaks, CA: SAGE Publications, Inc.

Korszun, A., Dinos, S., Ahmed, K., \& Bhui, K. (2012). Medical student attitudes about mental illness: Does medical-school education reduce stigma? Academic Psychiatry, 36(3), 197-204.

Krathwohl, D. R. (1980). The myth of value-free evaluation. Educational Evaluation and Policy Analysis, 2(1), 37-45. 
Kurtz, S., Silverman, J., \& Draper, J. (2005). Teaching and learning communication skills in medicine (2 ed.). Oxford, UK: Radcliffe Publishing.

Laakkonen, J., \& Nevgi, A. (2014). Relationships between learning strategies, stress, and study success among first-year veterinary students during an educational transition phase. Journal of Veterinary Medical Education, 41(3), 284-293. doi:10.3138/jvme.0214-016R1

Labbafinejad, Y., Danesh, H., \& Imanizade, Z. (2016). Comparison of the perceived quality of life between medical and veterinary students in Tehran. Journal of Veterinary Medical Education, 43(1), 41-46. doi:10.3138/jvme.0515-083R1

Légaré, F., Freitas, A., Thompson-Leduc, P., Borduas, F., Luconi, F., Boucher, A., . . Jacques, A. (2015). The majority of accredited continuing professional development activities do not target clinical behavior change. Academic Medicine, 90(2), 197-202. doi:10.1097/ACM.0000000000000543

Linnenbrink, E. A. (2006). Emotion research in education: Theoretical and methodological perspectives on the integration of affect, motivation, and cognition. Education Psychology Review, 18, 307-314. doi:10.1007/s10648-0069028-X

Lucas, C. C. (1969). Activism through the Student American Medical Association. Jounral of Medical Education, 44, 679-683.

MacLeod, A. (2014). The hidden curriculum: is it time to re-consider the concept? Med Teach, 36(6), 539-540. doi:10.3109/0142159X.2014.907876

Marinker, M. (1974). Medical education and human values. Paper presented at the Spring General Meeting of the Royal College of General Practitioners. 
Marn, T. M., \& Wolgemuth, J. R. (2016). Purposeful Entanglements: A New Materialist Analysis of Transformative Interviews. Qualitative Inquiry, 23(5), 365-374. doi: $10.1177 / 1077800416659085$

Martin, J. R. (1976). What should we do with a hidden curriculum when we find one? Curriculum Inquiry, 6(2), 135-151.

Mastenbroek, N. J. (2017). The art of staying engaged: The role of personal resources in the mental well-being of young veterinary professionals. Journal of Veterinary Medical Education, 44(1), 84-94. doi:10.3138/jvme.0216-041R1

McArthur, M., Andrews, J. R., Brand, C., \& Hazel, S. J. (2017). The prevalence of compassion fatigue among veterinary studets in Australia and the associated psychological factors. Journal of Veterinary Medical Education, 44(1), 9-21. doi:10.3138/jvme.0116-016R3

McArthur, M., Mansfield, C., Matthew, S., Zaki, S., Brand, C., Andrews, J., \& Hazel, S. (2017). Resilience in veterinary students and the predictive role of mindfulness and self-compassion. Journal of Veterinary Medical Education, 44(1), 106-115. doi:10.3138/jvme.0116-027R

McCartney, P. (1968). Martha, My Dear. On The White Album.

McCoy, S. K., \& Major, B. (2007). Priming meritocracy and the psychological justification of inequality. Journal of Experimental Social Psychology, 43(3), 341351. doi:10.1016/j.jesp.2006.04.009

McLennan, M. W., \& Sutton, R. H. (2005). Stress in veterinary science students: a study at the University of Queensland. Journal of Veterinary Medical Education, 32(2), 213-218. 
McNaughton, N., \& LeBlanc, V. (2012). The central role of emotional competence in medical training. In B. D. Hodges \& L. Lingard (Eds.), The question of competence: Reconsidering medical education in the twenty-first century. Ithaca, NY: Cornell University Press.

Merriam-Webster. (2018). Merriam-Webster Dictionary. Retrieved from https://www.merriam-webster.com/

Meyer-Parsons, B., Van Etten, S., \& Shaw, J. R. (2017). The Healer's Art (HART): Veterinary students connecting with self, peers, and the profession. Journal of Veterinary Medical Education, 44(1), 187-197. doi:10.3138/jvme.0116-022R

Miller, R., Mavis, B. E., Lloyd, J. W., Grabill, C. M., Henry, R. C., \& Patterson, C. C. (2015). Monitoring the veterinary medical student experience: An institutional pilot study. Journal of Veterinary Medical Education, 42(4), 353-363. doi:10.3138/jvme.0914-092R1

Missouri Chapter of the AVMA. (1965). Handbook for students in the school of veterinary medicine. In A. V. M. Association (Ed.).

Moore, D. A., Truscott, M. L., St Clair, L., \& Klingborg, D. J. (2007). Effects of a veterinary student leadership program on measures of stress and academic performance. Journal of Veterinary Medical Education, 34(2), 112-121.

Mossop, L. (2012). Is it time to define veterinary professionalism? Journal of Veterinary Medical Education, 39(1), 93-100. doi:10.3138/jvme.0411.041R1

Mossop, L., \& Cobb, K. (2013). Teaching and assessing veterinary professionalism. Journal of Veterinary Medical Education, 40(3), 223-232. doi:10.3138/jvme.0113-016R 
Mossop, L., Dennick, R., Hammond, R., \& Robbé, I. (2013). Analysing the hidden curriculum: use of a cultural web. Medical Education, 47(2), 134-143. doi:10.1111/medu. 12072

Napalm Death. (2006). Persona Non Grata. On Smear Campaign.

NCH Software. Express Scribe Transcription Software. Retrieved from http://www.nch.com.au/scribe/index.html

Nicolazzo, Z. (2017). Compulsory heterogenderism: A collective case study. NASPA Journal About Women in Higher Education, 1-17. doi:10.1080/19407882.2017.1351376

Nolen, R. S. (2018, 3/16/2018). Mental health, well-being problem serious, not dire: Study. Retrieved from https://www.avma.org/News/JAVMANews/Pages/180215i.aspx

Nordstrom, S. N. (2013). Object-interviews: Folding, unfolding, and refolding perceptions of objects. International Journal of Qualitative Methods, 22, 237-257.

Ochs, E. (1979). Transcription as theory. In E. Ochs \& B. Schieffelin (Eds.), Developmental Pragmatics (pp. 43-72). New York, NY: Academies Press.

Phillips, S. P., \& Clarke, M. (2012). More than an education: the hidden curriculum, professional attitudes and career choice. Medical Education, 46(9), 887-893. doi:10.1111/j.1365-2923.2012.04316.x

Pihlaja, S. (2017). More than fifty shades of grey: Copyright on social network sites. Applied Linguistics Review, 8(2-3), 213-228. 
Pollard-Williams, S., Doyle, R. E., \& Freire, R. (2014). The influence of workplace learning on attitudes toward animal welfare in veterinary students. Journal of Veterinary Medical Education, 41(3), 253-257. doi:10.3138/jvme.0114-006R1

Reisbig, A. M., Danielson, J. A., Wu, T. F., Hafen, M., Jr., Krienert, A., Girard, D., \& Garlock, J. (2012). A study of depression and anxiety, general health, and academic performance in three cohorts of veterinary medical students across the first three semesters of veterinary school. Journal of Veterinary Medical Education, 39(4), 341-358. doi:10.3138/jvme.0712-065R

Rezler, A. G. (1974). Attitude changes during medical school: A review of the literature. Journal of Medical Education, 49, 1023-1030.

Richardson, L., \& St. Pierre, E. A. (2005). Writing: A method of inquiry. In N. K. Denzin \& Y. S. Lincoln (Eds.), The SAGE Handbook of Qualitative Research. Thousand Oaks, CA: SAGE Publications, Inc.

Richman, J. A., Flaherty, J. A., Rospenda, K. M., \& Christensen, M. L. (1992). Mental health consequences and correlates of reported medical student abuse. Journal of the American Medical Association, 267(5), 692-694.

Ringrose, J., \& Renold, E. (2014). “F**k rape!”- Exploring affective intensities in a feminist research assemblage. Qualitative Inquiry, 20(6), 772-780.

Robinson, M. B. H. (1978). The woman veterinarian: Origins, education, and career. (Ph.D.), The Ohio State University,

Roder, C. A., \& May, S. A. (2017). The Hidden Curriculum of Veterinary Education: Mediators and Moderators of Its Effects. Journal of Veterinary Medical Education, 44(3), 542-551. doi:10.3138/jvme.0416-082 
Rodriguez, A. J. (1998). Busting open the meritocracy myth: Rethinking equity and student achievement in science education. Journal of Women and Minorities in Science and Engineering, 4(2\&3), 195-216. doi:10.1615/JWomenMinorScienEng.v4.i2-3.80

Root Kustriz, M. V. (2017). Pilot study of veterinary student mindset and association with academic performance and perceived stress. Journal of Veterinary Medical Education, 44(1), 141-145. doi:10.3138/jvme.1115-181R1

Royal, K. D. (2017). A plea to discontinue acknowledging "face validity" as a legitimate type of validity evidence. Journal of Veterinary Medical Education, 44(2), 206. doi:10.3138/jvme.0416-091

Rüdiger, S., \& Dayter, D. (2017). The ethics of researching unlikeable subjects. Applied Linguistics Review, 8(2-3). doi:10.1515/applirev-2016-1038

Scheidegger, J. (2015). Burnout, compassion fatigue, depression—what's the difference? Retrieved from http://veterinarynews.dvm360.com/burnout-compassion-fatiguedepression-what-s-difference

Schoenfeld-Tacher, R., Kogan, L. R., Meyer-Parsons, B., Royal, K. D., \& Shaw, J. R. (2015). Educational research report: Changes in students' levels of empathy during the didactic portion of a veterinary program. Journal of Veterinary Medical Education, 42(3), 194-205. doi:10.3138/jvme.0115-007R

Seigworth, G. J., \& Gregg, M. (2010). An inventory of shimmers. In The Affect Theory Reader (pp. 1-25). Durham, NC: Duke University Press.

Sherwin, S. (1996). Feminism and bioethics. In S. Wolf (Ed.), Feminism and Bioethics: Beyond Reproduction. New York, NY: Oxford University Press. 
Shoenfeld-Tacher, R. M., Shaw, J. R., Meyer-Parsons, B., \& Kogan, L. R. (2017).

Changes in affective and cognitive empathy among veterinary practitioners. Journal of Veterinary Medical Education, 44(1), 63-71. doi:10.3138/jvme.0116.009R2

Siqueira Drake, A. A., Hafen, M., Jr., Rush, B. R., \& Reisbig, A. M. (2012). Predictors of anxiety and depression in veterinary medicine students: a four-year cohort examination. Journal of Veterinary Medical Education, 39(4), 322-330. doi:10.3138/jvme.0112-006R

Sloss, M. W. (1939). Women in veterinary medicine. Margaret W. Sloss Papers. Library. Iowa State University. Univeresity Archives.

Smith, A. C., \& Kleinman, S. (1989). Managing emotions in medical school: Students' contacts with the living and the dead. Social Psychology Quarterly, 52(1), 56-69.

St. Pierre, E. A. (2011). Post qualitative research: The critique and the coming after. In N. K. Denzin \& Y. S. Lincoln (Eds.), The SAGE Handbook of Qualitative Research. Los Angeles, CA: SAGE.

St. Pierre, E. A., Jackson, A. Y., \& Mazzei, L. A. (2016). New empiricisms and new materialisms: Conditions for new inquiry. Cultural Studies $\leftrightarrow$ Critical Methodologies, 16(2), 99-110.

Strand, E. B., Zaparanick, T. L., \& Brace, J. J. (2005). Quality of life and stress factors for veterinary medical students. Journal of Veterinary Medical Education, 32(2), 182-192. 
Sutton, R. C. (2007). Veterinary students and their reported academic and personal experiences during the first year of veterinary school. Journal of Veterinary Medical Education, 34(5), 645-651. doi:10.3138/jvme.34.5.645

Taylor, K. A., \& Robinson, D. C. (2009). Unleashing the potential: Women's development and ways of knowing as a perspective for veterinary medical education. Journal of Veterinary Medical Education, 36(1), 135-144.

Ulmer, J. B. (2017). Writing slow ontology. Qualitative Inquiry, 23(3), 201-211.

Underman, K., \& Hirshfield, L. E. (2016). Detached concern?: Emotional socialization in twenty-first century medical education. Social Science and Medicine, 160, 94101.

University Partner. (2016). College of Veterinary Medicine 2016-2018 College Catalog. University Partner. (2017). Collected Rules and Regulations. In Faculty of College of Veterinary Medicine (Ed.), Promotion and tenure guidelines: University Partner.

University Partner College of Veterinary Medicine. (1998). Student handbook. In Technical standards related to physical and mental ability.

University Partner College of Veterinary Medicine. (2017). 2017-2018 Admissions Guide, (pp. 16).

University Partner. (1963). School of Veterinary Medicine 1963-1965 Announcement. University Partner. (1973). 1973-1974 School of Veterinary Medicine Bulletin.

Waddell, W. H. (1982). The Black Man in Veterinary Medicine: Afro-American-NegroColored (2 ed.): W.H. Waddell.

Wallace, D. F. (2005). This is water. Retrieved from https://web.ics.purdue.edu/ drkelly/DFWKenyonAddress2005.pdf 
Wear, D. (1998). On white coats and professional development: The formal and the hidden curricula. Annals of Internal Medicine, 129, 734-737.

Wear, D., \& Aultman, J. M. (2005). Sexual Harassment in Academic Medicine:

Persistence, Non-Reporting, and Institutional Response. Med Educ Online, 10(1), 4377. doi:10.3402/meo.v10i.4377

Wear, D., Aultman, J. M., \& Borges, N. J. (2007). Retheorizing Sexual Harassment in Medical Education: Women Students' Perceptions at Five U.S. Medical Schools. Teaching and Learning in Medicine, 19(1), 20-29. doi:10.1080/10401330709336619

Wear, D., \& Castellani, B. (2000). The development of professionalism: Curriculum matters. Academic Medicine, 75, 602-611.

Wear, D., \& Kuczewski, M. G. (2004). The professionalism movement: Can we pause? The American Journal of Bioethics, 4(2), 1-10.

Wear, D., \& Skillicorn, J. (2009). Hidden in plain sight: The formal, informal, and hidden curricula of a psychiatry clerkship. Academic Medicine, 84, 451-458.

Wear, D., Zarconi, J., Aultman, J. M., Chyatte, M. R., \& Kumagai, A. K. (2017). Remembering Freddie Gray: Medical education for social justice. Academic Medicine, 92, 312-317. doi:10.1097/ACM.0000000000001355

Weiss Roberts, L., McCarty, T., \& Obenshan, S. (1999). Comprehensive performance examination gives insights into the "hidden curriculum". Academic Medicine, 74(5), 597-598. 
Weston, J. F., Gardner, D. H., \& Yeung, P. (2017). Stressors and protective factors among veterinary students in New Zealand. Journal of Veterinary Medical Education, 44(1), 22-28. doi:10.3138/jvme.0116-014R1

Whitcomb, T. L. (2014). Raising Awareness of the Hidden Curriculum in Veterinary Medical Education: A Review and Call for Research. Journal of Veterinary Medical Education, 1-6. doi:10.3138/jvme.0314-032R1

Whittington, R. E., Rhind, S., Loads, D., \& Handel, I. (2017). Exploring the link between mindset and psychological well-being among veterinary students. Journal of Veterinary Medical Education, 44(1), 134-140. doi:10.3138/jvme.1215-192R

Wilkinson, T. J., Gill, D. J., Fitzjohn, J., Palmer, C. L., \& Mulder, R. T. (2006). The impact on students of adverse experiences during medical school. Medical Teacher, 28(2), 129-135. doi:10.1080/01421590600607195

Williams, S. M., Arnold, P. K., \& Mills, J. N. (2005). Coping with stress: A survey of Murdoch University veterinary students. Journal of Veterinary Medical Education, 32(2), 201-212.

Winter, P., Rix, A., \& Grant, A. (2017). Medical student beliefs about disclosure of mental health issues: A qualitative study. Journal of Veterinary Medical Education, 44(1), 147-156. doi:10.3138/jvme.0615-097R

Wolgemuth, J. R., \& Donohue, R. (2006). Toward an inquiry of discomfort: Guiding transofmration in "emancipatory" narrative research. Qualitative Inquiry, 12(5), 1022-1039. 
Woloschuk, W., Harasym, P. H., \& Temple, W. (2004). Attitude change during medical school: a cohort study. Medical Education, 38(5), 522-534. doi:10.1046/j.13652929.2004.01820.x

Zembylas, M. (2002). Constructing genealogies of teachers' emotions in science teaching. Journal of Research in Science Teaching, 39(1), 79-103. doi:10.1002/tea.10010

Zembylas, M. (2014). Making sense of the complex entanglement between emotion and pedagogy: contributions of the affective turn. Cultural Studies of Science Education, 11(3), 539-550. doi:10.1007/s11422-014-9623-y

Zimmer, M. (2010). "But the data is already public": on the ethics of research in Facebook. Ethics and Information Technology, 12(4), 313-325. doi:10.1007/s10676-010-9227-5 


\section{VITA}

Tamara S. Hancock was born April 24, 1981 in Houston, TX. Though having spent a significant portion of her childhood in central Iowa, and with her entire family still living there, she identifies Iowa as home.

As a high school student, Tamara was keen to graduate early — to get out. At the time, and as a brooding and creative teenager, she was ready to set aside 'book smarts' and move on. Yet, living on hourly wages lost its luster quickly. She loved creating and building things, so found a home in construction and design drafting. After completing an Associates of Applied Science in Mechanical Drafting at Ivy Tech in 2002, she worked as a drafter, producing and detailing blueprints for a company that built material handling systems for the limestone aggregate industry in the Kentucky-Indiana-Ohio area.

She bought a house with her luxurious salary, and as a young 20-something, had an existential crisis. Is this it? At work, she looked around and there were folks 10 and 20 years her senior doing the same thing. At home, she had found joy in spending her weekends at a local animal shelter, giving back to her community. If this was so much fun for free, imagine what it might be like to get paid, she thought. Maybe veterinary medicine was a place for her?

At the encouragement of her partner, Jason, she decided to move on from drafting and pursued the necessary prerequisites to apply to veterinary school. In an interesting twist, she worked with a biochemistry faculty on research projects and became enamored with organic chemistry. She pondered a career in chemistry, but ultimately decided she "didn't want to be in school forever pursuing a PhD," so stuck to her path to veterinary medicine. When Jason finished his seven-year bachelors, they relocated to central Iowa 
for his career, and Tamara applied to the in-state veterinary school, Iowa State University, once she met all the requirements. To her surprise, they accepted her, and she graduated with her Doctor of Veterinary Medicine in 2011.

While a veterinary student, Tamara was devoted to her community of peers and professional colleagues, and cultivated a passion for teaching and leading. Staying in academic medicine was attractive given these pleasures, so she nurtured an interest in an artistic and creative, yet chemistry-related discipline: Clinical Pathology. She completed her Clinical Pathology residency and Master's of Science in Veterinary Pathobiology at the University of Missouri in 2014. She passed her board certification and became a Diplomate of the American College of Veterinary Pathologists later that year. Immediately following, she entered the doctoral program in the Science Education emphasis of Learning, Teaching, and Curriculum at the University of Missouri. There, a passion for philosophy, sociology, and theory of teaching/learning/researching veterinary medical education was seeded. Her research interests focus on interrogating taken-for-granted assumptions, particularly regarding hidden curricula/professionalism, emotions/affect, and gender, as means for transformation. She is a strong advocate for mental health, well-being, and social justice and often incorporates these into her scholarship.

When not marveling at her meandering-yet-connected story, or laughing at the preposterous notion she was at one time determined 'to not be in school forever,' she is spending time with her family: Her wonderful partner, Jason; their child, Edward; and their dog, Sophie B. She loves running, cooking, gardening, finding beauty out in the world, and talking to people about their craft. 